\title{
مهارات الثورة الصناعية الرابعة اللازمة لطلاب المرحلة الثانوية العامة من وجهة نظر الخبراء
}

\section{Fourth Industrial Revolution Skills Required for Secondary School Students from the Perspectives of Experts}

\author{
إعداد \\ أ.د. محمود مصطقى محمد إبراهيم \\ أ.د.م. أحمد بن عبدالله السويكت

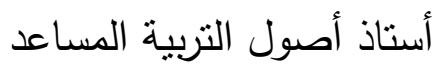

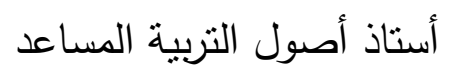 \\ كلية التربية - جامعة نجران \\ كلية التربية - جامعة القصيم

$$
\text { كلية ألد. جمال أحمد السبسىى أصبية - جامعة القصية }
$$

مجلة الدراسات التربوية والانسانية ـ كلية التربية ـ جامعة دمنهور

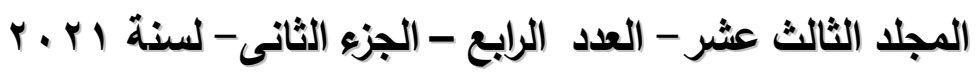


مهارات الثورة الصناعية الرابعة اللازمة أ.د. حمال السيسى أ.د.م. أحمد السويكت أ.د.م. محمود مصطفى 
مهارات الثورة الصناعية الرابعة اللازمة لطلاب المرحلة الثانوية العامة من وجهة نظر الخبراء

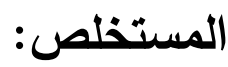

هدفت الدراسـة إلى تحديد مهارات الثورة الصـناعية الرابعـة اللازمـة لطـلاب المرحلة

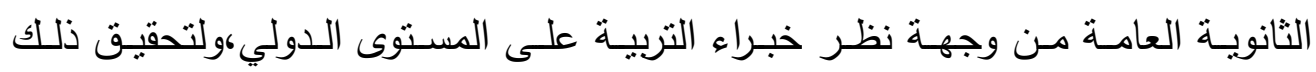

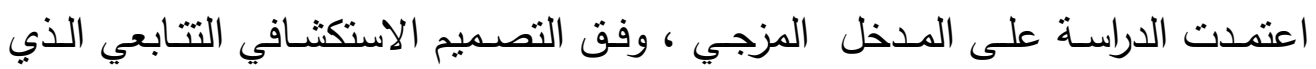

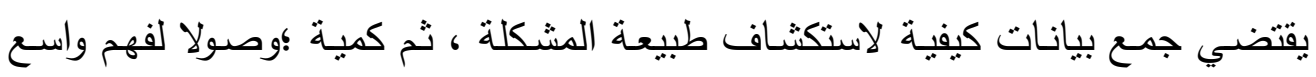

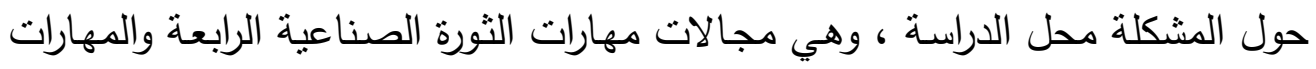

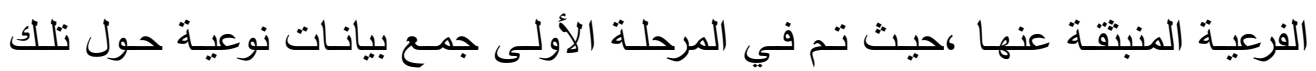

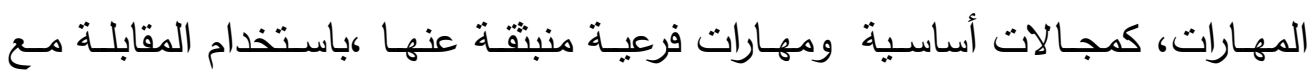

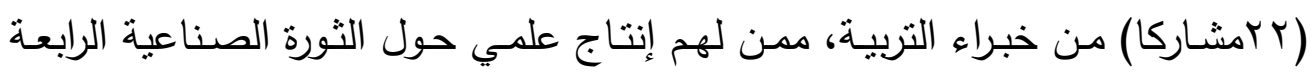

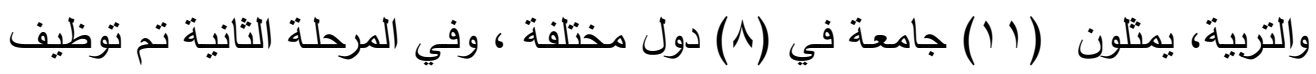

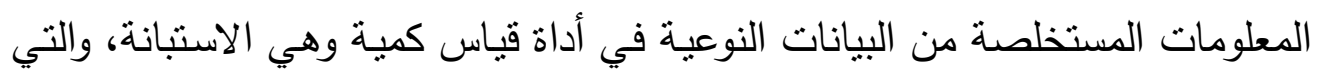

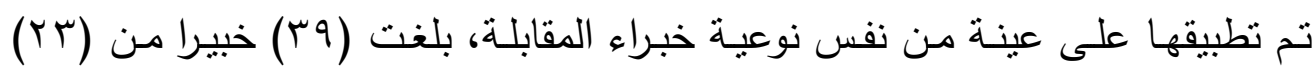

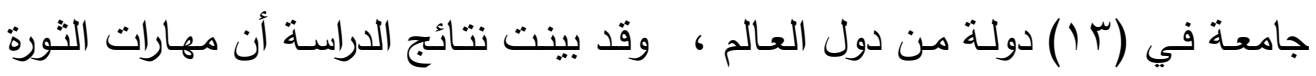
الصناعية الرابعة اللازمة لطلاب المرحلة الثانوية العامة تتدرج في ستة مجالات رئيسة، دوله

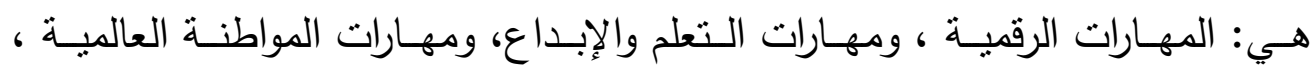
ومهارات التفكير الأخلاقي، والمهارات الثخصية ،والمهارات الحياتية والوظيفية.

الكلمات المفتاحية: الثورة الصناعية الرابعة، مهارات، المرحلة الثانوية. 
مهارات الثورة الصناعية الرابعة اللازمة أد. حمال السيسى أ.د.م. أحمد السويكت أ.د.م. محمود مصطفى

Fourth Industrial Revolution Skills Required for Secondary School Students from the Perspectives of Experts

\begin{abstract}
:
The study aims at determining skills for the Fourth Industrial Revolution required for secondary school students from the perspectives of educational experts at the international level. For achieving that, the study adopts mixed methods design, and a sequential exploratory employed to collect qualitative and quantitative data. First phase, the exploratory way using in-depth interviews; a sample of (22) experienced participants in education who have scientific contribution on the Fourth Industrial Revolution and education, representing (11) universities, and distributed on (8) different countries. Second phase, sequential in which the information extracted from qualitative data employed onto a quantitative measurement, and applied on a sample of (39) educational experts using a questionnaire measure that represents (23) universities selected from (13) countries around the world. The results of the study indicated that secondary school students are required to obtain the following six main fields skillfully for the Fourth Industrial Revolution. They are: Digital skills, learning and creativity skills, communication skills, global citizenship skills, ethical thinking skills, personal skills, and life and career skills.
\end{abstract}

Keywords: The Fourth Industrial Revolution, skills, secondary stage. 
تواجه المجتمعات على مر العصور سلسلة من الثورات المتلاحقة، سريعة في تحولاتها، عميقة في

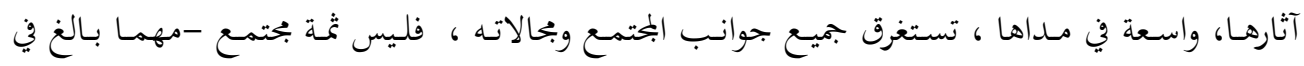
انعزاله- إلا وقد بلغت منه ت تلك الثورات مبلغاً كبيراً ، ولعل من أعمق هذه الثورات وأقواها وأبلغها أثراً ما يطلق عليها الثورة الصناعية الرابعة ، التي تغيرت الحياة بعلها في مختلف المُتمعات ، وهي في سبيلها لمزيد

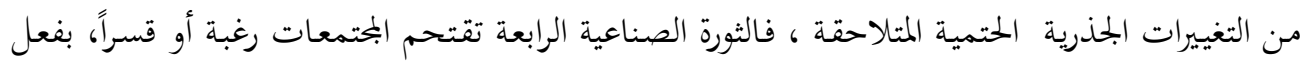

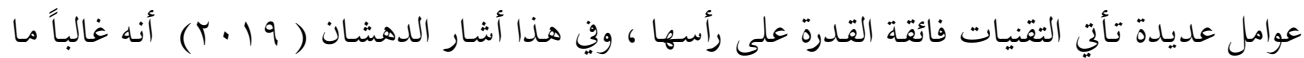
تكون التقنيات الأحدث، والأكثر تقدماً ، والأحسن أداءً ، والأقل كلفـة ، والأصغر حجماً، والأخف حملاً ، والأكبر تعقيداً من سابقتها هي عماد الحياة ، كما أن المعارف والمعلومات اللازمة لإنتاجها أكثر واترك كثافة ، وتتطلب مستويات متزايدة من القدرات البشرية : علماء وتقنيين ومطورين و مخترعين ، وبفعل ذلك غيرت تلك الثورة معالم الحياة التي يعيش فيها الإنسان ، ففي كل بحال ، وفي كل مكان ، يمكن أن نلمس وبكل سهولة آثار التقدم التقني ؛ باعتباره أساس الثورة الصناعية الرابعة وقوها التنفيذية،المدعمة بالذكاء الاصطناعي ،الذي تمخض عنه تدفقات هائلة لم يسبق لها مثيل من المخترعات الذكية في عالم

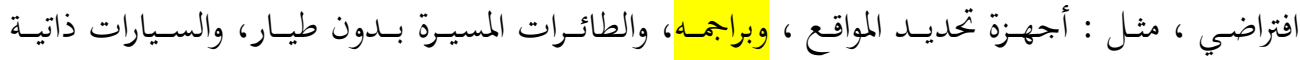
القيادة، و والحاسبات الذكية، والروبوتات المذهلة، وبرجميات الترجمة، وإنرنت الأشياء، والطابعات ثلاثية الأبعاد، والنانو تكنولوجي، والطباعة الرقمية بالحاسبات الذكية، والتكنولوجيا الحيوية والفضاء السيرباني، والمكتبات الرقمية ، والمحامـاة البربجية، ووسائل التواصل الاجتماعي الرقمي ، والسفر الافتراضي في دائرة

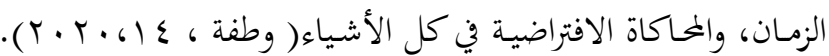
فبعـد ظهـور الثـورة الصـناعية الأولى في بدايـة النصـف الثـاني مـن القـرن الثـامن عشـر قرابـة عــام (IVT ( ) ) والتي شاع فيها استخدام الآلة البخارية في عملية الإنتاج ، ظهرت الثورة الصناعية الثانية طليعة القرن العشرين، والتي اعتمد الإنتاج فيها على الطاقة الكهربائية ،ثم ظهرت الثورة الصناعية الثالثة في بداية النصف الثاني من القرن العشرين، واعتمد الإنتاج فيها بصفة أساسية على الحاسبات الآلية والإنترنت

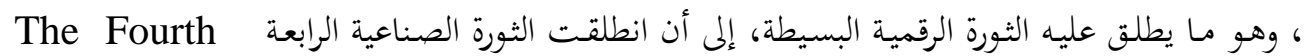
rindustrial Revolution (4IR كمصطلح لأول مرة عام (11 · (1) في معرض هانوفر بألمانيا ، ونوقشت بعدها بخمس سنوات بشكل

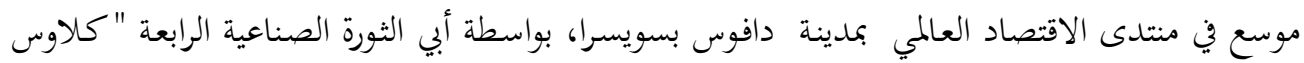

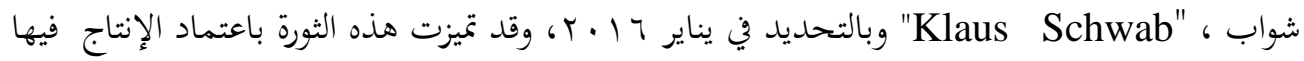


على الآلات والنظم التي تعمل بشكل مستقل ، ومن تلقاء نفسها دون الاعتماد على القوى البشرية، ومن ثم تم بنـاء المؤسسـات الإنتاجيـة الرقميـة ( Karpov,2017)، وإذاكانـت الثـورة الصـناعية الثالثـة تتميز بالرقمنة البسيطة ، فإن الثورة الصـاعية الرابعة تمثل الرقمنة الإبداعية المعقدة ، القائمة على الإمكانات

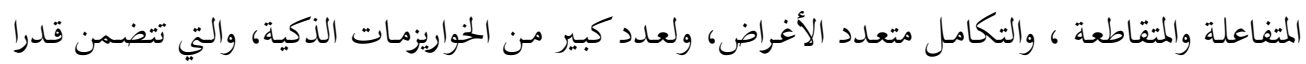
كبيرا وهائلا من المعلومات والبيانات المعقدة ( Gillies,2015)، ودمج التقنيات التي تزيل الفواصل بين

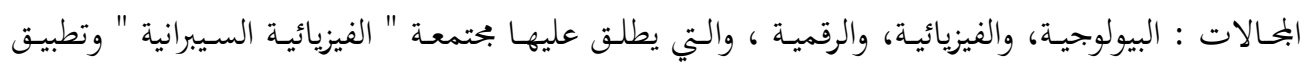

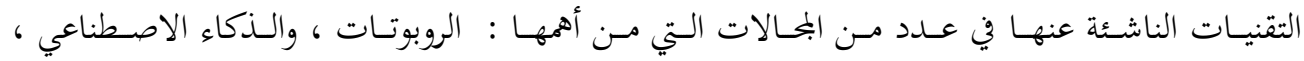
والتكنولوجيا الحيوية ، وتقنيات النانو ، وإنترنت الأشياء ، والحوسبة الكمومية ، والتقنيات اللاسلكية من الجيل الخـامس ، والإجمـاع اللامركزي ، وإنترنت الأشياء الصناعية، والطباعـة ثناثيـة الأبعاد ، والتصنيع الإضافي ، والمركبات المستقلة بالكامل (Schwab,2017 ). وحيث إنه كما يكون المجتمع تكون التربية ، أو هكذا ينبغي أن تكون العلاقة بينهما،فمن الضروري مواكبة

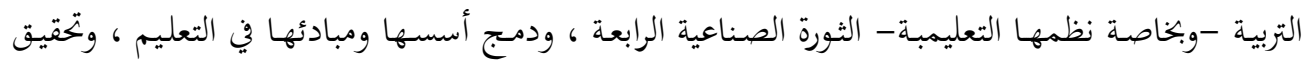
متطلباتما وشروطها ، التي باتت تغيراتها وتحولاتا في الحياة التي تحياها المختمعات جذرية وعميقة وشاملة ؛ ومـن ثم فبإن " مـا يشهـده العصر الحسالي مـن مبادئ وإفرازات الثورة الصناعية الرابعة سوف يجبر النظم التعليمية علي تعديل أساليبها وطرائقها التربوية؛ وذلك لظهور توجهات جديدة في في التعليم، والتعلم ، منها: تعامل المتعلمين مع بحموعة متنوعة من البحالات المعرفية، والنظر إلى عملية التعلم باعتبارها عملية مستمرة مدى الحياة ، وتنمية العديد من عمليات المعالجة المعرفية للمعلومات بواسطة التقنيات المتقدمة، ودعم مبدأ

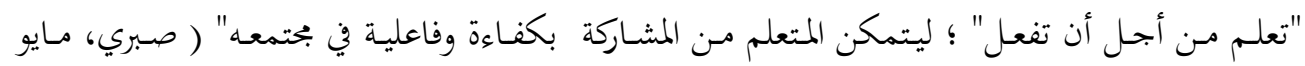

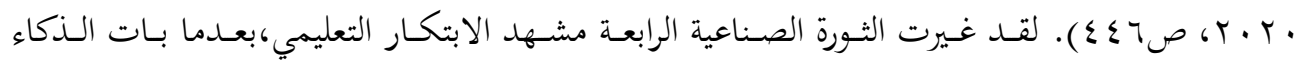
الاصطناعي والأطر المادية الرقمية تسيطر عليها ، فقدمت نموذجًا آخر في الابتكار لتعليم المستقبل ، تعليم أكثر تخصيصًا ، ذكي، وفـائق ، عـالمي ،وافتراضي ،ومحمول، قائم على المهارات المتقدمـة ، كالـذكاء الاصطناعي ، و البيانات والمعلومات الضخمة و الحوسبة السحابية،و إنترنت الأشياء والترتيب المحمول ، والواقع الافتراضي والواقع المعزز ،والشبكات عبر الإنترنت (Shahroom et al, 2018) ،وهذا يقتضي

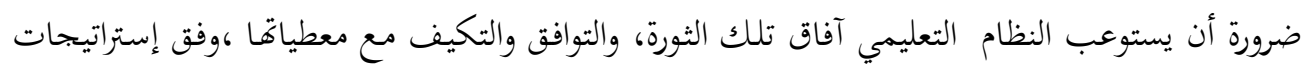
تعليمية شاملة ومتكاملة ومتطورة ، وأدوات تربوية جديدة ومبتكرة ، وبسلم تعليمي مرن ومتنوع، تتكامل

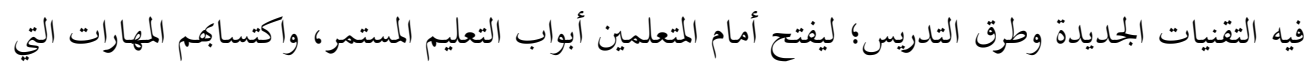

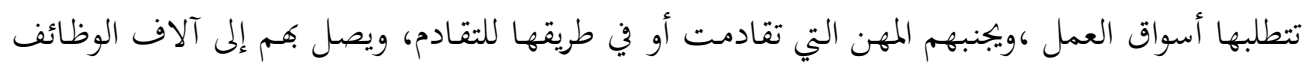
وفرص العمل التي أفرزها الثورة الصناعية الرابعة ، ويستكشف معهم التخصصات الدقيقة المستقبلية التي 
تزخر بها، ويعدهم لها (Eberhard, et al,2017) . وفي السياق نفسه أكدت دراسة ( Richert et) 2016, al) على أن التعليم هو الطريق للتوافق والتكيف مع تحديات الثورة الصناعية الرابعة عن طريق

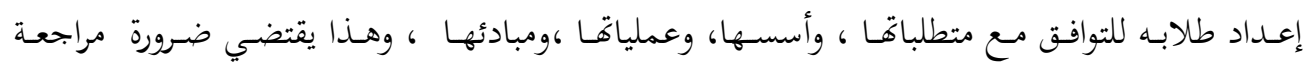

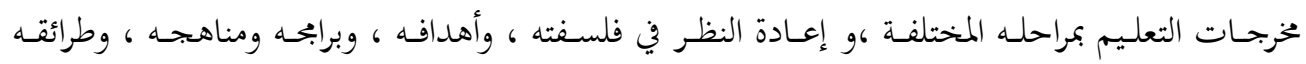
وعملياته ، و والمعارف والمهارات التي ينشدها في طلابه ، والتأكيد على أدوار الذكاء الاصطناعي ، وتنمية قدرة أفراده على العمل الافتراضي بمستوياته المتعددة والمتنوعة. وطبقا لما سبق فإن التعليم لابد له أن يتواكب مع مستقبل تحدده وترسم ملامحه الثورة الصناعية الرابعة، التي تتطلب تغيرات جذرية وجوهرية للتوافق مع الحياة في هذا المستقبل، الذي يقتضي التركيز لا على المعرفة، بل على المهارات الضرورية للحياة ، وهي في ظل الثورة الصناعية الرابعة ، مهارات نوعية تختلف عن تلك المهارات التي درج طلابنا عليها ،والتي شاع تسميتها مهارات المستقبل، أو مهارات القرن

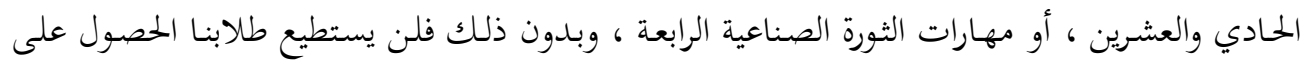

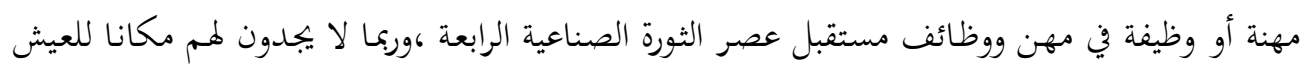
فيها، مالم يمتلكوا ويتقنوا تلك المهارات ، التي تعتبر من الشروط الضرورية للحياة، وفق متطلبات الثورة الصناعية الرابعة ، وبحسب - ما يذكر (2019) Marr فإن هدف التعليم ينبغي أن يتطور لا لإعداد طلابه طبقا لاحتياجات المستقبل ، بل للقيام بمهام الوظيفة وفق ما تكون عليه في المستقبل ، ومن ثم دعم هؤلاء الطلاب لتطوير المهارات للقيام بأي شيء في المستقبل، بدلا من القيام بشيء ما معين الآن، أو في المستقبل القريب.

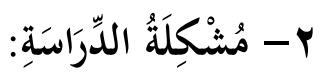

الثورة الصناعية الرابعة تتطلب مهارات جديدة مختلفة عن التي عرفتها الإنسانية على مدار تاريخها ،وتمكين طلاب مراحل التعليم منها ، وخاصة طلاب مرحلة التعليم الثانوي العام؛ للتوافق مع متطلبات

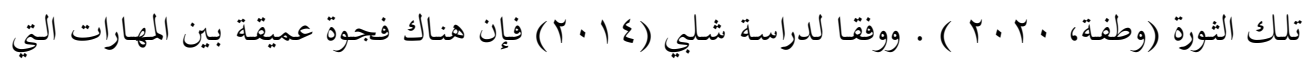

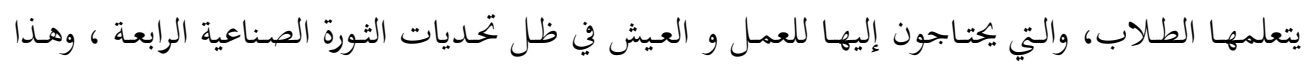
يتطلب من مؤسسات التربية إعادة النظر في المهارات التي يحتاج إليها المتعلمون بحصرها وتحديدها تحديدا دقيقا ، ووضع الإستراتيجيات والبرامج اللازمة لإعدادهم إعدادا مناسبا للحياة والعمل في عصر تلك الثورة ،بيد أنه ثمة جدل كبير ،وتباين واسع النطاق حول ماهية ونوعية تلك المهارات، وهذا يتأكد من خحلال

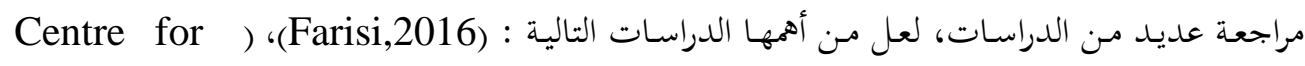
(Dwiyanti et al,2018 )، (Future-ready Graduates, 2017 
مهارات الثورة الصناعية الرابعة اللازمة أ.د. حمال السيسى أ.د.م. أحمد السويكت أ.د.م. محمود مصطفى

من الدراسات العلمية المتخصصة؛ مما يستوجب ضرورة فحص هذه المهارات وتحليلها وفق مجالات محددة ،

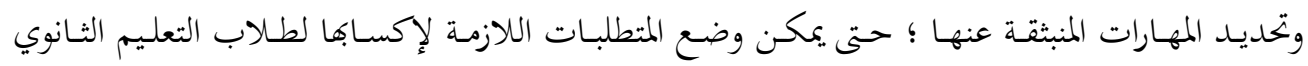

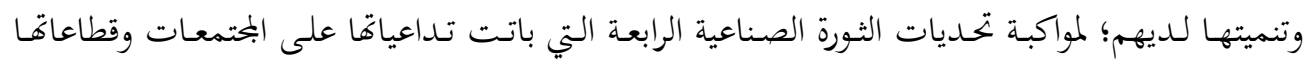
المختلفة اقتحامية وحتمية، ومن ثم فإنه يمكن تحديد مشكلة الدراسة في السؤالين التاليين: ما مجالات مهارات الثورة الصسناعية الرابعة اللازمة لطلاب المرحلة الثانوية العامة من وجهة نظر خبراء التربية؟ مـا المهـارات الفرعيـة المنبثقـة عـن مجـالات مهـارات الثـورة الصسناعية الرابعـة اللازمـة لطلاب المرحلة الثانوية العامة من وجهة نظر خبراء التربية؟

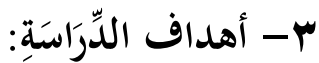
تسعى الدراسة الحالية إلى تحديد بجالات المهارات اللازمة لطلاب المرحلة الثانوية لمواكبة تحديات الثورة الصناعية الرابعة ، والمهارات المنبثقة عنها، من وجهة نظر خبراء التربية على المستوى الدولي. ع- ع أهميَّةُ الدّراسَةِّة يمكن توضيح أهمية الدراسة الراهنة في ضوء الاعتبارات التالية:

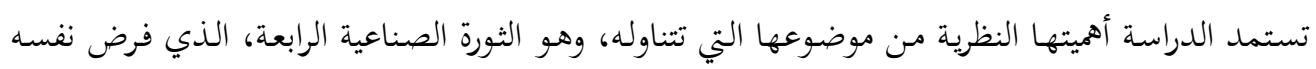
على الساحة العالمية، ومسن المتوقع أن يستمر لفترة طويلة: نظرا لحيويته، وأهميته كقضية محورية ذات تأثير كبير وفعال على حياة الفرد والمجتمع في شتى البحالات، أما من الناحية التطبيقية؛فإن نتائج الدراسة الراهنة يمكـن أن تفيد مسؤولي التربيـة ومخططيها -مـن خـلال تعريفهم بالمهارات اللازمهة لمواكبـة تـداعيات الثورة

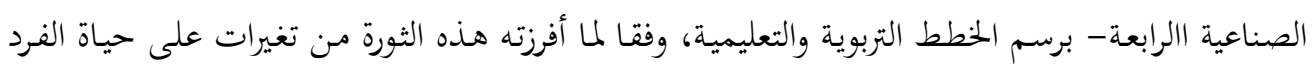
- ولمتمع - الجحل المثار حول ماهية مهارات الثورة الصناعية الرابعة ، والنتائج المتباينة حول بجالات تلك المهارات

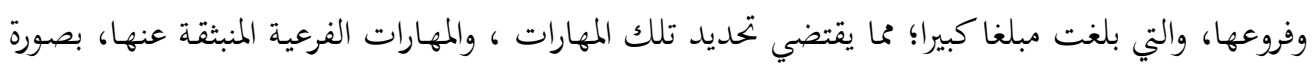

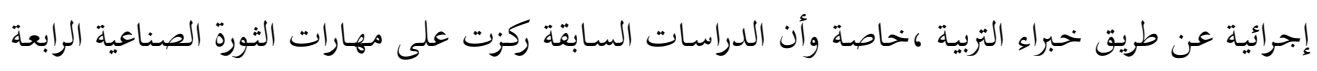
لطلاب الجحامعة، وطلاب الثانوية الفنية، دون طلاب المرحلة الثانوية العامة.

$$
\text { ه- الإطار النظري للدراسة: }
$$

๑- 1 - مفهوم مهارات الثورة الصناعية الرابعة:

يتطلب تعريف مهارات الثورة الصناعية الرابعة تعريف المهارة، وتعريف الثورة الصناعية الرابعة،وذلك على نحو ما يلي: 


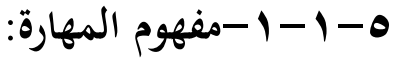

تطلق المهارة لتـدل على سمـة مركبـة مـن الصفات العقليـة، والخصـائص البدنيـة التي تتطلـب -لاكتسـابها

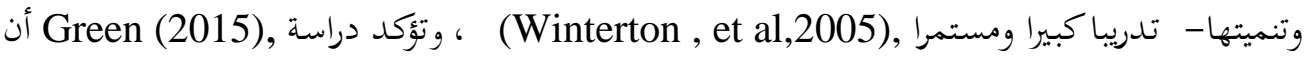
المهارة صفة شخصية تتطلب توظيف المعرفة لإنتاج شيء ذي قيمة مضافة ،وأنه يمكن تنميتها وتطويرها

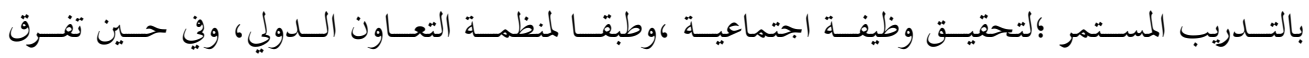

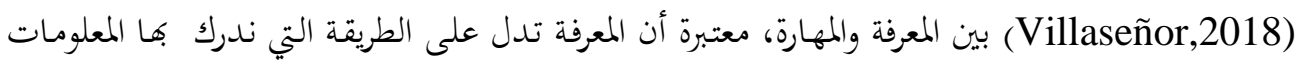
ونتذكرها ونفهمها ، بينما تشـير المهارة إلى الطريقة التي نختار بهـا المعرفة ونوظفها ونطبقها مع مواجهـة تحديات وظروف متنوعة، قد تكون غير متوقعة أو محتملة ، ويرى الباحثون أن الفصل بين المعرفة والمهارة فيه شيء من التعسف، فالمهارة في جميع الأحوال تتضمن بعدا معرفيا، والمعارف تحتاج إلى تطبيقها وتوظيفها ، وإلا عُدت دون فائدة، فهي سلسلة مترابطة الحلقـات، ويدعم ذلك تعريف منظمة التعاون الاقتصادي والتنمية ) (Development للمهارة على أها: استخدام المعرفة وتنفيذ العمليات بطريقة مسؤولة؛ لتحقيق الهدف المنشود،ومن خهلال مـا سبق يمكن تعريف المهارة بأهـا: القدرة على توظيف المعرفة ، وتطبيقها في بعـال معين، بالدقة والسرعة المطلوبة؛ لتنفيذ أغراض محددة اجتماعيا.

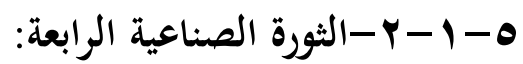
يعتبر مصطلح الثورة الصناعية الرابعة مصطلحًا حديثًا نسبيَّا ، حيث ظهر على الساحة العالمية لأول مرة

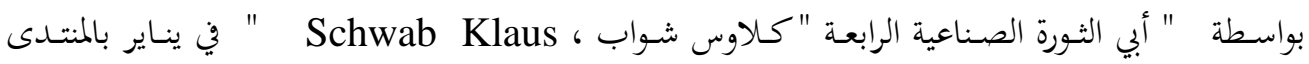

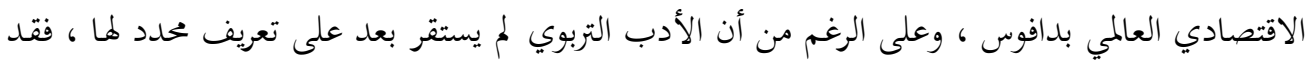
عرفها " كلاوس شواب ، Schwab Klaus " بأها العصر الصناعي الرابع بعد عصور الثورات الصناعية

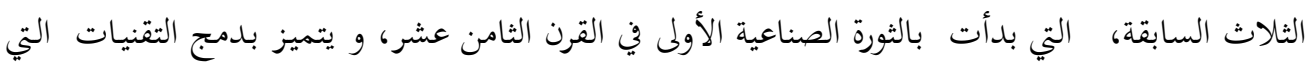

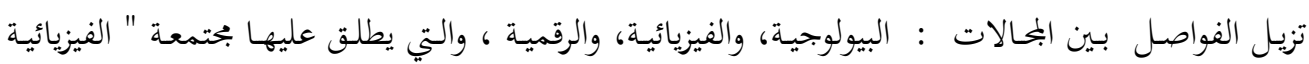

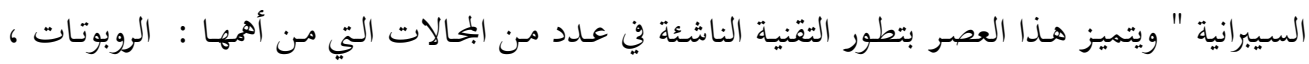
والذكاء الاصطناعي ، والتكنولوجيا الحيوية ، وتقنيات النانو ، وإنترنت الأشياء ، والحوسبة الكمومية ، والتقنيات اللاسلكية من الجيل الخامس ، والإجماع اللامركزي ، وإنترنت الأشياء الصناعية، والطباعة ثلاثية

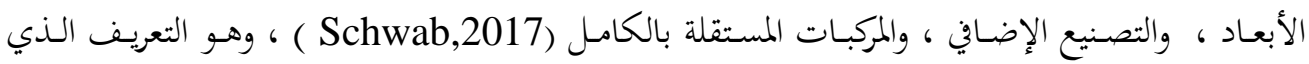


مهارات الثورة الصناعية الرابعة اللازمة أ.د. حمال السيسى أ.د.م. أحمد السويكت أ.د.م. محمود مصطفى

وعلى ضوء ما سبق يمكن تعريف مهارات الثورة الصسناعية الرابعة على أنها: القدرة على القى

توظيف المعارف المرتبطة بالثورة الصناعية الرابعة وتقنياهـا المختلفة ، وتطبيقها في بحالات الحياة والعمل ،

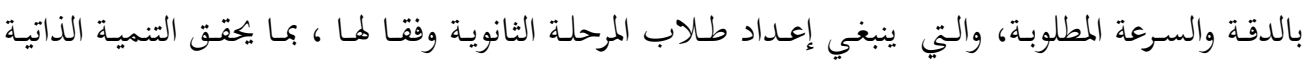
الشاملة لمبم وبمتمعهم.

ه- 1-ب- مهارات الثورة الصسناعية الرابعة في الدراسـات السـابقة، وبعض المنظمـات

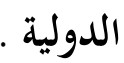

في الوقت الذي تعددت فيه الدراسات التي استهدفت تحديد مهارات الثورة الصناعية الرابعة اللازمة

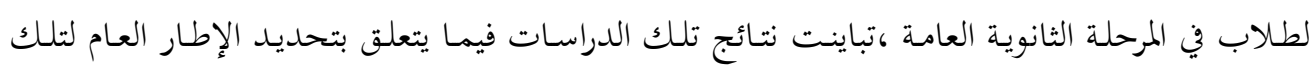
المهارات والمهارات المنبثقة عنها، وفيما يلي عرض لنتائج تلك الدراسات :

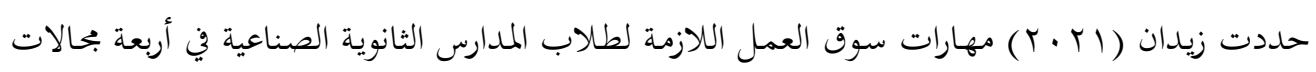
رئيسة، هي: المهارات الشخصية: و تتضمن مهارات المرونة والتفكير النقدي والتحليل والتعلم مدى الحياة، وصنع القرار ، والإبداع والأصالة والمبادرة، و مهارات التواصل ـ المهارات التقنية: و تشمل صيانة المعدات

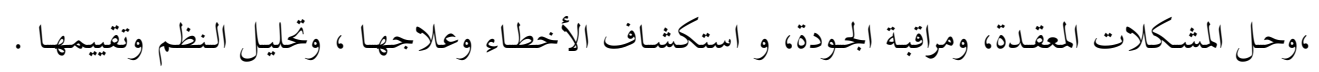

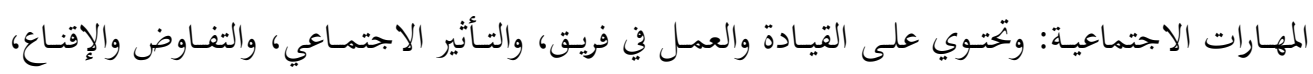
والذكاء العاطفي. ومهارات إدارة الموارد: و تشمل إدارة الوقت، وإدارة الموارد المادية والمالية، وإدارة الأفراد.

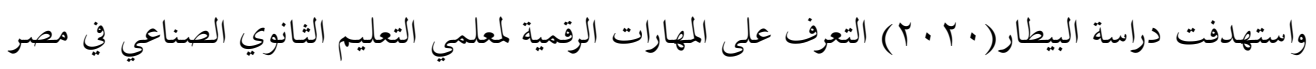

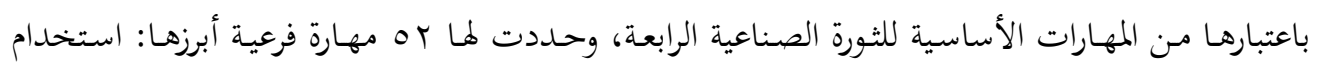
بـرامج database Excel، Power Point ،Word ، Microsoft واستخدام محركات البحتث في شبكة الإنترنت في تخصص التعليم الصناعي، وتصميم الكتب الإلكترونية

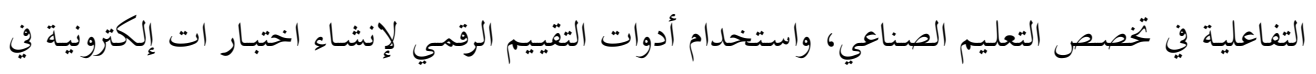

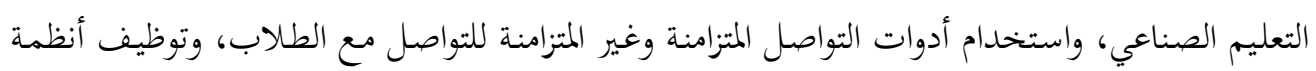
التحكم والاتصالات والشبكات في التدريس للطلاب. وحصر (2020) World Economic Forum مهارات الثورة الصـناعية الرابعة لطسلاب التعليم العـام في ثمـاني مهارات هي: مهارات المواطنـة العالميـة

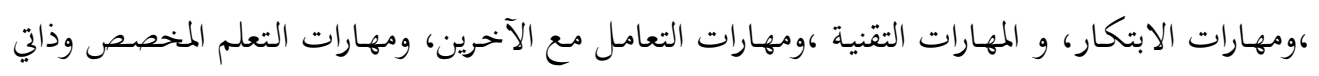
الخطى، ومهارات التعلم الشامل، ومهارات التعلم القائم على المشكلات والتعلم التعاوني ، ومهارات التعلم

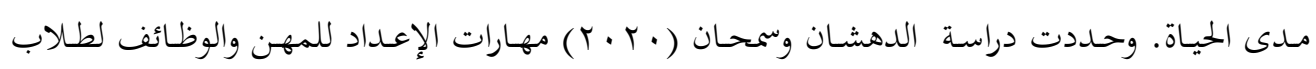
التعليم الجامعي في مصر في ثلاث مهارات رئيسة عامة هي : مهارات الثقافة الرقمية، و مهارات التعلم

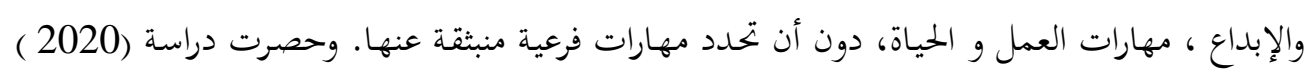


مهارات الثورة الصناعية الرابعة لطلاب المدارس الثانوية في الهند في ثلاث مهارات رئيسة هي: مهارات المواطنة العالمية (GCS)، ومهارات الابتكار والإبداع ،ومهارات التكنولوجيا ـ وحددت دراسة Fouda ( 2020) الصناعية الرابعة كمهارات أساسية للطلاب؛ لتطوير البحث العلمي في بحال الهندسة الزراعية، في كل من مصر والعالم العربي. وصممت دراسة Dewi et al (2020) أداة لقياس مهارات الطهي لدى طلاب ليكاب التعليم الثانوي المهني ، والتي شملت مهارات القراءة والكتابة ،و مهارات الحساب ، وتكنولوجيا المعلومات والاتصالات ، ومهارات التفكير النقدي والإبداعي ، والمهارات الشخصية والاجتماعية ، و مهارات الفهم

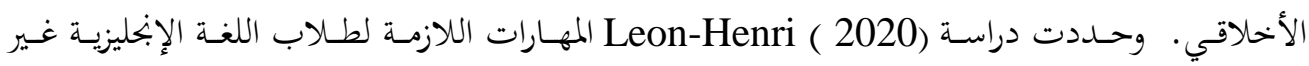
المتخصصين بجامعة Franche-Comté, Besançon ، بفرنسا ، والتي أسمتها المهارات اللينة ، وحصرتحا في مهارات التعلم مدى الحياة ، والمهارات الشخصية، ومهارات الاتصال اللفظية وغير اللفظية ،والمهارات التقنية. وسعت دراسة (2020) Karsten, et al إلى التعرف على مهارات الطلاب المحاسبين بالتعليم

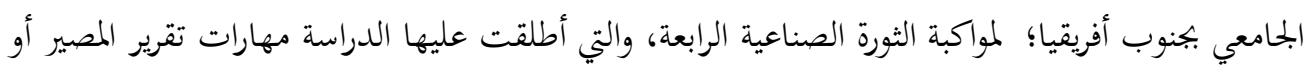
مهارات القرن الحادي والعشرين ، وحددثقا في مهارات التعلم والابتكار والمعلومات ومهارات التكنولوجيا والإعـلام و المهارات الحياتيـة والوظيفية. وتوصلت دراسة (Reaves 2019 إلى أن مهارات المرونة ، والقدرة على التكيف ، والتعاطف والملاحظة ،والابتكار ، والإبداع ، وتعلم كيفية التعلم؛ من المهارات التي

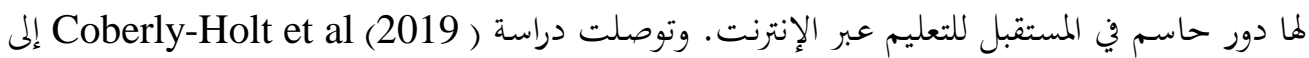
أن مهارتي التفكير الإبداعي والنقدي من المهارات الحاسمة اللازمة للبقاء في العمل للخريجين قبل التحاقهم بسوق العمل في ظل الثورة الصناعية الرابعة. وبحملها دراسة Dwiyanti et al (2018 ) في مهارات استخدام التقنيات الرقمية ، والتعلم الذاتي، وتشارك المعلومات ، و و التوافق مع الصناعات الجلديدة ، وقدم Kemp(2018)

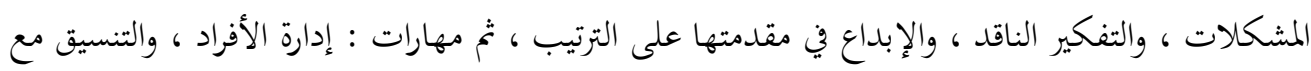
الآخـرين ، والـذكاء العـاطفي في المرتبـات الرابعـة والخامسـة والسادسـة على الترتيـب كـذلك ، ثم مهـارات :الحكم وصنع القرار ، والتفاوض عند الاقتضاء ، وتوجيه الخدمة ، و المرونة المعرفية في المراكز من السابع: حتى العاشر على الترتيب. وقدمت دراسة (2017 مing et al ثماني مهارات للثورة الصناعية الرابعة هي : مهارات التفكير النقدي ، والذكاء العاطفي، و إدارة الأفراد ، ومهارات التفاوض، ومهارات الحكىم ،

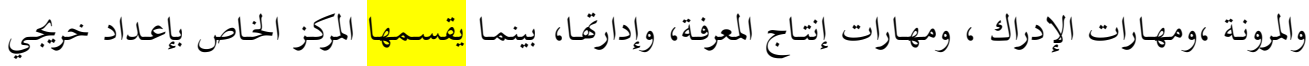
المسـتقبل بجامعة سـنغافورة الوطنيـة في كل مـن : المرونـة بأنواعها ، والـذكاء العـاطفي ، والعمل في ظل فركل 


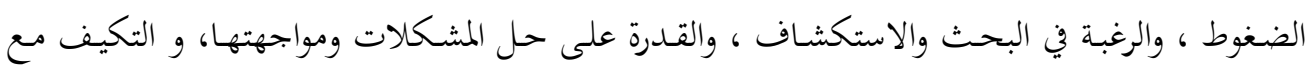
التغـير واحداثـه ،والتفكير النقـدي ، و مشـاركة الآخـرين والعمل معهـم في واقع افتراضي ، و و المشـاركة في التحسـين المستمر (Centre for Future-ready Graduates, 2017) وحـدمدما دراسـة Farisi(2016) في مهارات التفكير الناقد ، ومهارات الإبداع ،وحل المشكلات ،والابتكار، و التعاون والتواصل، و استخدام و توظيف تقنية المعلومات والاتصـالات ، ومهارات القيادة والمسؤولية الشخصية

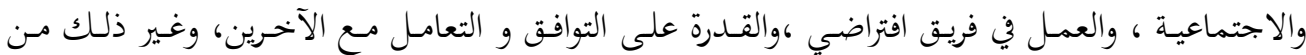
التقسيمات. ويلاحظ على تقسيمات الدراسات السابقة لمهارات الثورة الصناعية الرابعة يأتي: - أن ثمة تباينا كبيرا بين تلك التقسيمات ،حتى إنه لا يوجد اتفاق بين دراستين منها ،ولو في المحالات

- أن عددا غير قليل من تلك الدراسات لم يصنفها لمجالات عامة. - أن معظم الدراسات التي صنفتها إلى بحالات عامة لم تحدد المهارات الفرعية المنبثقة من كل بحال.

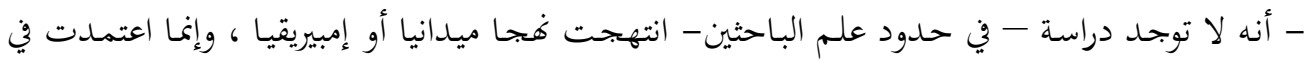
تحديد تلك المهارات على تحليلات نظرية ؛ مما يستوجب ضرورة فحص هذه المهارات وتحليلها ؛لتحديدها كمجحالات وفروع مـن خـلال الدراسـة الحاليـة معتمـدة على المـنهج المزجي، وفق التصـميم الاستكشـافي التتابعي الذي يعتمد على توظيف البيانات النوعية -التي حصل عليها الباحثون من خحلال مقابلة الخبراء - ي - استبانة كمية لتأكيد النتائج النوعية.

\section{7 - و منهجية الدراسة:}

يتناول هذا الجزء من الدراسة منهجها، وعَيِنَّها وأداتيها ، ثم النتائج التي توصلت إليها ومناقشتها.

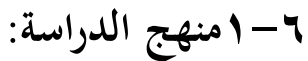

تعتمـد الدراسـة الراهنـة في تحقيـق هـدفها في تحديـــ المحـالات الرئيسـة لمهارات الثـورة الصـناعية الرابعـة

والمهارات الفرعية المنبثقة عنها لطلاب المرحلة الثانوية ، على المدخل المزجي (Mixed Method) وهو أحد المداخل البحثية " التي تتضمن جمع بيانات نوعية وكمية، ودبحهما معا من خلال استخدام تصاميم بحثية متمايزة، والفكرة المحورية للبحث المزجي هي أن دمج التصميمين النوعي والكمي في دراسة واحدة يعطي فهماً أشمل وأعمق لمشكلة الدراسة، وينطلق المدخل المختلط من النموذج الفلسفي البراغماتي؛ الذي لا يتقيـد بنظـام فلسفي محـد أو يقتصـر على واقع معسين، حيـث يتيح للباحـث حريـة الاختيـار مـن بـين المنهجيات والآليات والإجراءات بما يتوافق مع احتياجاته البحثية (Creswell, 2014)، وتبدو الحاجة إلى استخدام المنهج المختلط في هذه الدراسة، بعد ما تبين للباحثين -من خلال التحليل الموضوعي للدراسات 
السابقة- وجود تباين واختلاف في نتائج تلك الدراسات في التحديد الدقيق لمحالات لتلك المهارات، والمهارات الفرعية المنبثقة عنها، حيـث أشار (2016) Vincent إلى أنه مـ م-بررات استخحام المنهج المختلط وجود تباين في نتائج الدراسات السابقة حول الظاهرة المدروسة.

\section{:}

لتحقيق أهـاف الدراسـة، ولحاجتها إلى تحديد المجالات الرئيسـة لمهارات الثورة الصـناعية الرابعة اللازمـة لإعداد طلاب المرحلة الثانوية العامة حيث كثر الجدل حولما،واستكشافا للمهارات الفرعية التي تنبثق عن تلك المحالات؛ تستعين الدراسة بالتصميم التتابعي الاستكشافي ( Sequential exploration) ،باعتباره

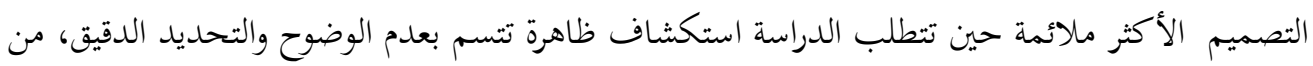
خلال تصورات الخبراء المتخصصين في هذا المجال، وهذا ما لاحظه الباحثون عند تحليلهم لنتائج الدراسات السابقة وبعض المنظمات الدولية ذات الشأن، والتباين والاختلاف الشديد في نتائجها ، وهو مـا ينطبق على الظاهرة محل الدراسة الراهنة ،ويتطلب هذا التصميم مرحلتين رئيستين، هما: المرحلة الأولى: ويتم في هذه المرحلة الاستكشافية جمع بيانات نوعية حول تلك المهارات باستخدام

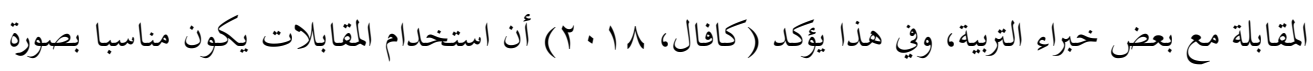

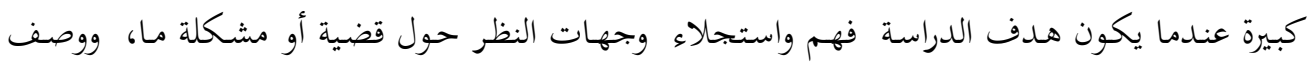

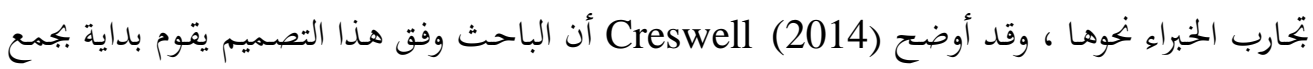

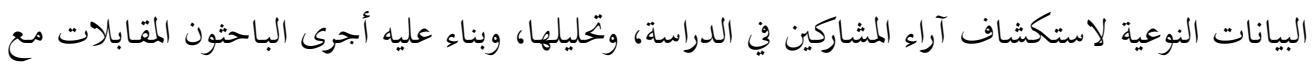
خبراء التربية ، وتحليل نتائجها؛ لاستكشاف المحالات الرئيسة لمهارات الثورة الصناعية الرابعة اللازمة لإعداد طلاب المرحلة الثانوية العامة ، والمهارات الفرعية المنبثقة عنها . المرحلة الثانية: أشار (2014) Creswell إلى أنه في المرحلة الثانية يتم توظيف المعلومات المستخلصة

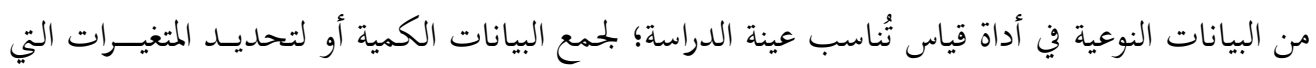
تحتـاج إلى استكشاف أوسع في المرحلة الكمية، وطبقا لذلك قام الباحثون ، واعتمادا على نتائج المقابلات بناء استبانة ، وتطبيقها على عينة موسعة ، وتحليل نتائجها وتفسيرها.

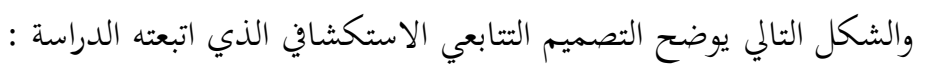


مهارات الثورة الصناعية الرابعة اللازمة أ.د. حمال السيسى أ.د.م. أحمد السويكت أ.د.م. محمود مصطفى

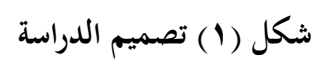

\section{بناء الأداة الكمية \\ (الاسنبانة)

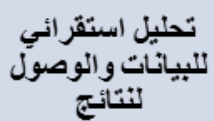 \\ واستخلاص البيانات نتائج \\ تفسير نتائج

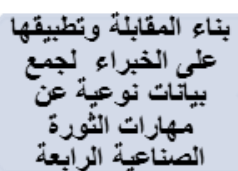

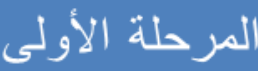

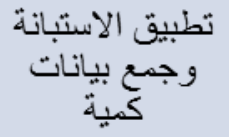 \\ المر حلة الثانية}

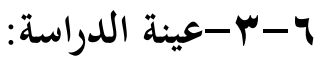

Sequential MM ) يتطلب المدخل المزجي المتبع في الدراسة الراهنة اختيار عينة تتابعية Sampling والكمية، أو الكمية والنوعية بالتتابع الزمني، سواء بإستراتيجيات العينات الاحتمالية أو غير الاحتمالية ؛ وذلك للاستفادة من نتائج بيانات الخطوة الأولى في تعيين واختيار المشاركين في الخطوة الثانية من الدراسة؛ بهدف الاستفاضة والتوسع، وتأكيد النتائج الأولية التي تظهر في الخطوة الأولى في جمع البيانات ؛وصولا لفهم واسع و شامل وعميق للظاهرة محل الدراسة (Collins et al, 2006). وتُعَدّ العينة في الدراسة الحالية عينة تتابعية، تبدأ نوعية ثم كمية Quan Qual، وفيما يلي توضيحها: أ-عينة المرحلة النوعية: المشاركون في المقابلات: وفيها تم اختيار عينة قصدية من خبراء التربية من إحدى عشرة جامعة على مستوى العالم ، ممن يشغلون درجة أستاذ بجامعاقم ، ولمم إنتاج علمي مرتبط بالثورة الصناعية الرابعة والتربية ، والجدول التالي يوضح بعض خصائص تلك العينة:

جدول (1): توزيع عينة مقابلة الدراسة في ضوء بعض المتغيرات، وترميزها

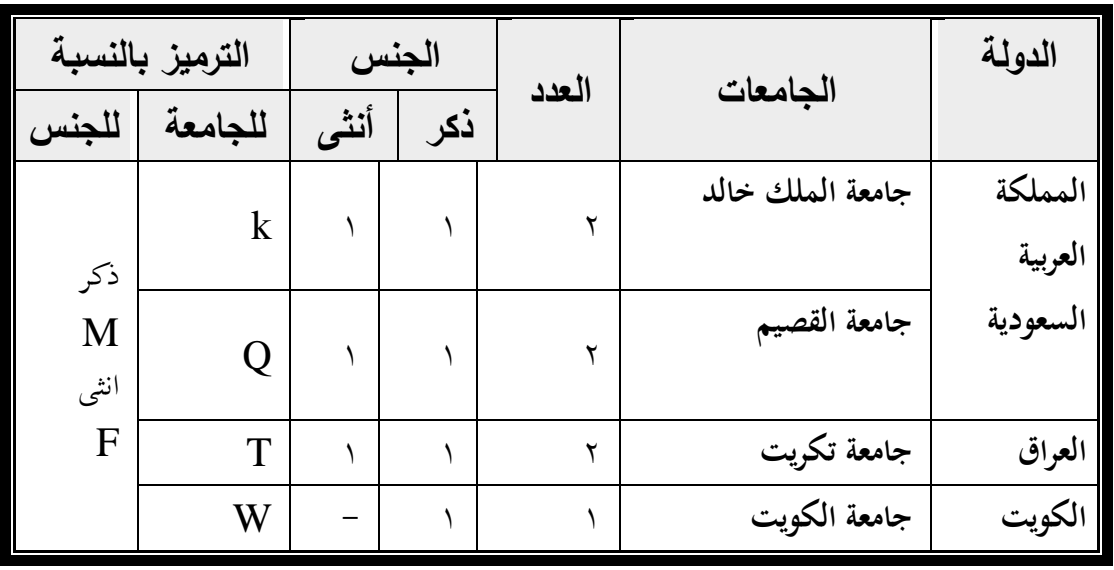


مجلة الدراسات التريوية والانسانية ـ كلية التربية ـ جامعة دمنهور ـ المجلد الحادى عثر - العدد الرابع - الجزء الثانى- لسنة 9 . ب r

\begin{tabular}{|c|c|c|c|c|c|c|}
\hline \multicolumn{2}{|c|}{ الترميز بالنسبة } & \multicolumn{2}{|c|}{ الجنس } & \multirow{2}{*}{ العدد ال العد } & \multirow{2}{*}{ الجامعاث } & \multirow[t]{2}{*}{ الدولة } \\
\hline للجنس & للجامعة & أنثى & ذكر & & & \\
\hline & $\mathrm{C}$ & 1 & 1 & r & جامعة القاهرة & \multirow[t]{2}{*}{ مصر } \\
\hline & Z & - & 1 & 1 & جامعة المنوفية & \\
\hline & $\mathrm{G}$ & 1 & 1 & r & جامعة قابس & تونس \\
\hline & $\mathrm{N}$ & 1 & 1 & $r$ & $\begin{array}{r}\text { Kent } \quad \begin{array}{r}\text { tate } \\
\text { University }\end{array}\end{array}$ & USA \\
\hline & $\mathrm{R}$ & 1 & r & r & Reading University & $\mathbf{U K}$ \\
\hline & $\mathrm{S}$ & 1 & t & r & Monash University & \multirow[t]{2}{*}{ أستراليا } \\
\hline & & 1 & 1 & $r$ & $\begin{array}{l}\text { Melbourne } \\
\text { University }\end{array}$ & \\
\hline & & 9 & IT & tr & إحدى عشرة جامعة & الإجمالي \\
\hline
\end{tabular}

وقد بلغ عدد المشاركين (T) خبيرا ،منهم (T T) من جامعات تتحدث اللغة العربية بنسبة 54.5

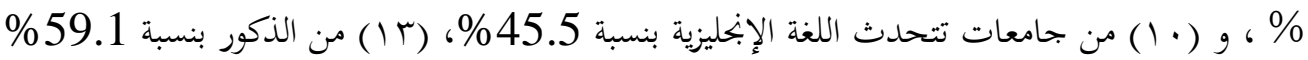

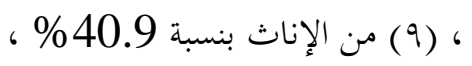

ب-عينة المرحلة الكمية : المشاركون في الاستبانة:

تحقيقا لأهداف الدراسات المزجية ،التي تتمثل في الاستفاضة والتوسع، وتأكيدا للنتائج الأولية التي حصلت عليها الدراسة في المرحلة الأولى مرحلة البيانات النوعية ،تم اختيار عينة موسعة عن عينة المقابلة ،بطريقة قصدية من خبراء التربية من خمس وعشرين جامعة، ممن يشغلون درجة أستاذ بجامعاقم ، ولهم إنتاج علمي عن الثورة الصناعية الرابعة والتربية ، والجدول التالي يوضح بعض خصنئ خصائص تلك العينة:

جدول (Y): توزيع عينة استبانة الدراسة في ضوء بعض المتغيرات

\begin{tabular}{|c|c|c|c|c|}
\hline \multicolumn{2}{|c|}{ الجنس } & \multirow{2}{*}{ العدد } & \multirow{2}{*}{ الجامعات } & \multirow[t]{2}{*}{ الدولة الد } \\
\hline أنثى & 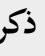 & & & \\
\hline 1 & 1 & $r$ & جامعة الملك سعود & المملكة العربية السعودية \\
\hline 1 & - & 1 & جامعة القصيم & \\
\hline- & 1 & 1 & سعود & \\
\hline- & r & r & جامعة نجران & \\
\hline
\end{tabular}




\begin{tabular}{|c|c|c|c|c|}
\hline & 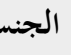 & 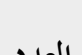 & 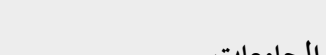 & 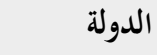 \\
\hline أنثى & ذكر & & & \\
\hline 1 & - & 1 & جامعة الكوفة & العراق \\
\hline- & 1 & 1 & جامعة السلطان قابوس & \multirow[t]{2}{*}{ سلطنة عمان } \\
\hline 1 & - & 1 & جامعة نزوى & \\
\hline- & 1 & 1 & جامعة البلقاء التطبيقية & \multirow[t]{2}{*}{ الأردن } \\
\hline- & 1 & 1 & جامعة اليرموك & \\
\hline 1 & 1 & $r$ & جامعة جابر الأحمد & الكويت \\
\hline 1 & 1 & r & جامعة القاهرة & \multirow[t]{3}{*}{ مصر } \\
\hline 1 & 1 & r & جامعة الأزهر & \\
\hline 1 & 1 & r & جامعة عين شمس & \\
\hline 1 & 1 & r & جامعة قابس & 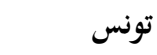 \\
\hline 1 & - & 1 & جامعة الجزيرة & \multirow[t]{2}{*}{ ل لسودان } \\
\hline$r$ & 1 & $r$ & $\begin{array}{r}\text { Pennsylvania } \\
\text { University }\end{array}$ & \\
\hline 1 & 1 & r & University YORK & كندا \\
\hline 1 & 1 & $r$ & Leeds University & UK \\
\hline 1 & 1 & r & Istanbul University & \multirow[t]{2}{*}{ زوكيا } \\
\hline 1 & 1 & r & Ege university & \\
\hline 1 & 1 & r & University Monash & \multirow[t]{2}{*}{ أستراليا } \\
\hline 1 & 1 & r & Melbourne University & \\
\hline- & $r$ & $r$ & $\begin{array}{l}\text { WAIKATO } \\
\text { University }\end{array}$ & نيوزيلندا \\
\hline 11 & YI & rq & Tr T Y Tامعة & الإجمالي \\
\hline
\end{tabular}

عمد الباحثون إلى اختيار عينة الدراسة في المرحلة الكمية من مجتمع الدراسة ذاته، بحيث تكون أكبر منها في المرحلة النوعية

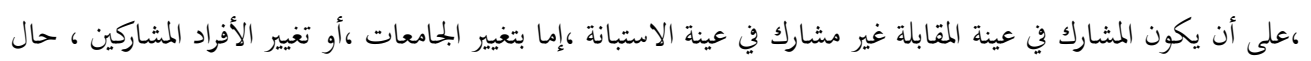

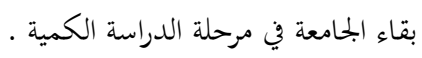


اعتمدت الدراسة بحسب طبيعتها على أداتين، هما: المقابلة والاستبانة ،فيما يلي تفصيل عنهما: צ-

تُقسم المقابلات حسب طُرق إجرائها إلى ثلاثة أنواع: مقابلة هاتفية، مقابلة إلكترونية، و مقابلة شخصية، حيث يتم الحوار مع المبحوثين وجها لوجه، أو عن طريق الهاتف، أو بأي طريقة إلكترونية: البريد

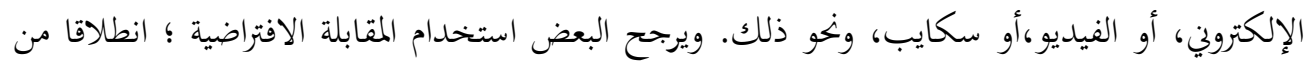
كوها تتيح الفرصة لإجراء المقابلة مع المبحوثين في بيئهم الثقافية أي في أماكن إقامتهم؛ مما يتيح فرصة كبيرة للحصول على بيانات ومعلومات مهمة ، وبتعل المبحوثين يشعرون بالراحة أثناء إجراء المقابلة

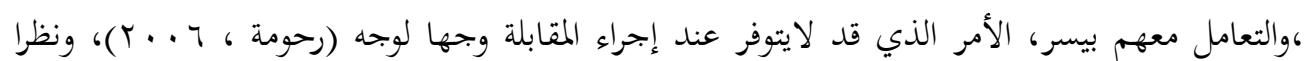
لذلك ولظروف جائحة كورونا، علاوةً على الرغبة في توفير كثير من الجهاده و الوقت والمال ،ولطبيعة أفراد العينة من الخبراء باعتبارهم من النخبة في المجتمعات ، وما يناط بهم من مسؤوليات؛ فقد تم إجراء

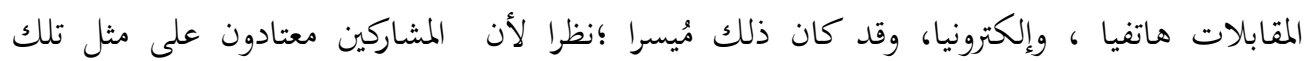

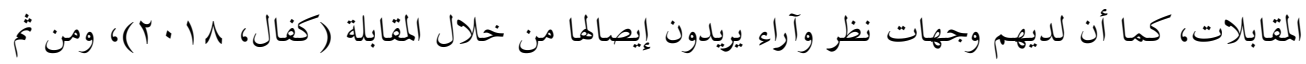
فقد أجريت جميع المقابلات، إما عن طريق الاتصال هاتفيا بالمبحوثين، أو عبر برنامج زووم Zoom

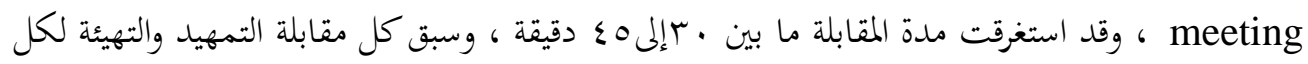
مبحوث ، وإرسال نسخة إلكترونية على إيميله ، بعد التواصل معه عن طريق بعض زملائه من المبتعثين في

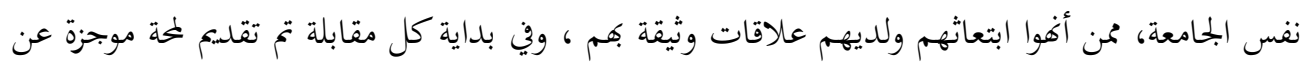
الدراسة وأهدافها وأهمية معرفة وجهة نظر المشارك حول مشكلة الدراسة ،كما تم إبلاغهم بأن مشاركتهم اختياريه ،و التأكيد لهم بأن جميع المعلومات الشخصية التي يقدموها ستبقى موضع سرية تامة، وأن لديهم

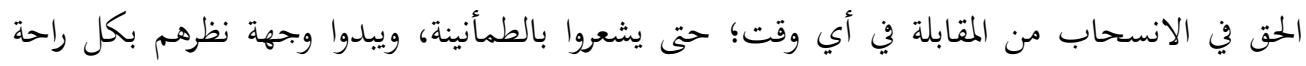
(Creswell,2012)، وقد تم تسجيل المقابلات صوتيا بعد استئذان المبحوثين من أجل حفظ المقابلات

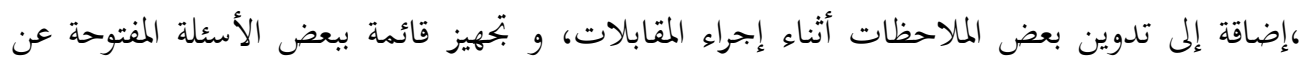
الموضوعات التي يجب تغطيتها أثناء المقابلات، تم تجهيزها من خلال الأدب التربوي المرتبط بموضوع المقابلة ؛ لأها تَدف إلى إجراء تحليل كيفي للمعلومات المجمعة (1998 Belisle).

\section{جودة بيانات المقابلات.}

لضمان جودة البيانات التي تم جمعها من المبحوثين اتبع الباحثون عدة إجراءات، من أهمها ما يأتي:

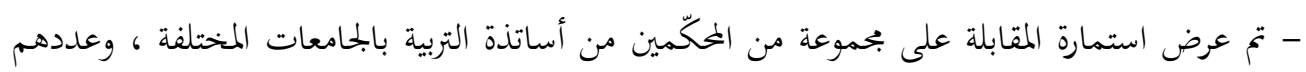
(11) ممن لهم خبرات في مجال الثورة الصناعية الرابعة والتربية، و ممن لديهم خبرات في مجال إعداد

ro 
مهارات الثورة الصناعية الرابعة اللازمة أ.د. حمال السيسى أ.د.م. أحمد السويكت أ.د.م. محمود مصطفى

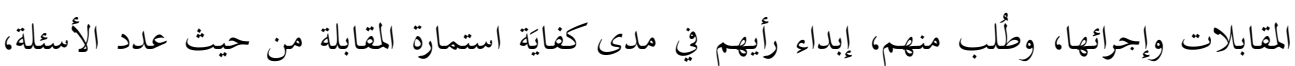
وتنوُع محتواها، وشثمولها، وتقويم مستوى الصياغة اللغويَّة، وبعد الاطلاع على ملاحظات المحكمين، واقتراحاقهم؛ تم إجراء التعديلات اللازمة في ضوء توصيات وآراء المحكمين.

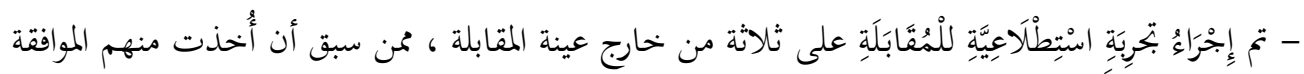
على المشاركة في المقابلات ؛ملمرفة مدى وضوح الهدف من إجراء المقابلة ، ودرجة وضوح الأسئلة المتضمنة فيها ،وقد اتضح للباحثين وضوح الهدف من المقابلة وأسئلتها قبل البدء في إجراءاتما. - تم تفريغ البيانات الصوتية إلى بيانات مكتوبة، و تم قراءها عدة مرات ،ثم بعد ذلك تم تنظيم البيانات وترتيبها إلى موضوعات أولية وفرعية وإنشاء الرموز، ثم دمج المواضيع المتشابهة تحت رمز واحد وتسميتها ،ثم بعد ذلك تم الشروع في كتابة تقرير النتائج (Braun et al,2006). -تبادل الباحثون بعضهم مع بعضهم ، مراجعة تفريغ وتحليل المقابلات التي تم إجرائها من قبل أحد أعضائها دون الآخرين ، حسب ما تم من تنظيم بينهم.

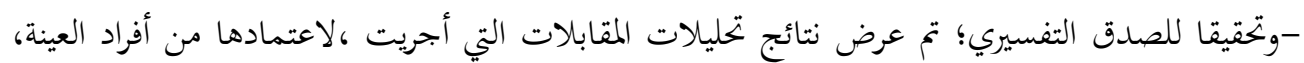
باستخدام أسلوب المشاركة الاسترجاعية ، للتحقق من موافقتهم على ما توصلت إليه من تفسيرات.

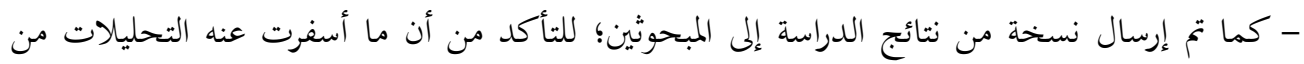
نتائج تمثل وجهات نظرهم حول المشكلة محل الدراسة (Creswell,2012). وطبقا لما سبق أصبحت استمارة المقابلة صالحة للتطبيق في صورةا النهائيَّة، وقد تكوَّنت من جزأين، هما: -البيانات الشخصية للمبحوثين من حيث الجنس، والدرجة العلمية، وسنوات الخبرة ، والدولة، والجامعة التي يعمل بها. -ثمانية أسئلة مفتوحة: السؤال الأول عن المهارات اللازمة لطلاب المرحلة الثانوية لمواكبة متطلبات الثورة الصناعية الرابعة، وستة أسئلة عن بحالات مقترحة لتلك المهارات لإبداء وجهة نظرهم عن درجة أهميتها،

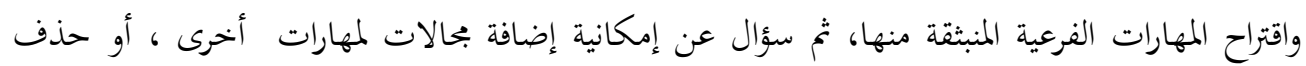

$$
\text { بعضها، أو دمج بعض بحالات المهارات المقترحة. }
$$

Y

بناء على ما توصلت إليه نتائج تتعلق بالمحاور الرئيسة لمهارات الثورة الصناعية الرابعة اللازمة لطلاب المرحلة الثانوية العامة ، والمهارات الفرعية المنبثقة من كل محور منها، تم بناء استبانة للممع البيانات

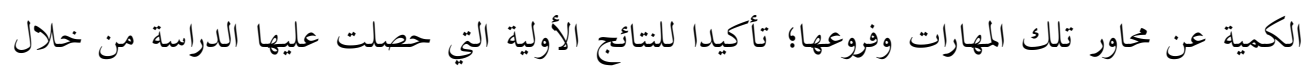
المقابلة، وتعميقا لها من وجهة نظر أوسع. وقد مر إعداد الاستبانة بالخطوات التالية: - إعداد صورة أولية للاستبانة في ضوء نتائج المقابلة. 
- تحقيقا للصدق الظاهري للاستبانة ؛تم عرض الاستبانة في صورتا الأولية على بحموعة من المحكميني، وعددهم (r I ) من جامعات مختلفة، من لهم خبرة في بحوث ودراسات الثورة الصناعية الرابعة

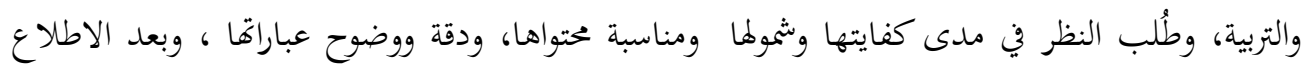

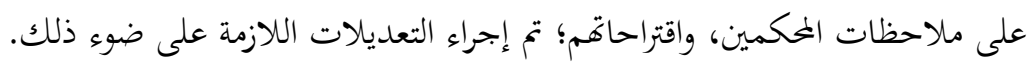
- وتأكيدا لصدق الاتساق الداخلي للاستبانة ؛ تم تطبيقها على عدد (7 ( ) خبيرا ،وحساب معامل ارتباط بيرسون، بين متوسط درجة كل مهارة فرعية ، ومتوسط درجات المحال العام الذي تنتمي

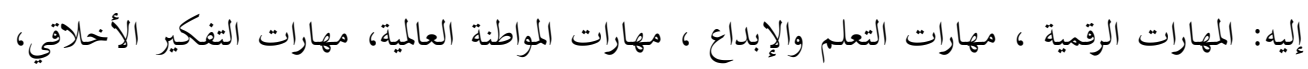
المهارات الشخصية ، المهارات الحياتية والوظيفية ،وقد تراوحت معاملات الارتباط في كل بعد من الأبعاد

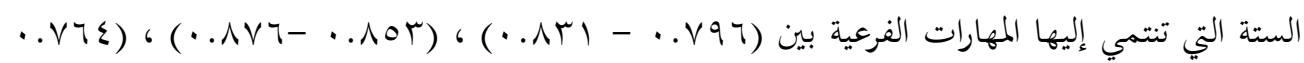
ووجميع هذه النتائج ذات دلالة إحصائية عند مستوى دلالة ( ( . . )؛ مما يشير إلى وجود ارتباط كبير بين المهارات الفرعية، والنتيجة الإجمالية لكل بحال من المجالات العامة للمهارات ؛ مما يؤكد قوة ارتباط كل مهارة فرعية بمجالها ، وقوة الاتساق الداخلي للاستبانة.

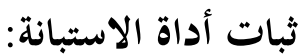

للتحقق من مدى ثبات الاستبانة تم استخدام معادلة (ألفا كرونباخ Cronbach Alpha)؛وذلك بعد تطبيقها على أفراد عينة الدراسة، ويوضح الجدول التالي معاملات الثبات لكل بحال من مجالات مهارات الثورة الصناعية الرابعة والدرجة الكلية للاستبانة:

$$
\text { جدول (r) (r) }
$$

معاملات ثبات ألفا كرونباخ للمجالات العامة للمهارات وأداة الاستبانة مجملة

\begin{tabular}{|c|c|c|c|}
\hline معامل, الثبات & المجال & معامل, الثبات & المجال \\
\hline$\cdot, \sqrt{9} 9$ & مهارات التفكير الأخلاقي & $\cdot, \vee \vee \wedge$ & المهارات الرقمية \\
\hline$\cdot, \wedge r_{0}$ & المهارات الشخصية & $\cdot, 9 \cdot 1$ & مهارات التعلم والإبداع \\
\hline$\cdot, \wedge \vee r$ & المهارات الحياتية والوظيفية & $\cdot, \wedge 19$ & مهارات المواطنة العالمية \\
\hline$\cdot, \Lambda r V$ & & & الدرجة الكليَّة للاستبانة \\
\hline
\end{tabular}

في ضوء نتائج معامل الثبات بلمالات المهارات التي تضمنتها الاستبانة، يتضح أها تتسم بقدر مناسب من الثبات ،يؤكد موثوقية الاعتماد عليها في قياس ما وضعت من أجله. الاستبانة في صورتها النهائية: 
مهارات الثورة الصناعية الرابعة اللازمة أ.د. حمال السيسى أ.د.م. أحمد السويكت أ.د.م. محمود مصطفى

تكونت الاستبانة في صورتا النهائية من جزأين:

الجزء الأول: وقد تضمَّن بيانات أوليَّة عن المبحوثين من حيث الجنس، والدرجة العلمية، وسنوات

الخبرة، والدولة ،و الجامعة.

الجزء الثاني: وقد تضمَّن ستة محاور هي :محور المهارات الرقمية ،ومحور مهارات التعلم والإبداع ،

ومحور مهارات المواطنة العالمية، ومحور مهارات التفكير الأخلاقي، ومحور المهارات الشخصية ، ومحور المهارات الحياتية والوظيفية، وينبثق من كل محور عدة مهارات فرعية، يمكن توضيحها من خلال التحليل الإحصائي ومناقشة النتائج.

\section{- V}

$$
\text { استخدمت الدراسة الأساليب التالية: }
$$

- اختبار ألفا-كرو نباخ، ومعاملات الارتباط بيرسون؛ للتأكد من صدق وثبات أداتي الدراسة. - المتوسطات Means والانحرافات المعيارية Std Deviations ؛ للتعرف على درجة موافقة الخبراء على البحالات العامة للمهارات والمهارات الفرعية المنبثقة منها. -وللحكم على مستوى استجابات أفراد العينة؛ تستخدم الدراسة في أداتا مقياس ليكرت الخماسي، وبالتالي فإنه يمكن تحديد درجات المقياس على أساس (كبيرةجدا = ه، كبيرة = ع، متوسط = ب، قليلة = = قليلة جدا = (1)، ويمكن تحديد ه مستويات متساوية المدى لمتوسطات المقياس وفقاً لطول الفئة التي

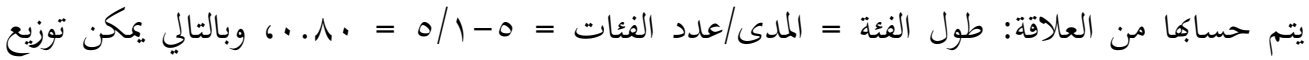
المستويات الخمسة كما هو في الجحدول التالي:

(๕) جدول

توزيع فئات المتوسطات وفقاً لتدرج ليكرت الخماسي كمحكات للحكم على نتائج الدراسة

\begin{tabular}{|c|c|c|c|}
\hline \multirow{2}{*}{ تقدير كل مستوى } & \multicolumn{2}{|c|}{ المتوسط الحسابي } & \multirow[t]{2}{*}{5} \\
\hline & إلى & من & \\
\hline قليلة جدا & 1.8 & 1 & 1 \\
\hline قلبلة & 2.6 & أكثر من 1.8 & 2 \\
\hline متوسطة & 3.4 & أكثر من 2.6 & 3 \\
\hline كبيرة & 4.2 & أكثر من 3.4 & 4 \\
\hline كبيرة جدا & 5 & أكثر من4.2 & 5 \\
\hline
\end{tabular}

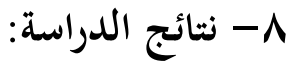

اعتمدت الدراسة الراهنة على المدخل المزجي ، وبالتحديد التصميم الاستكشافي التتابعي؛ لتحقيق أهدافه بتحديد مهارات الثورة الصناعية الرابعة اللازمة لطلاب المرحلة الثانوية العامة ، وبالتالي فقد تم تحليل تمبليل 
إجابات المشاركين بشكل نوعي وكمي في محاولة لتحقيق فهم أعمق، وتفسير أفضل لمهارات الثورة الصناعية

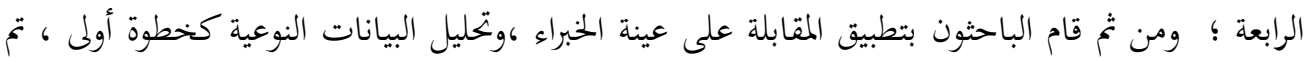

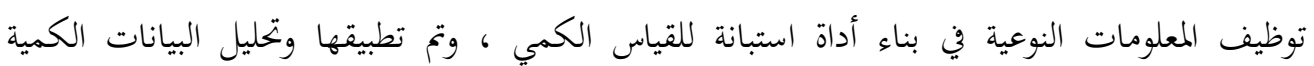

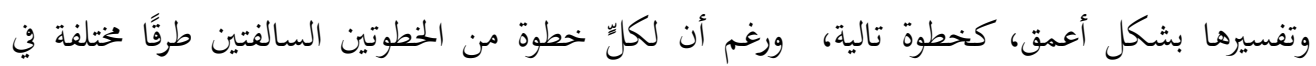

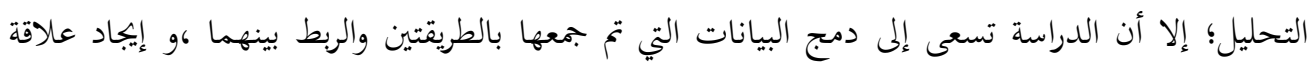
تكاملية بينهما ؛ للتوصل إلى الاستنتاجات الرئيسة (Creswell, 2012) بشأن مهارات الثورة الصناعية الرابعة كمحاور رئيسة وفرعية. وفيما يلي تفصيل ذلك:

\section{1-1 - المرحلة الأولى : مرحلة البيانات النوعية( تحليل نتائج المقابلة ).}

أعد الباحثون استمارة المقابلة ، وتم تطبيقها على (Yr) خبيرا من أساتذة التربية من (11) جامعة، من (8) ) دول مختلفة على مستوى العالم ، ممن لهم بكوث ودراسات في الثورة الصناعية الرابعة والتربية، وقام

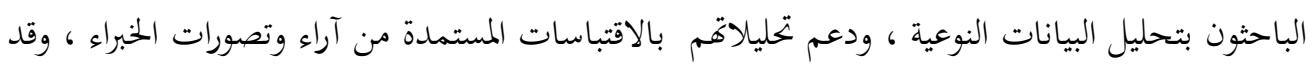
كان التركيز على نوعية هذه الآراء و التصورات، وليس عدد أصحاهما وتكرارها، وبالتالي فإن القوة التفسيرية

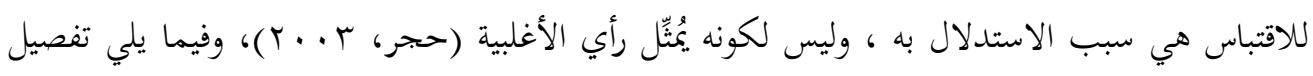
ذلك :

\section{- المهارات اللازمة لطلاب المرحلة الثانوية العامة لمواكبة متطلبات الثورة الصناعية}

\section{الرابعة.}

فيما يتعلق بسؤال: ما المهارات اللازمة لطلاب الثانوية العامة لمواكبة متطلبات الثورة الصناعية الرابعة ؟ تم فحص بيانات وإجابات أفراد العينة من الخبراء لتنظيمها وترميزها، وقد لُوحِظ توافق إجابات المشاركين

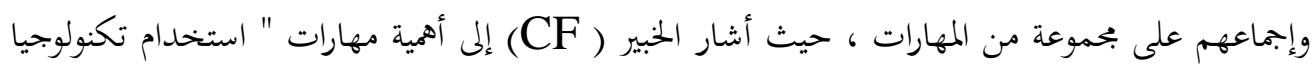
المعلومات والاتصال، والاستخدام الكفء لوسائل التواصل الاجتماعي، والاستخدام الأخلاقي للشبكة العلمية للمعلومات ، والقدرة على التفكير الناقد ،اولقدرة على إنتاج المعرفة ،والقدرة على نشر المعرفة

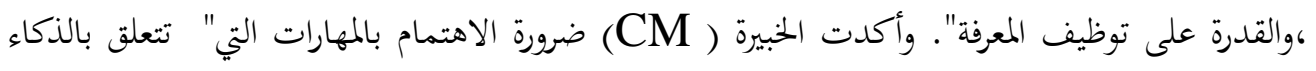
الصناعي والأجهزة الذكية، وإنترنت الأشياء ومعالجة المعلومات والمهارات الرقمية، ومهارات التواصل

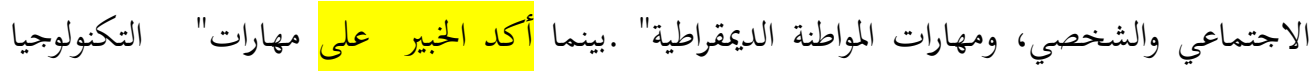
المتطورة والذكاء الاصطناعي، والتفكير الناقد والإبداعي ، والتواصل مع الآخرين ، وحل المشكلات و وغيرها

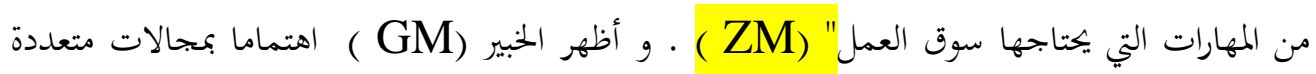
لمهارات الثورة الصناعية الرابعة حين ذكر " أعتقد أننا في الحقيقة في أمس الحاجة لهذا العمل، و التركيز في 
الوقت الحالي وفي ظل الظروف الراهنة من وجهة نظري على المهارات التقنية والمهارات المهنية، والأخلاقية والاجتماعية وواجبات وحقوق المواطنة". وأشارت أخرى إلى أن " مواكبة التحديات التي يفرضها القرن الحادي والعشرين، سواء الثورة الصناعية وغيرها تفرض ضرورة تنشئة طلابنا على مهارات المواطنة المحلية والعالمية ،والديمقراطية الرقمية ، والمهارات التقنية والإعلامية ، ومهارات العمل الافتراضي، ومهارات التواصل الرقمي"(GF) ) وأكدت الخبيرة ( KF ) على أن " أهم المهارات اللازمة لطلاب المرحلة الثانوية العامة لمواجهة الثورة الصناعية الرابعة ، هي مهارات التعلم والابتكار، والتفكير الإبداعي والتفكير الناقد، والتواصل عبر الوسائط المتفلة، واستخدام التقنية، وريادة الأعمال، ومهارات الأخلاق العامة والمهنية". وذكر

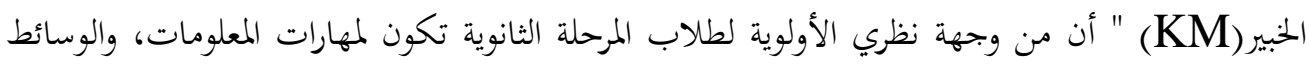
التكنولوجية، والتفكير الناقد والابتكار في التعلم، والمهارات الاجتماعية والأخلاقية والمحاسبية، ومهارات

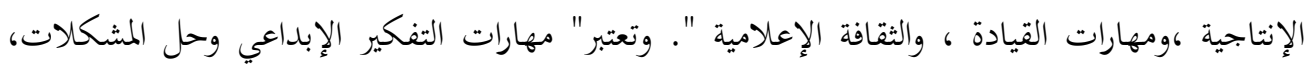
والتفكير النظمي ،والمهارات التقنية والتعامل مع الحاسوب، ومهارات النانوتكنولوجي، ومهارات التعلم الذاتي ،ومهارات التعايش الثقافي، والمهارات الاجتماعية من أهم مهارات التوافق مع الثورة الصناعية الرابعة

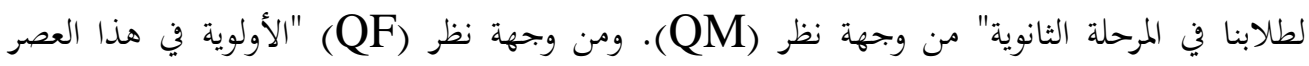
للمهارات المهنية، والتقنية، ومهارات الحياة، فالمهارات الاجتماعية باتت ضرورة جدا، والذكاء العاطفي، وتحمل ضغوط الحياة ". ويؤكد (WM) على "مهارات الذكاء الاصطناعي، وإنترنت الأشياء، والتعليم الابتكاري، والعمل الابتكاري، وتحويل الأفكار إلى ابتكارات ملموسة، والمهارات الاجتماعية والأخلاقية ".

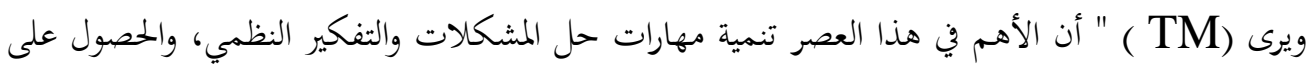
المعلومات رقميا وبالطرق التقليدية ، وتقييمها ، ومشاركتها وتوظيفها، والتعاون والتواصل مع الآخرين "

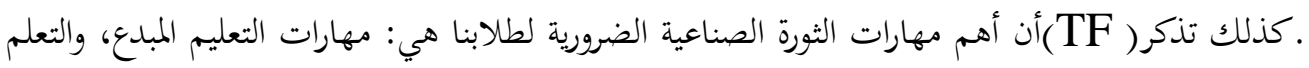
الابتكاري، ومهارات العمل العادي والافتراضي ، ومهارات الأخلاق ضرورة للحياة خاصة التقنية،

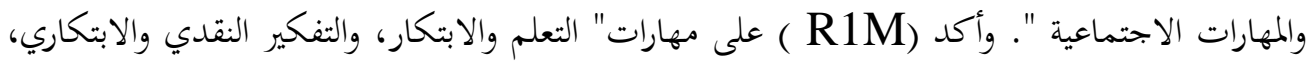
ومهارات المواطنة الرقمية، والمهارات الاجتماعية والأخلاق والضوابط الرقمية". وفي نفس الاتحاه يدعم الخبيز (R2M) " مهارات المواطنة والديمقراطية الرقمية ، ومهارات الحياة في بحتمع تقليدي ورقمي، ومهارات التفكير بأنماطه المختلفة، وتنميتها من خلال التعلم والعمل بشرط أن يتم ذلك في ضوء قواعد الأخلاق". وتذكر) RF) أن " الأهم من وجهة نظري مهارات التعلم الابتكاري والإبداعي، ومهارات تقنية المعلومات والاتصال، والمهارات الاجتماعية على اختلاف مستوياتا". وترى (NF) ) أن " الاهتمام من وجهة نظري يجب أن ينصب على المهارات الرقمية، والمحاسبية والمسؤولية الاجتماعية والأخلاقية ،

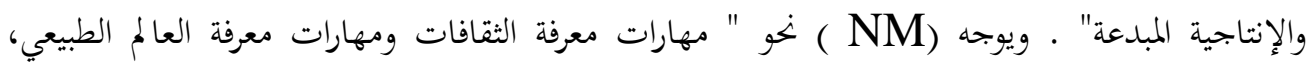


ومهارات التحليل والاستقصاء، والعمل في فريق ، ومهارات الثقافة المعلوماتية، وحل المشكلات بطريق غير مألوفة ". ويعتقد (M1M) أن أهم " مهارات الثورة الصناعية للطلاب هي مهارات تطبيقات الثورة الصناعية الرابعة :كالذكاء الاصطناعي، والحوسبة السحابية ، وإنترنت الأشياء، والتعامل مع البيانات

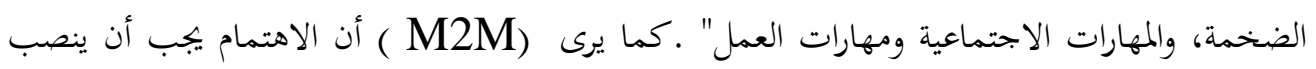

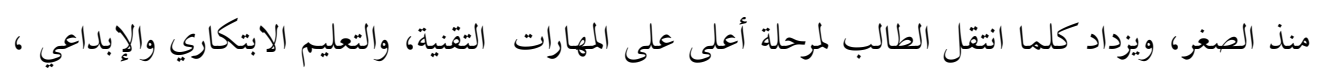

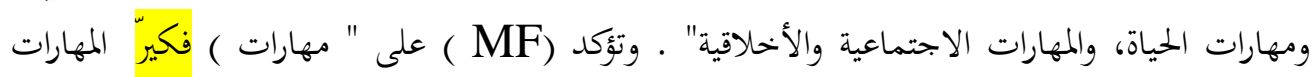
الفرعية، وهي مهارات التفكير الناقد وحل المشكلات، ومهارات التواصل والتشارك، ومهارات الابتكار

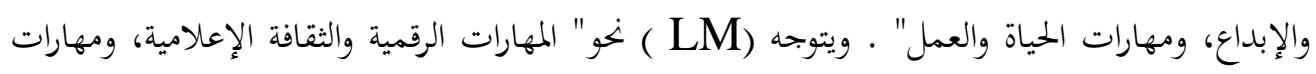

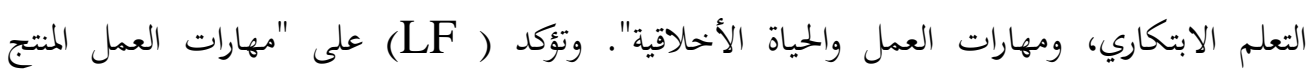
والمحاسبية، ومهارات القيادة، والعمل في ظل بيئات رقمية وغير رقمية، ومع ثقافات وديانات وجنسيات ولغات مختلفة ". وبصورة إجمالية يتضح توافق خبراء التربية على بحالات رئيسة لمهارات الثورة الصناعية الرابعة اللازمة لطلاب المرحلة الثانوية العامة، كالمهارات الرقمية ، ومهارات التعلم والابتكار، ومهارات المواطنة الرقمية، ومهارات

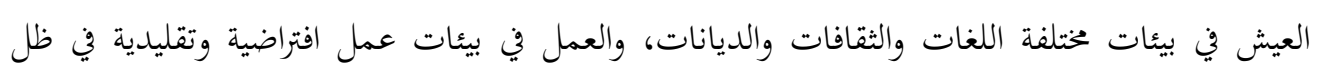
القواعد والمعايير الأخلاقية والاجتماعية.

-المهارات الرقمية اللازمة لطلاب المرحلة الثانوية العامة لمواكبة مثطلبات الثاعية الثورة الصناعية الرابعة.

وقد قام الباحثون بتلخيص النتائج التي حصلوا عليها من حلال المقابلات، واستخدموا في ذلك الك

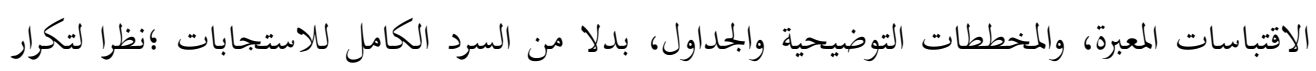
عديد من إجابات الخبراء عن المهارات الفرعية ، وهي تقنية تحليلية بتعل الأفكار مرئية ، ومختصرة ، ومركزة

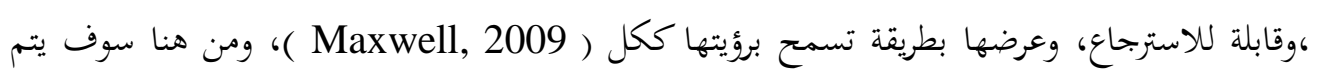

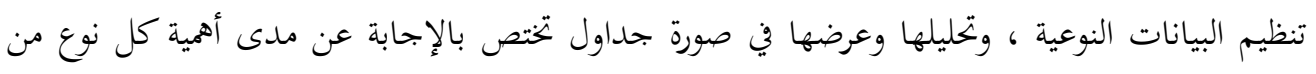

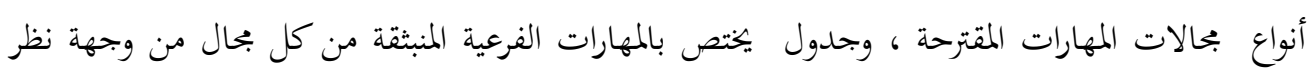
الخبراء، وفيما يلي تفصيل ذلك:

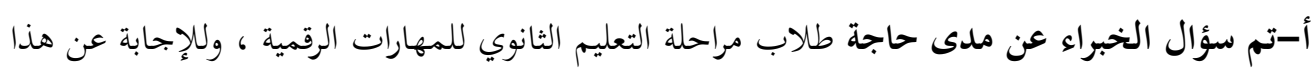

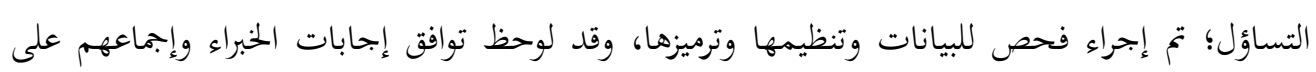
أهمية هذه المهارة، والجدول التالي يوضح تحليل ذلك: إنكري 
مهارات الثورة الصناعية الرابعة اللازمة أ.د. حمال السيسى أ.د.م. أحمد السويكت أ.د.م. محمود مصطقى

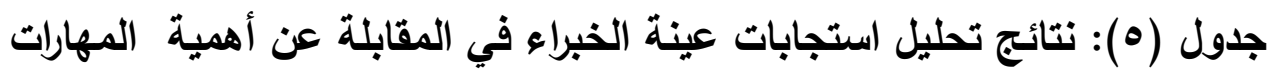
الرقمية

\begin{tabular}{|c|c|c|c|}
\hline أمثلة لنصوص الاقتباسات الدالة & أصحاب الرأي من & الأهمية & b \\
\hline 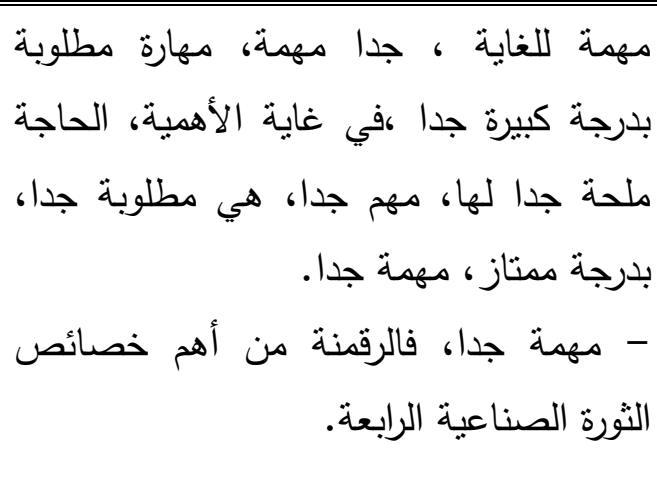 & 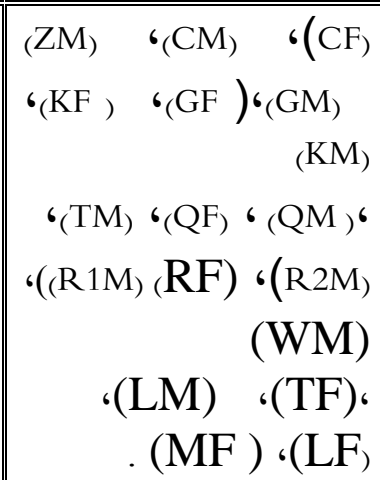 & كبيرة جدا & \\
\hline بالصبحت ضبرجة كبيرة أن هذا أمر هام، المهارات الرقمية مهية بدرجة كبيرة، مطلوبة & $\begin{array}{l}\text { ،(M1M ) (NM ) } \\
\text { ،(NF) (M2M ) }\end{array}$ & كبيرة - كبرة & \\
\hline
\end{tabular}

ب- تم سؤال الخبراء عن المهارات الفرعية المنبثقة عن المهارات الرقمية ، وجاعت إجاباتهم كما هو موضح من التحليل المدون بالجدول التالي:

جدول (†): نتائج تحليل استجابات عينة الخبراء في المقابلة عن المهارات الفرعية

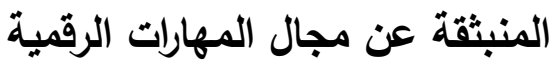


- مهارات نوظيف نطبيقات الثورة الصناعية الرابعة في العمل والحياة.

-مهارات تتفيذ المهام في البيئات الرقمية. -مهارات استخدام المعلومات بكفاءة في تتفيذ المهام المطلوبة.

-مهارات الحصول على المعلومات بالدقة والسرعة اللازمنين.

-مهارات تقييم البيانات، والمعلومات، والمحتوى الرقمي.

- مهارات بناء النطبيقات الرقمية وليس فقط

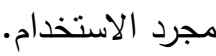
- مهارات البحث في المصادر الرقمية. - نطبيقات الذكاء الاصطناعي. - مهارات ريادة الأعمال. - -

-مهارات تبني ونثر الأفكار المستحدثة. - مهارات التفكير البصري.

- مهارات قراءة المثيرات البصرية وتقويم

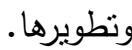

- ريادة الأعمال الرقمية - حل الشكلات الرقية عند حدوثها.

- الدعاية والتسويق الرقمي- مهارات الأرشفة

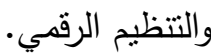

- مهارة التسويق الإلكتروني - مهارات الترميز .
$(\mathrm{ZM}$ ،( CM) ،CF) ) ،) $(\mathrm{GM})(\mathrm{KF})$ (KM) (QM (GF) (QF ) )

)،(R1M )، (R2M) $(\mathrm{WM}) \cdot(\mathrm{RF})(\mathrm{TF}$ (NF ) ،

(M1M ) (NM ) (M2M (MF) (LM .) (LF) (TM) التي تواجهه -التفاعل مع نظم إدارة المحتوى والتعلم الرقمي - مهارة ريادة

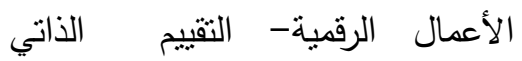
لمعارفه ومهاراته الرقمية - مهارة إعداد المدونات العلمية والمنصات الرقمية الثخصيةوالرسائل عبر وسائط إعلامية متتوعةمهارات توظيف تطبيقات الثورة الصناعية الرابعة في العمل والحياةالسلامة والحماية للبيانات الثخصية والخصوصية والأجززة- مهارة حل حل المشكلات الرقمية الناشئة- التواصل مهاره والعمل المشترك من خلال التقنيات الرقمية- مهارة الدعماية الرقمية والتسويق الرقمي- الحكم علي دقة المعلومات من المصادر المطبوعة المبن والإلكترونية- - مهارات الأرشفة والتصنيف الرقمية- مهارات معالجة المعلومات المعتدة على الوسائط المتعددة التفاعلية. 
مهارات الثورة الصناعية الرابعة اللازمة أ.د. حمال السيسى أ.د.م. أحمد السويكت أ.د.م. محمود مصطفى

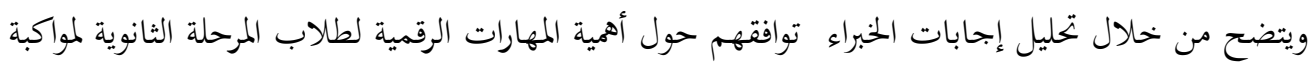

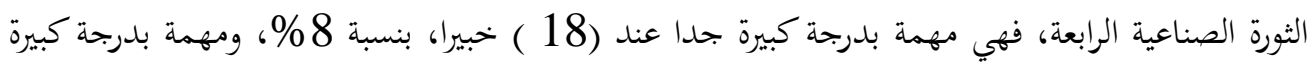

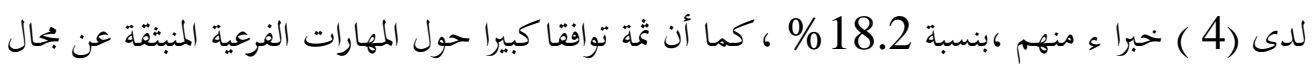
المهارات الرقمية.

-مهارات التعلم والإبداع اللازمة لطلاب المرحلة الثانوية العامة لمواكبة متطلبات الثورة الصناعية الرابعة.

أ- تم سؤال الخبراء عن مدى حاجة طلاب مرحلة التعليم الثانوي لمهارات التعلم والإبداع ، وللإجابة عن هذا التساؤل؛ تم إجراء فحص للبيانات وتتظيمها وترميزها، وقد لوحظ توافق إجابات الخبراء وإجماعهر على أهمية هذه المهارة، والجدول النالي يوضح تحليل ذللك:

جدول (V)): نتائج تحليل استجابات عينة الخبراء في المقابلة عن أهمية مجال مهارات التعلم والإبداع

\begin{tabular}{|c|c|c|c|}
\hline أمثلة لنصوص الاقتباسات الدالة & أصحاب الرأي من & الأهمية & \\
\hline 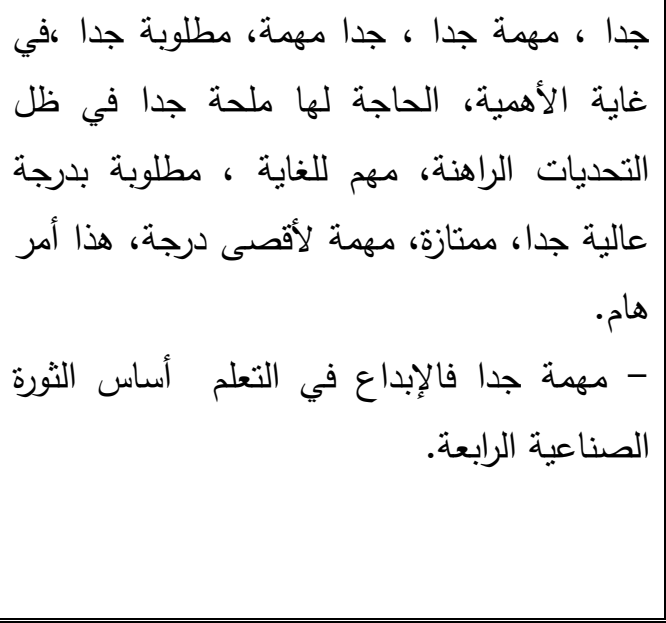 & 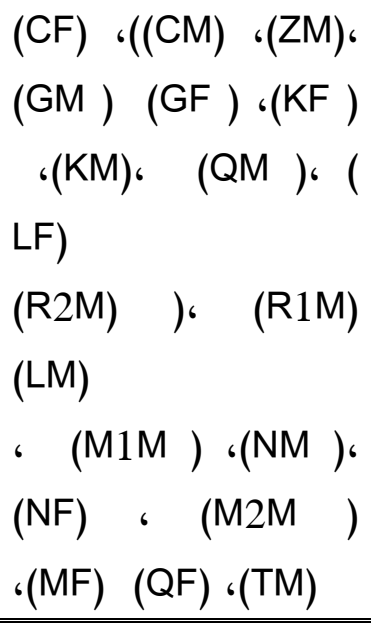 & كبيرة جدا & \\
\hline مهمة بدرجة كبيرة، الحاجة إليها مهمة. كبيرة الأهمية ، & $\begin{array}{lll}(\mathrm{RF}) & \text { (WM) }(\mathrm{T} \\
\mathrm{F}) & & \\
\text { ، } & \end{array}$ & كبيرة & \\
\hline
\end{tabular}


ب-تم سؤال الخبراء عن المهارات الفرعية المنبثقة عن مهارات التعلم والإبداع، وجاءت إجاباتهم كما هو موضح من التحليل المدون بالجدول التالي:

جدول (^): نتائج تحليل استجابات عينة الخبراء في المقابلة عن المهارات الفرعية

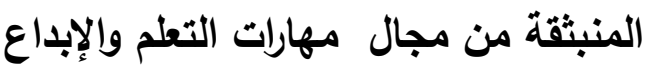

\begin{tabular}{|c|c|c|}
\hline أمثلة لنصوص الاقتباسات الدالة على & أصحاب الرأي من & المهارة الفرعية المنبثقة عن \\
\hline 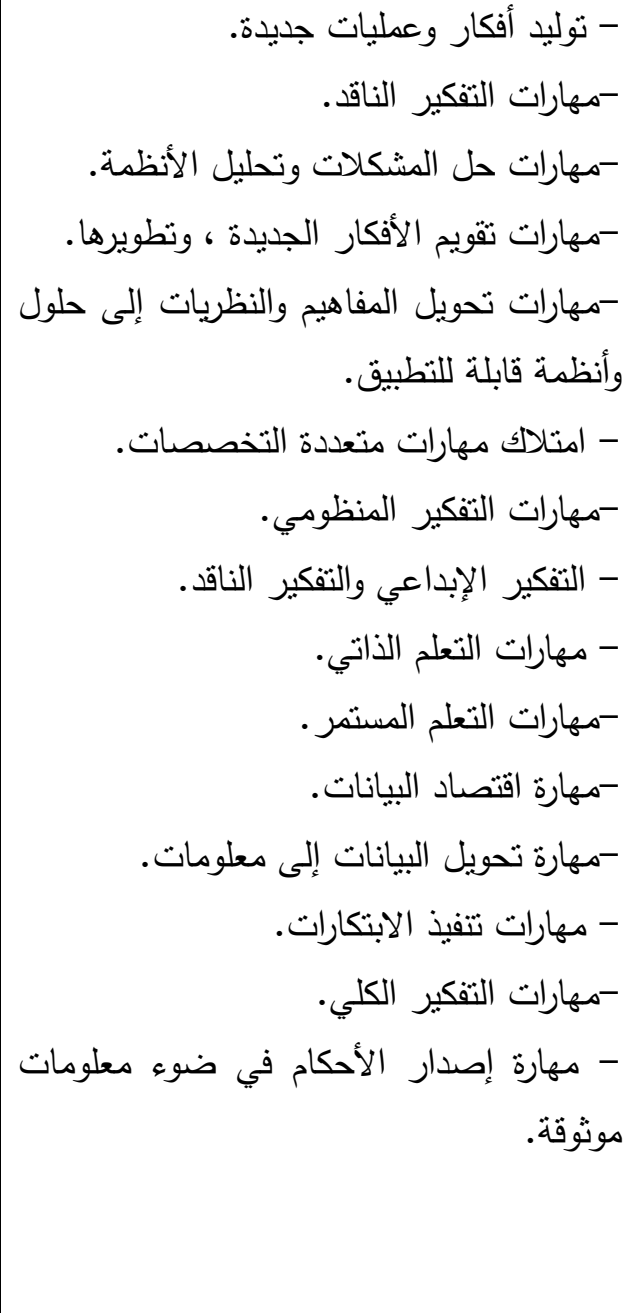 & $\begin{array}{l}(\mathrm{CF}) ،(\mathrm{CM}) \bullet(\mathrm{ZM}) \\
(\mathrm{KF}) \text { ‘(GF })(\mathrm{KM}) \\
(\mathrm{QM})(\mathrm{QF} \cdot(\mathrm{R} 1 \mathrm{M}) \text { ‘ } \\
(\mathrm{TF})(\mathrm{GM})(\mathrm{TM}) . \\
(\mathrm{R} 2 \mathrm{M})(\mathrm{RF}) \cdot(\mathrm{WM}) \\
(\mathrm{NF})(\mathrm{M} 1 \mathrm{M})(\mathrm{NM}) \\
(\mathrm{M} 2 \mathrm{M}(\mathrm{MF})(\mathrm{LM})(\mathrm{LF})\end{array}$ & 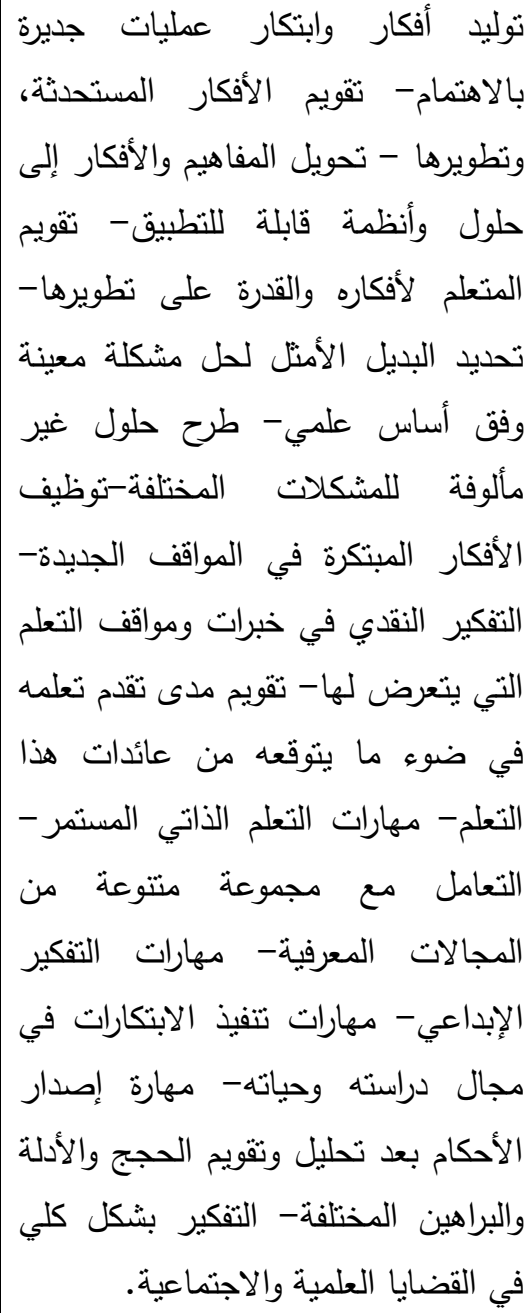 \\
\hline
\end{tabular}

ويتضح من خلال تحليل إجابات الخبراء توافقهم حول أهمية مهاراة التعلم والإبداع لطلاب المرحلة الثانوية لمواكبة الثورة الصناعية الرابعة، فهي مهمة بدرجة كبيرة جداء కo 
مهارات الثورة الصناعية الرابعة اللازمة أ.د. حمال السيسى أ.د.م. أحمد السويكت أ.د.م. محمود مصطفى

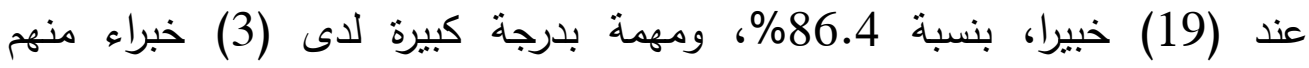
كبنسبة 13.6\%، كما أن ثمة نوافقا كبيرا حول المهارات الفرعية المنبثقة عن مجال مهارات التعلم والابتكار . - مهات -مهارات المواطنة العالمية اللازمة لطلاب المرحلة الثانويـة العامـة لمواكبة متطلبات الثورة الصناعية الرابعة. أ-تم سؤال الخبراء عن مدى حاجة طلاب مرحلة التعليم الثانوي لمهارات المواطنة العالمية ، ولإجحابة عن

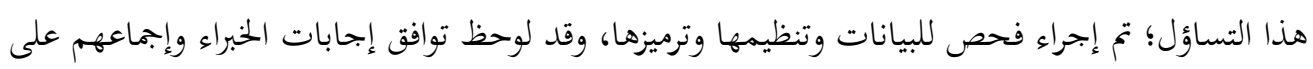

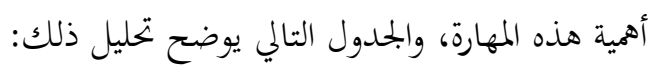

جدول (9): نتائج تحليل استجابات عينة الخبراء في المقابلة عن أهمية مجال مهارات المواطنة العالمية

\begin{tabular}{|c|c|c|c|}
\hline أمثلة لنصوص الاقتباسات الدالة & ألخحبراء & الأهمية & त \\
\hline 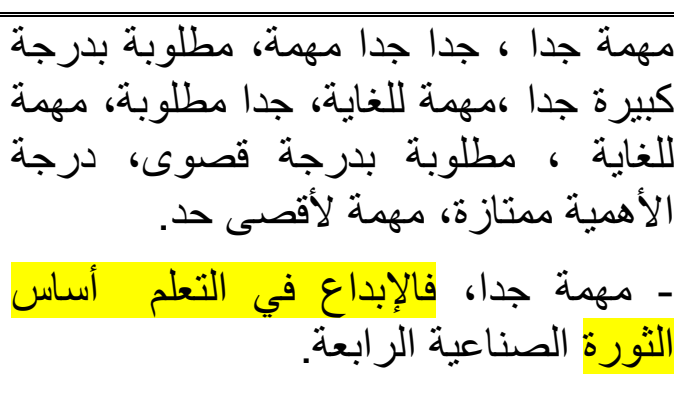 & 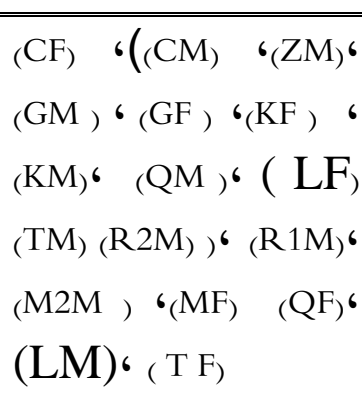 & كبيرة جدا & .1 \\
\hline 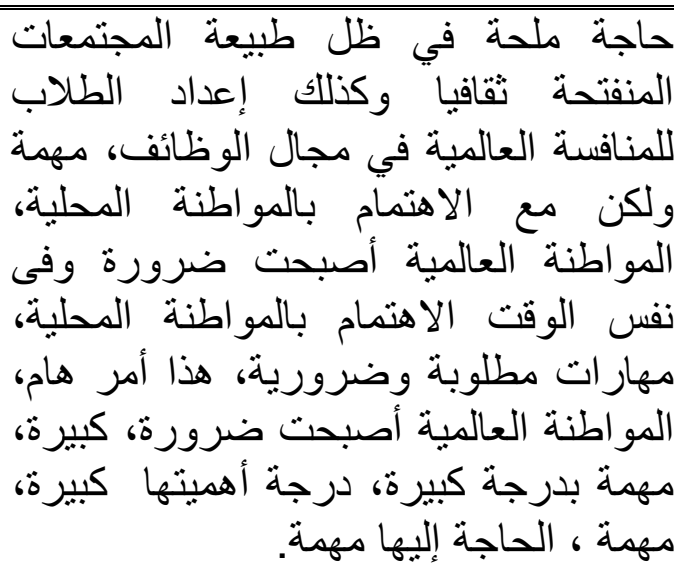 & $\begin{array}{l}(\mathrm{RF}) \cdot(\mathrm{WM}) \\
\text { ' }(\mathrm{M} 1 \mathrm{M})(\mathrm{NM}) \cdot(\mathrm{NF})\end{array}$ & كبيرة &.$r$ \\
\hline
\end{tabular}


ب-تم سؤال الخبراء عن المهارات الفرعية المنبثقة عن مهارات المواطنة العالمية، وجاءت إجاباتهم كما هو موضح من التحليل المدون بالجدول التالي:

جدول (• (1): نتائج تحليل استجابات عينة الخبراء في المقابلة عن المهارات الفرعية المنبثقة عن مجال مهارات المواطنة العالمية

\begin{tabular}{|c|c|c|}
\hline 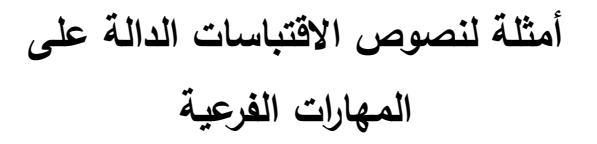 & أصحاب الرآي من & ه العالمب \\
\hline -مهارة المعرفة والتفكير النقدي في القضايا & $\begin{array}{l}(\mathrm{CF}) \cdot(\mathrm{CM}) \cdot(\mathrm{ZM}) \\
(\mathrm{KF}) \cdot(\mathrm{GF})(\mathrm{KM}) \\
(\mathrm{QM}) \quad(\mathrm{QF}\end{array}$ & 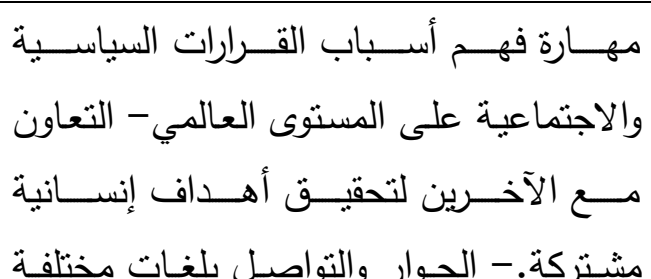 \\
\hline -مهارات أداء أدوار نشطة لمواجهة & $\begin{array}{l}\text { ،) }(\mathrm{R} 1 \mathrm{M}) \\
(\mathrm{GM})(\mathrm{TM}) .\end{array}$ & 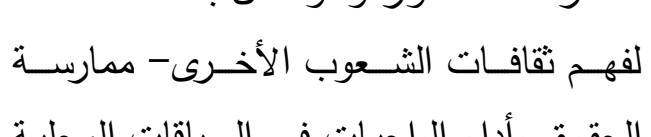 \\
\hline 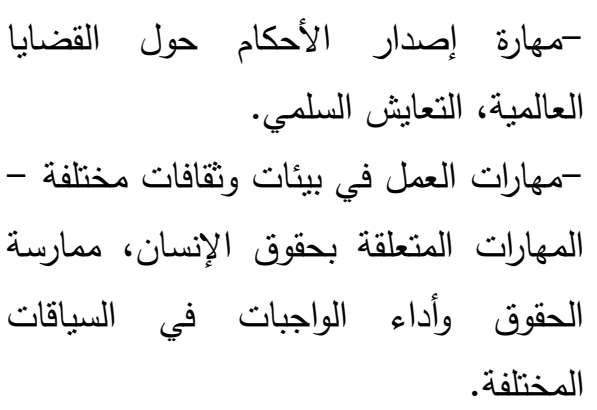 & $\begin{array}{l}(\mathrm{R} 2 \mathrm{M}) \quad(\mathrm{RF}) \\
6(\mathrm{WM}) \quad \text { (NF }) \\
(\mathrm{M} 1 \mathrm{M})(\mathrm{NM}) \\
(\mathrm{M} 2 \mathrm{M}(\mathrm{MF})(\mathrm{LM}) \\
(\mathrm{LF})\end{array}$ & 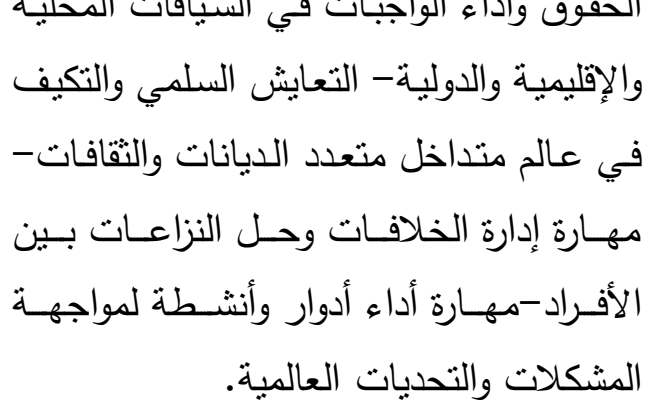 \\
\hline 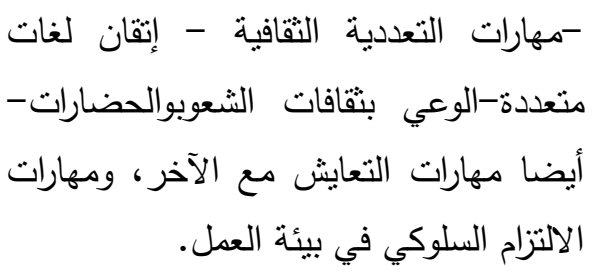 & & \\
\hline
\end{tabular}

ويتضح من خلال تحليل إجابات الخبراء توافقهم حول أهمية مهارات المواطنة العالمية لطلاب المرحلة الثانوية

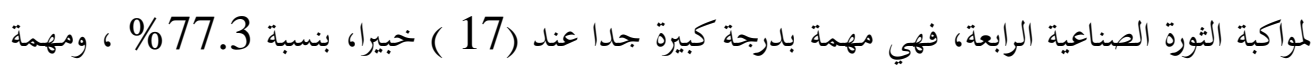
بدرجة كبيرة لدى (5 ) خبراء منهم ،بنسبة 22.7\% ، كما أن ثمة توافقا كبيرا حول المهارات الفرعية المنبثقة عن بحال مهارات المواطنة العالمية. 
مهارات الثورة الصناعية الرابعة اللازمة أ.د. حمال السيسى أ.د.م. أحمد السويكت أ.د.م. محمود مصطفى

-مهارات النفكير الأخلاقي اللازمة لطلاب المرحلة الثانوية العامة لمواكبة مثطلبات الثورة الصناعية

الرابعة.

أ-تم سؤال الخبراء عن مدى حاجة طلاب مرحلة التعليم الثانوي لمهارات التفكير الأخلاقي ، ولإججابة عن هذا التساؤل؛ تم إجراء فحص للبيانات وتنظيمها وترميزها، وقد لوحظ توافق إجابات الخبراء وإجماعهم على لهي

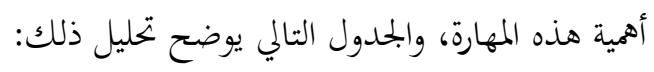

جدول ( (1 ) : نتائج تحليل استجابات عينة الخبراء في المقابلة عن أهمية مجال مهارات التفكير الأخلاقي

\begin{tabular}{|c|c|c|c|}
\hline أمثلة لنصوص الاقتباسات الدالة & أصحاب الرأي من & درجةة & r \\
\hline 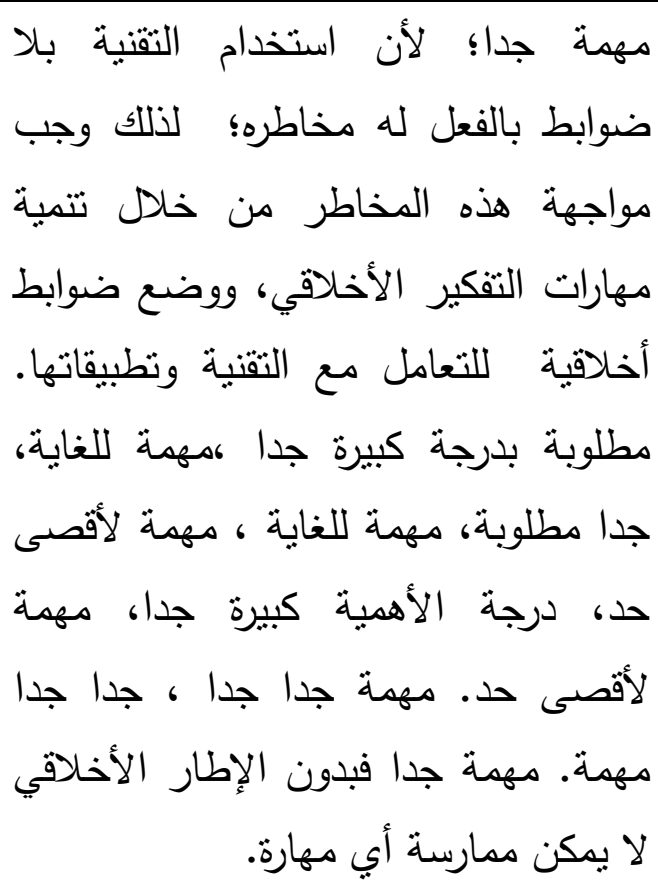 & 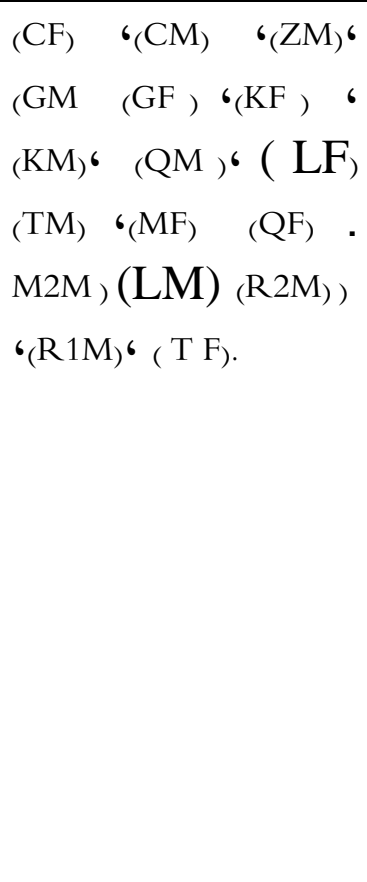 & كبيرة جدا & 1 \\
\hline ملحهة جدا فلا علم ولا عمل دون إطار & $\begin{array}{l}(\mathrm{RF}) \cdot(\mathrm{WM}) \\
6(\mathrm{M} 1 \mathrm{M})(\mathrm{NM})^{6}(\mathrm{NF})\end{array}$ & كبيرة & $r$ \\
\hline
\end{tabular}


مجلة الدراسات التريوية والانسانية ـ كلية التربية ـ جامعة دمنهور ـ المجلا الحادى عشر - العدد الرابع - الجزء الثانى - لسنة 9 ا ـ

أهميتها كبيرة، مهمة ، الحاجة إليها

عالية، مطلوبة بدرجة كبيرة.

ب-تم سؤال الخبراء عن المهارات الفرعية المنبثة عن مهارات التفكير الأخلاقي ، وجاءت لبهرة

إجاباتهم كما هو موضح من التحليل المدون بالجدول التالي:

جدول(Y Y): نتائج تحليل استجابات عينة الخبراء في المقابلة عن المهارات الفرعية المنبثقة عن

مجال مهارات التفكير الأخلاقي.

\begin{tabular}{|c|c|c|}
\hline 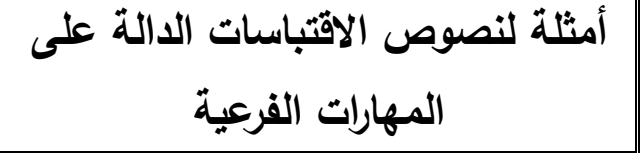 & إs & ملاقي \\
\hline 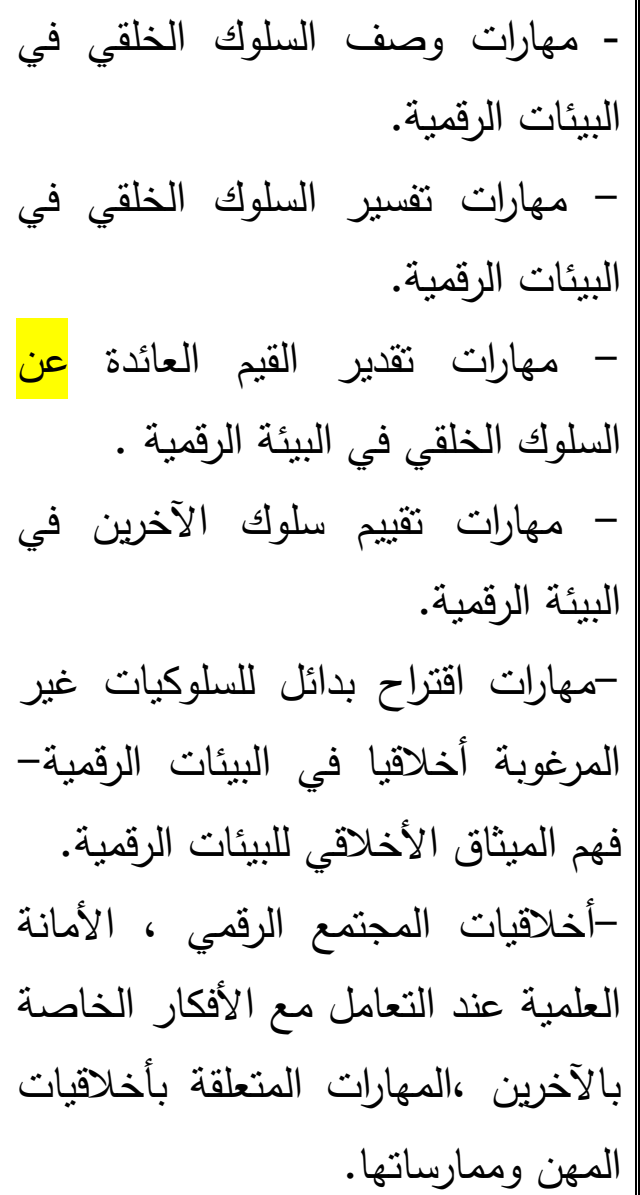 & $\begin{array}{l}(\mathrm{KF}) \text { ‘(GF })(\mathrm{KM}) \\
(\mathrm{QM}) \quad(\mathrm{QF} 6)(\mathrm{R} 1 \mathrm{M}) \text { ‘ } \\
(\mathrm{TF})(\mathrm{GM})(\mathrm{TM}) . \\
(\mathrm{R} 2 \mathrm{M})(\mathrm{RF}) \cdot(\mathrm{WM}) \\
(\mathrm{NF})(\mathrm{M} 1 \mathrm{M})(\mathrm{NM}) \\
(\mathrm{M} 2 \mathrm{M}(\mathrm{MF})(\mathrm{LM})(\mathrm{LF})\end{array}$ & 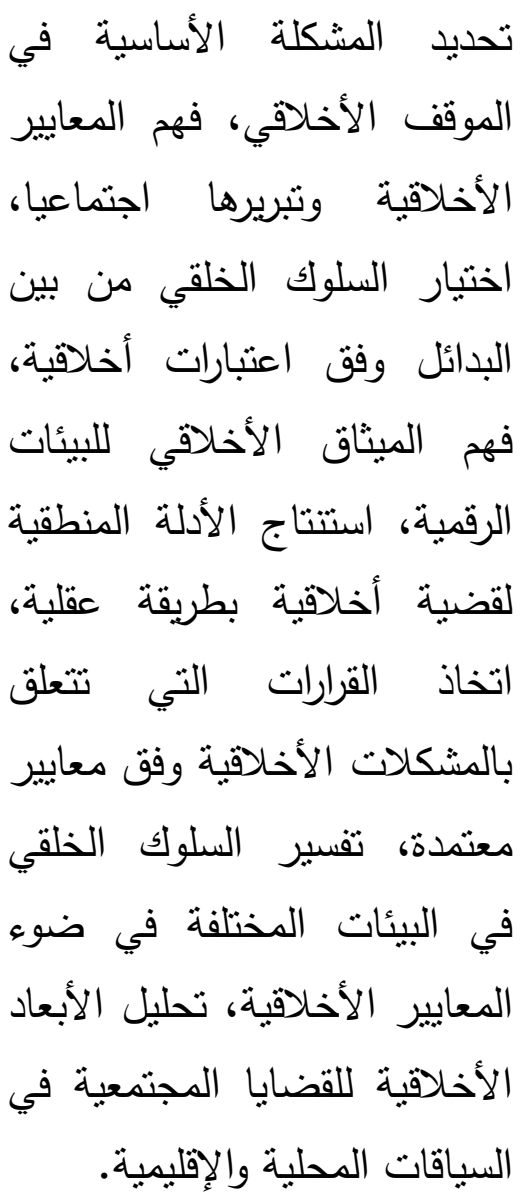 \\
\hline
\end{tabular}


مهارات الثورة الصناعية الرابعة اللازمة أ.د. حمال السيسى أ.د.م. أحمد السويكت أ.د.م. محمود مصطفى

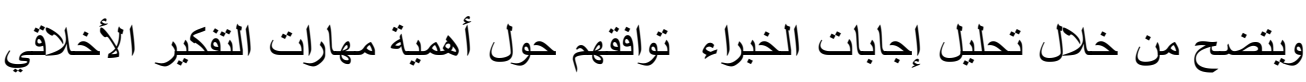

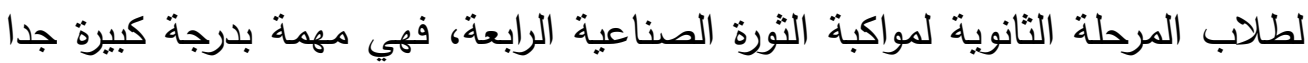

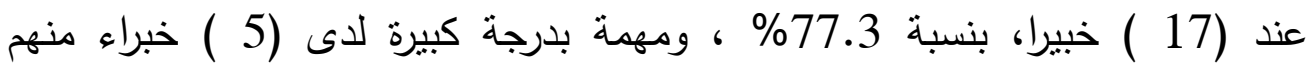
كبنسبة 22.7\% ، كما أن ثمة نوافقا كبيرا حول المهارات الفرعية المنبتقة عن مجال

$$
\text { مهارات التفكير الأخلاقي. }
$$

-المهارات الشخصية اللازمة لطلاب المرحلة الثانوية العامة لمواكبة متطلبات الثورة

الصناعية الرابعة.

أ- تم سؤال الخبراء عن مدى حاجة طلاب مرحلة التعليم الثانوي للمهارات الشخصية، وللإجابة عن هذا التساؤل؛ تم إجراء فحص للبيانات وتنظيمها وترميزها، وقد لوحظ توافق مأق إجابات الخبراء وإجماعهم على أهمية هذه المهارة، والجدول التالي يوضح تحليل ذلك: جدول (با (1): نتائج تحليل استجابات عينة الخبراء في المقابلة عن أهمية مجال المهارات المواطنة الشخصية

\begin{tabular}{|c|c|c|c|}
\hline أمثثة لنصوص الاقتباسات الدالة & أصحاب الرأي من & الأهمية & r \\
\hline 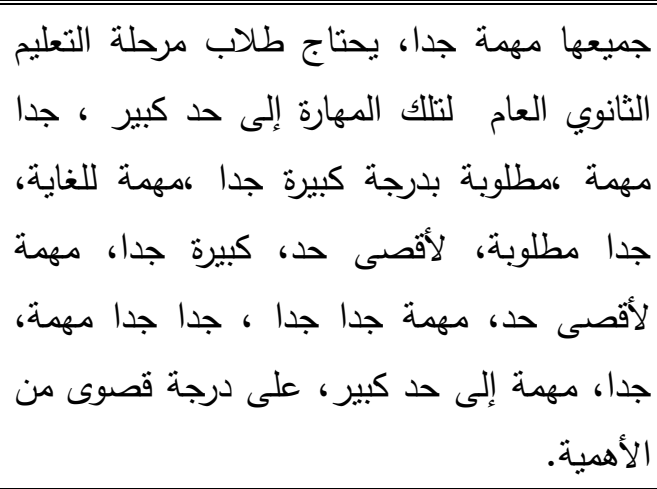 & 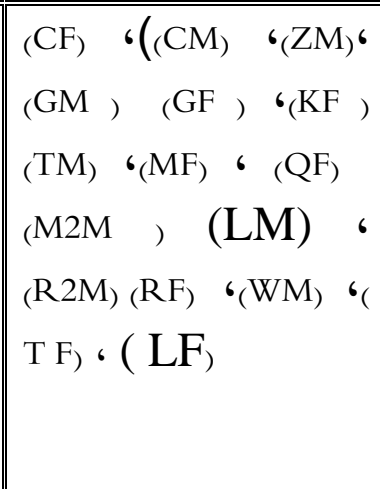 & كبيرة جدا & .1 \\
\hline 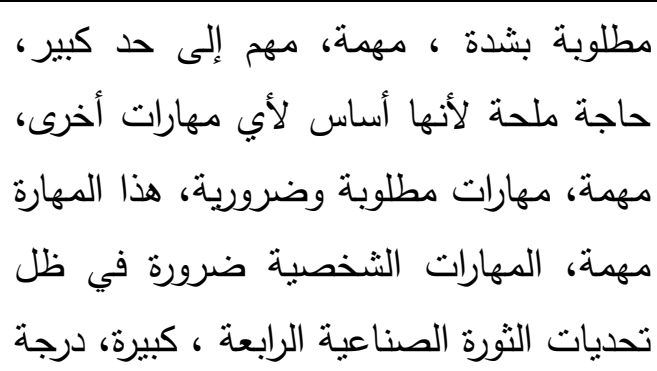 & $\begin{array}{l}6(\mathrm{M} 1 \mathrm{M})(\mathrm{NM})^{6}(\mathrm{NF}) \\
6(\mathrm{R} 1 \mathrm{M})(\mathrm{KM})^{6}(\mathrm{QM})^{6}\end{array}$ & كبيرة & $r$ \\
\hline
\end{tabular}


مجلة الدراسات التريوية والانسانية ـ كلية التربية ـ جامعة دمنهور ـ المجلد الحادى عشر - العدد الرابع - الجزء الثانى - لسنة 9 .

أهميتها كبيرة، مهمة ، الحاجة إليها عالية،

مطلوبة بدرجة كبيرة. مطلوبة.

ب- تم سؤال الخبراء عن المهارات الفرعية المنبثقة عن المهارات الشخصية ، وجاءت إجاباتهم

كما هو موضح من التحليل المدون بالجدول التالي:

جدول (ع ( ): نتائج تحليل استجابات عينة الخبراء في المقابلة عن المهارات الفرعية المنبثقة عن

مجال المهارات الثخصية

\begin{tabular}{|c|c|c|}
\hline أمثلة لنصوص الاقتباسات الدالة على & أصحاب الرأي من & المهارة الفرعية المنبثقة عن \\
\hline 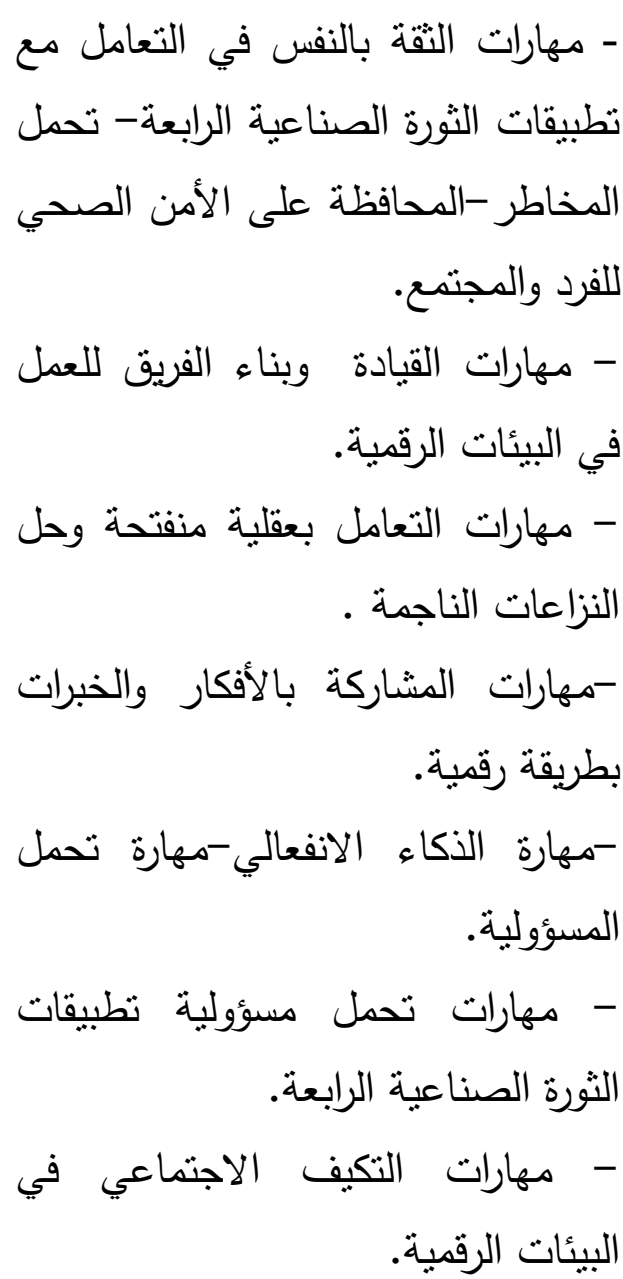 & $\begin{array}{rrr}(\mathrm{ZM}) & 6(\mathrm{CM}) & 6 \mathrm{CF}) \\
(\mathrm{GF}) & 6(\mathrm{GM} & (\mathrm{KF}) \\
& (\mathrm{QF})(\mathrm{KM})(\mathrm{QM} \\
& \\
(\mathrm{TF}) & \\
(\mathrm{R} 1 \mathrm{M}) & (\mathrm{R} 2 \mathrm{M}) \\
(\mathrm{NF}) & 6(\mathrm{WM}) & 6(\mathrm{RF}) \\
& \\
(\mathrm{M} 1 \mathrm{M}) & (\mathrm{NM}) & (\mathrm{M} 2 \mathrm{M} \\
(\mathrm{MF}) & (\mathrm{LM}) & (\mathrm{LF}) \\
& \\
& (\mathrm{TM})\end{array}$ & 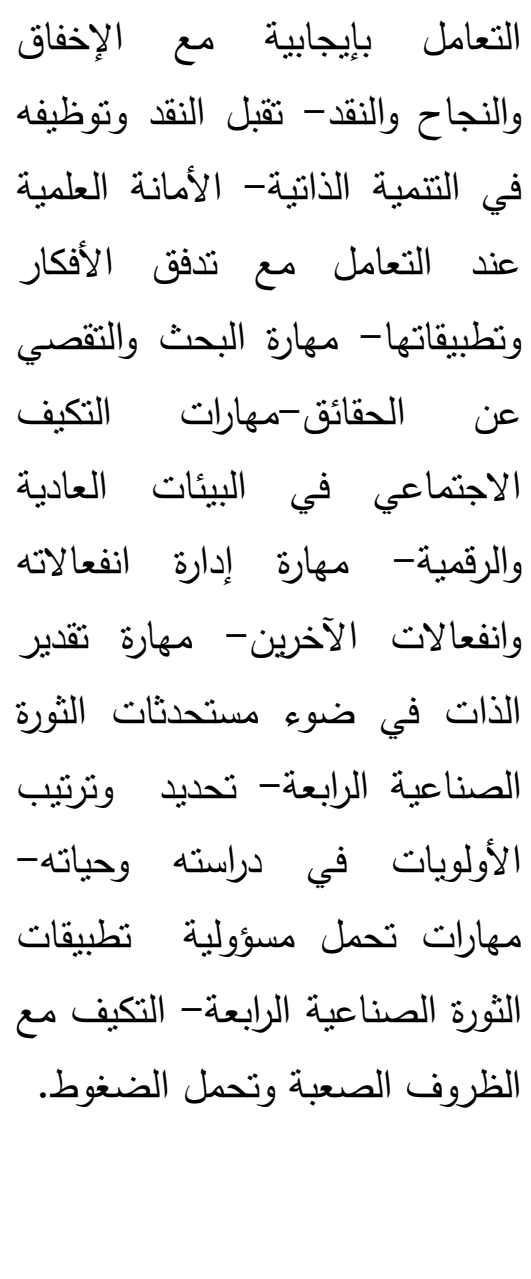 \\
\hline
\end{tabular}


مهارات الثورة الصناعية الرابعة اللازمة أ.د. حمال السيسى أ.د.م. أحمد السويكت أ.د.م. محمود مصطفى

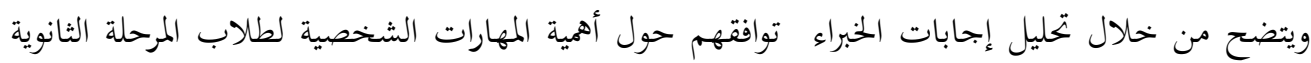

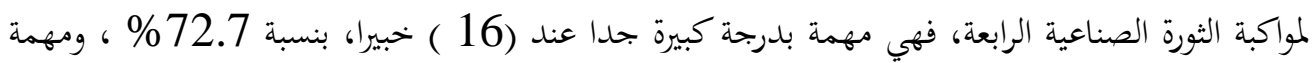

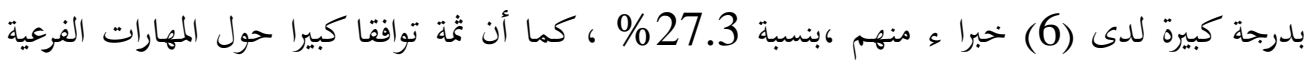
المنبثقة عن بحال مهارات الشخصية.

-المهارات الحياتية والوظيفية اللازمة لطلاب المرحلة الثانوية العامة لمواكبة متطلبات الثورة

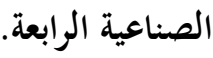

أ-تم سؤال الخبراء عن مدى حاجة طلاب مرحلة التعليم الثانوي للمهارات الحياتية والوظيفية ، ولإجابة إنابة

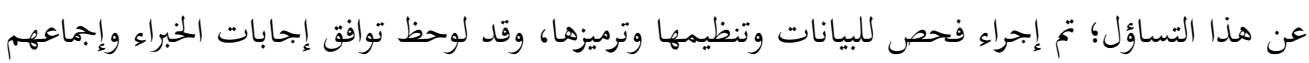

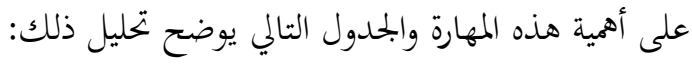
جدول (0) (1): نتائج تحليل استجابات عينة الخبراء في المقابلة عن أهمية مجال المهارات الحياتية والوظيفية

\begin{tabular}{|c|c|c|c|}
\hline أمثلة لنصوص الاقتباسات الدالة & أصحاب الرأي من & الأهمية & r \\
\hline 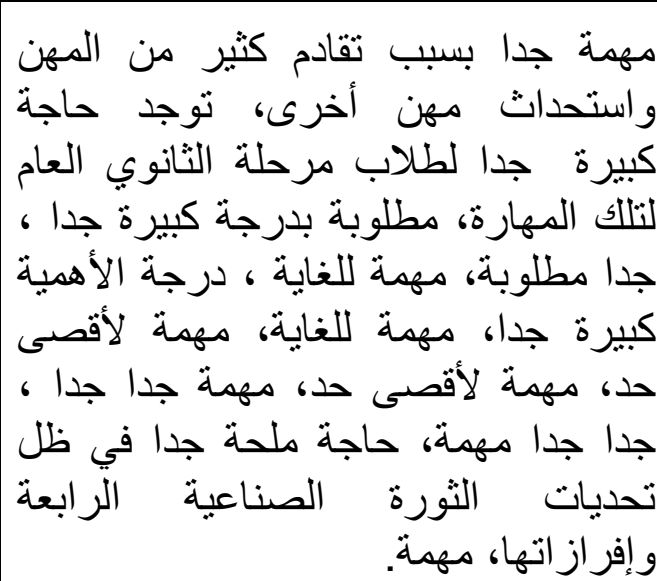 & 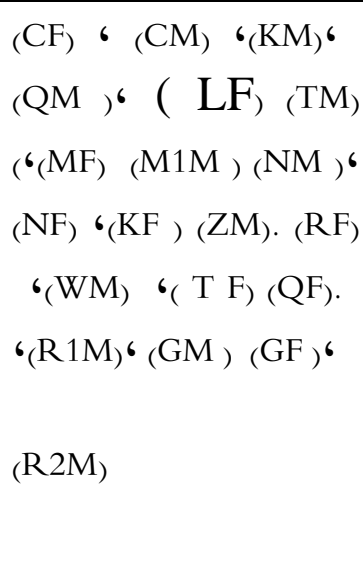 & كبيرة جدا & .1 \\
\hline 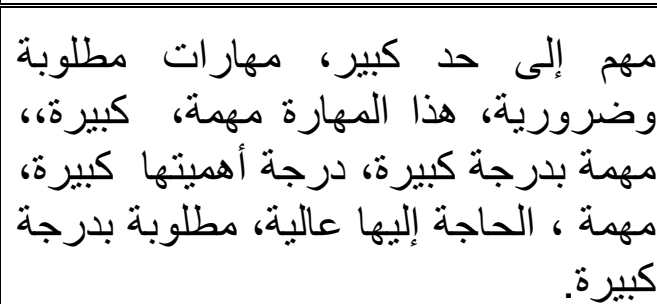 & (M2M) (LM) & كبيرة & $\overline{. r}$ \\
\hline
\end{tabular}


ب- تم سؤال الخبراء عن المهارات الفرعية المنبثقة عن المهارات الحياتية والوظيفية، ولإجابة عن هذا التساؤل؛ تم إجراء فحص للبيانات وتنظيمها وترميزها، وقد لوحظ توافق إجابات الحبراء وإجماعهم على أهمية هذه المهارة، والجحدول التالي يوضح تحليل ذلك:

جدول (ع ا): نتائج تحليل استجابات عينة الخبراء في المقابلة عن مهارات الفرعية المنبثة عن

مجال المهارات الحياتية والوظيفية

\begin{tabular}{|c|c|c|}
\hline 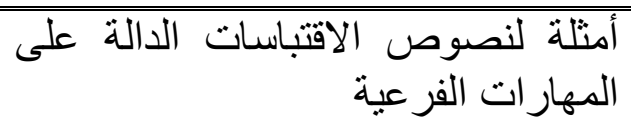 & أحبر اء & المهار ات الحهارة الفرعية و المنبيثة ع عن \\
\hline 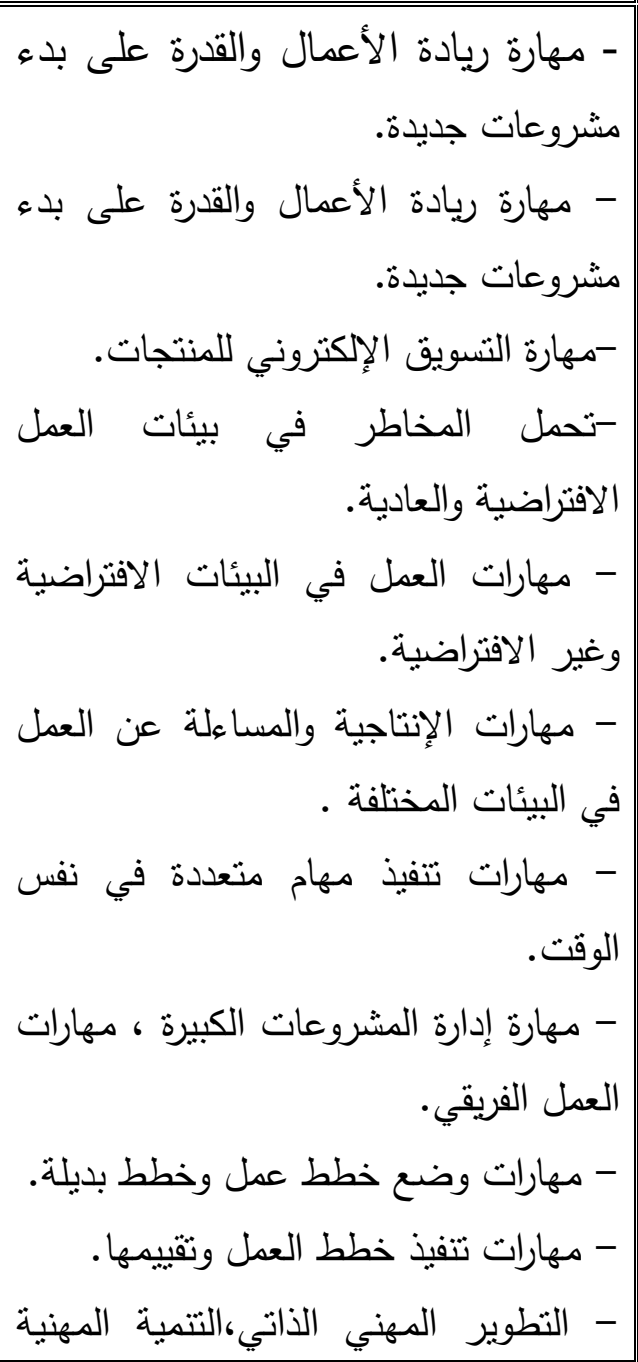 & 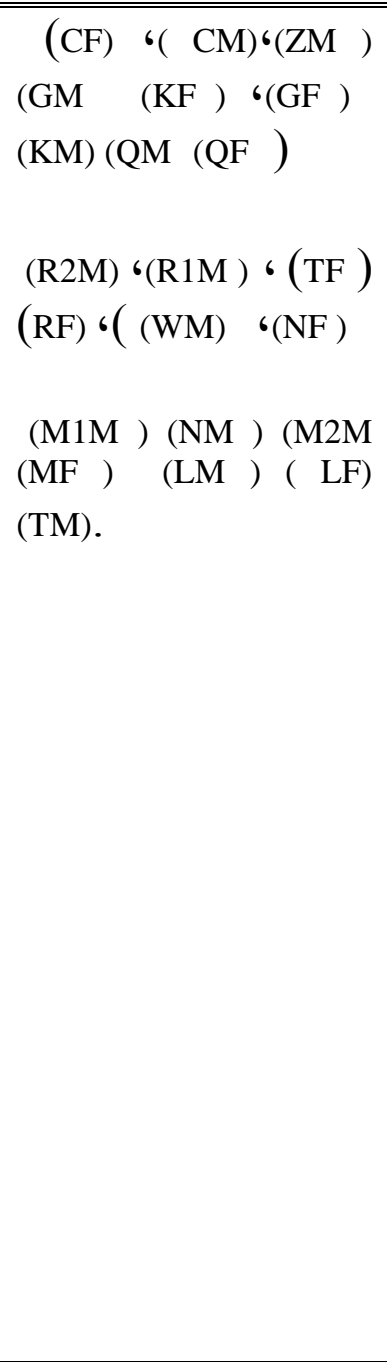 & 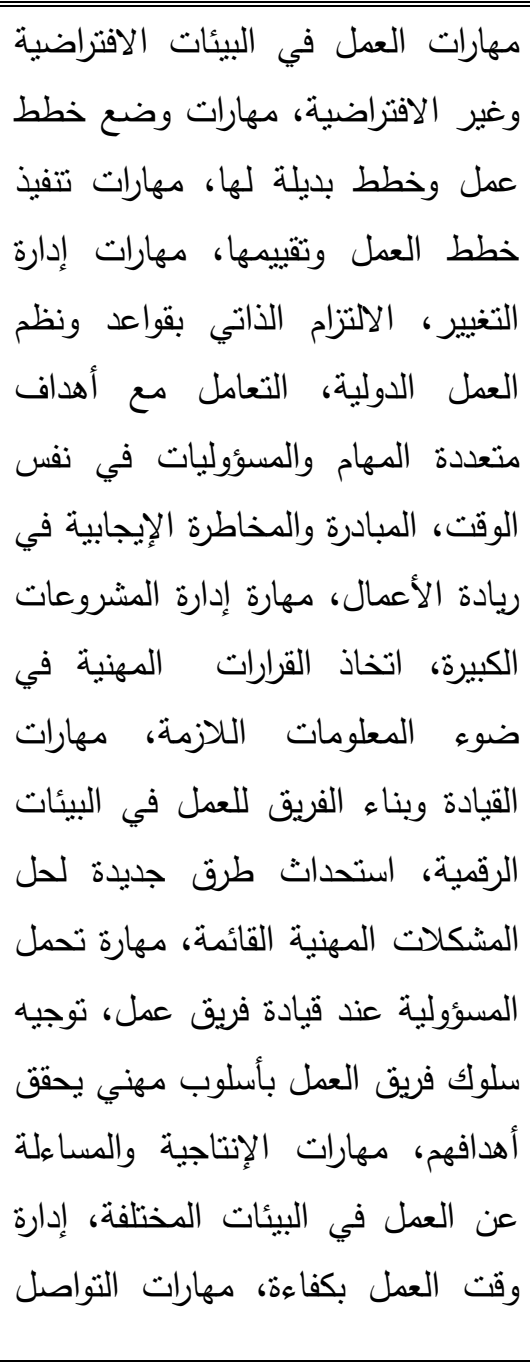 \\
\hline
\end{tabular}


مهارات الثورة الصناعية الرابعة اللازمة أ.د. حمال السيسى أ.د.م. أحمد السويكت أ.د.م. محمود مصطفى

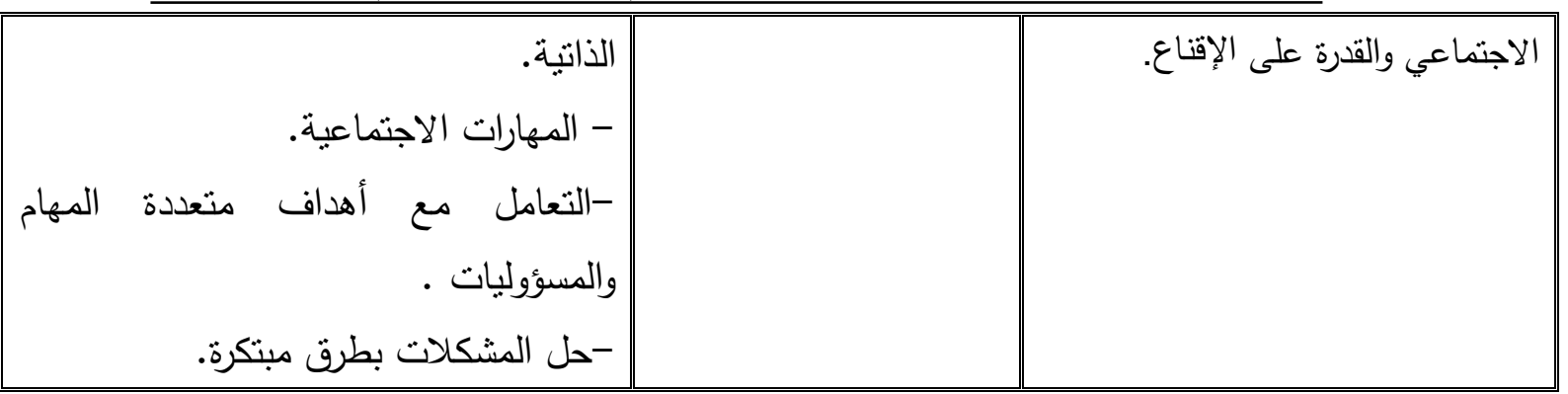

ويتضح من خلال تحليل إجابات الخبراء توافقهم حول أهمية المهارات الحياتية والوظيفية لطلاب المرحلة

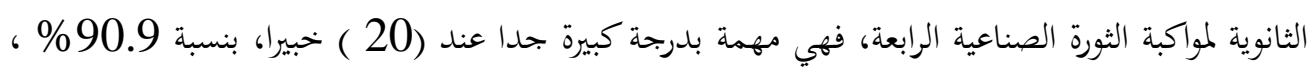
ومهمة بدرجة كبيرة لدى (2 ) خبيرين منهم، بنسبة 9.1\%، كما أن ثمة توافقا كبيرا حول المهارات الفرعية المنبثقة عن بحال المهارات الحياتية والوظيفية. المناقشة الإجمالية لمهارات الثورة الصناعية الرابعة اللازمة لطلاب المرحلة الثانوية العامة مِنْ وجهة نظر المشاركين بالمقابلات : أظهرت نتائج المقابلات توافقا كبيرا حول مهارات الثورة الصناعية الرابعة بصفة عامة ، وفي جميع

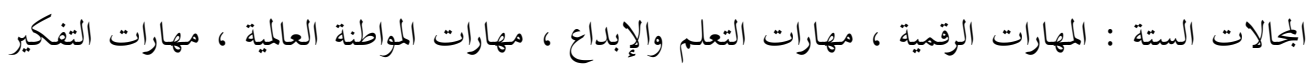
الأخلاقي، المهارات الشخصية ،المهارات الحياتية والوظيفية، كما أظهر الخبراء توافقا حول المهارات الفرعية

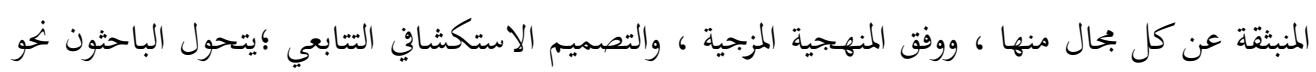
المرحلة الثانية مرحلة البيانات الكمية .

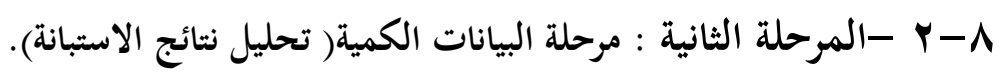
بناء على ما توصل إليه الباحثون من تحليلات ، وما توصلوا إليه من بيانات نوعية عن المحالات

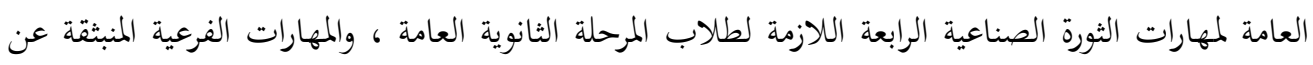

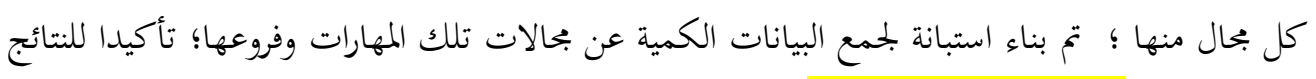
الأولية النوعية التي حصلوا عليها الدراسة من خلال المقابلة، وتعميقا لها من وجهة نظر أوسع. وفيما يلي

$$
\text { عرض مفصل لتلك النتائج ، وفق مستويين هما: }
$$

- مستوى المهارات الفرعية المنبثقة عن كل بحال.

- درجة أهمية مجالات مهارات الثورة الصناعية الرابعة اللازمة لطلاب المرحلة الثانوية العامة من وجهة نظر الخبراء: 
مجلة الدراسات التريوية والانسانية ـ كلية التربية ـ جامعة دمنهور ـ المجلد الحادى عثر - العدد الرابع - الجزء الثانى- لسنة 9 . ب r

ويمكن توضيح ذلك من خلال الجحدول التالي:

جدول (15) نتائج استجابات عينة الخبراء حول درجة أهمية مهارات الثورة الصناعية الرابعة اللازمة

لطلاب المرحلة الثانوية العامة.

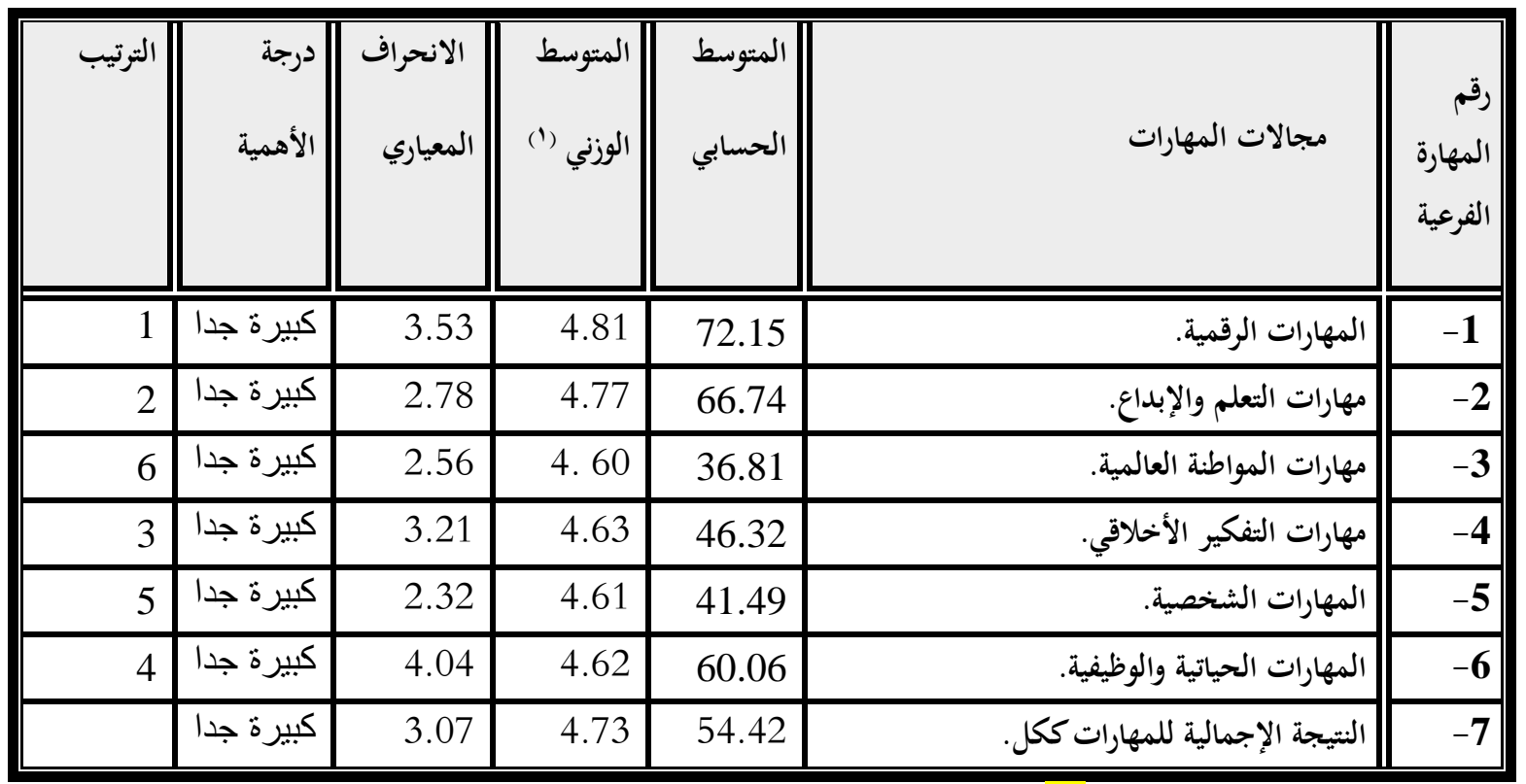

يتبين من الجدول رقم (15) ما يلي:

- أن درجة أهمية مهارات الثورة الصناعية الرابعة لطلاب التعليم الثانوي العام على مستوى

الاستبانة ككل من وجهة نظر الخبراء ، جاءت كبيرة جدا ، حيث بلغت قيمة المتوسط الوزني بلمالات

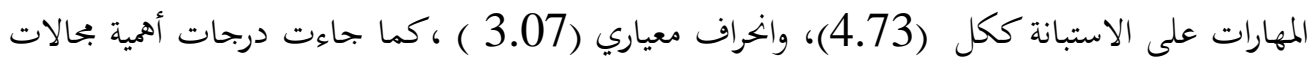

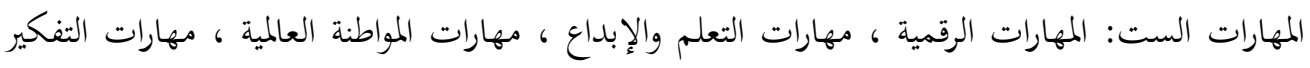
الأخلاقي، المهارات الشخصية ،المهارات الحياتية والوظيفية، كبيرة جدا كذلك ، حيث بلغت بهات متوسطاتها

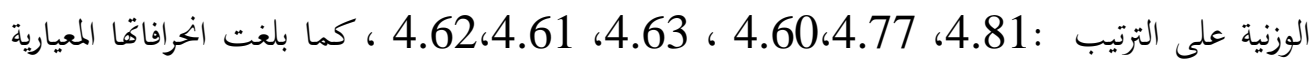
على الترتيب كذلك 3.53،2.78،2.56، 213.21، 2.32، 4.04 ،وذلك مقارنة بالمعايير الإحصائية التي اعتمدت عليها الدراسة ،حيث وقعت جميعا في مدى الاستجابة كبيرة جدا ، والذي يمتد مداه من لهن

4.2 إلى 5 جدول (4).

' ـ التوسط الوزني للمحور = المتوسط الحسابي للمحور / عدد مهاراته الفرعية.

00 
مهارات الثورة الصناعية الرابعة اللازمة أ.د. حمال السيسى أ.د.م. أحمد السويكت أ.د.م. محمود مصطفى

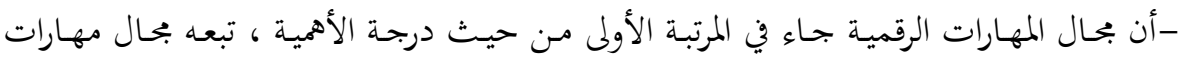

التعلم والإبـداع ، وأخسيرا جـاء بحـال مهارات المواطنـة العالميـة في المرتبـة السادسـة، يسبقه بحـال المهارات

الشخصية في المرتبة الخامسة. وتدل هذه النتائج على التوافق الكبير بين الخخبراء حول أهمية تلك المهارات

لطلاب المرحلة الثانوية العامة لمواكبة الثورة الصناعية الرابعة.

-درجـة أهميـة المهارات الفرعيـة المنبثقـة مـن مجـالات مهارات الثورة الصـناعية الرابعـة

اللازمة لطلاب المرحلة الثانوية العامة من وجهة نظر الخبراء:

ويمكن توضيح ذلك من خلال الجدول التالي:

جدول (16) نتائج استجابات عينة الخبراء في الاستبانة عن درجة أهمية المهارات الرقمية وفروعها.

\begin{tabular}{|c|c|c|c|c|}
\hline الأهمية & الانحراف & المتوسط الحسابي & المهارات الفرعية المنبثقة عن مجال المهارات الرقمية. & المهارة \\
\hline كبيرة & 0.55 & 4.89 & مهارات تنفيذ المهام بالأجهزة الذكية و البيئات الرقمية. & -1 \\
\hline كبيرة & 0.69 & 4.88 & الحصول على المعلومات من مصادر رقمية موثوق فيها. & $-r$ \\
\hline كبيرة & 0.62 & 4.97 & نقد المعلومات الرقمية المتاحة وتقويمها . & 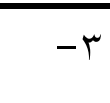 \\
\hline كبيرة & 0.74 & 4.81 & توليد معلومات جديدة مفيدة من المعلومات الرقمية المتاحة. & $-\varepsilon$ \\
\hline كبيرة & 0.61 & 4.83 & توظيف المعلومات الرقمية لمعالجة المشكلات التي تواجهه. & -0 \\
\hline كبيرة & 0.54 & 4.93 & التفاعل مع نظم إدارة المحتوى والتعلم الرقمي. & -7 \\
\hline كبيرة & 0.67 & 4.17 & مهارة ريادة الأعمال التقليدية والرقمية. & $-V$ \\
\hline
\end{tabular}


مجلة الدراسات التربوية والانسانية ـ كلية التربية ـ جامعة دمنهور ـ المجلد الحادى عشر - العدد الرابع - الجزء الثانى - لسنة 9 ـ ـ

\begin{tabular}{|c|c|c|c|c|}
\hline كبيرة & 0.45 & 4.81 & التقييم الذاتي لهعارفه ومهاراته الرقمية . & $-\Lambda$ \\
\hline كبيرة & 0.76 & 4.92 & توصيل المعلومات والرسائل عبر وسائط إعلامية متنوعة. & -9 \\
\hline كبيرة & 0.51 & 4.89 & مهارات تأسيسية للتعامل مع تطبيقات الثورة الصناعية الرابعة. & -1 \\
\hline كبيرة & 0.70 & 4.82 & السلامة والحماية لبيانات الشخصية والخصوصية والأجهزة. & -11 \\
\hline كبيرة & 0.64 & 4.87 & مهارة حل المشكلات الرقمية الناشئة. & $-1 r$ \\
\hline كبيرة & 0.71 & 4.85 & التواصل والعمل المشترك من خلال التقنيات الرقمية. & r \\
\hline كبيرة & 0.39 & 4.81 & الحكم على دقة المعلومات من المصادر المطبوعة والإلكترونية. & $-1 \varepsilon$ \\
\hline كبيرة - كبرة & 0.48 & 4.75 & مهارات الأرشفة والترميز والتصنيف الرقمي. & -10 \\
\hline كبيرة & 3.53 & 4.81 & المتوسط الحسابي لمجال المهارات الرقمية & --- \\
\hline الأهمية & الانحراف & المتوسط الحسابي & المهارات الفرعية المنبثة عن مجال مهار ات التعلم و الإبداع & رقم \\
\hline كبيرة & 0.44 & 4.89 & توليد أفكار وابتكار عمليات جديرة بالاهتمام. & -17 \\
\hline كبيرة & 0.51 & 4. 91 & تقويم الأفكار المستحدثة، وتطويرها. & $-1 V$ \\
\hline 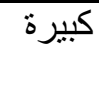 & 0.61 & 4.16 & مهارات تحويل الأفكار إلى مشروعات قابلة للتطبيق. & -11 \\
\hline
\end{tabular}




\begin{tabular}{|c|c|c|c|c|}
\hline كبيرة & 0.54 & 4.86 & تقويم المتعلم لأفكاره والقدرة على تطويرها. & -19 \\
\hline كبيرة & 0.66 & 4.93 & طرح حلول غير مألوفة للمشكلات المختلفة. & $-r \cdot$ \\
\hline كبيرة & 0.64 & 4.91 & توظيف الأفكار المبتكرة في المواقف الجديدة. & $-r_{1}$ \\
\hline كبيرة & 0.65 & 4.95 & التفكير النقدي في خبرات ومواقف التعلم التي يتعرض لها. & $-T^{2}$ \\
\hline جدبيرة & 0.46 & 4.89 & تقويم مدى تقدم تعلمه في ضوء ما يتوقعه من عائدات هذا التعلم. & $-r t$ \\
\hline كبيرة & 0.65 & 4.92 & مهارات التعلم الذاتي المستمر . & $-T \varepsilon$ \\
\hline 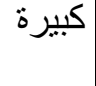 & 0.61 & 4.12 & التعامل مع مجموعة متنوعة من المجالات المعرفية. & $-r_{0}$ \\
\hline كبيرة & 0.64 & 4.92 & 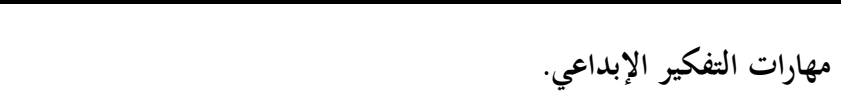 & $-r_{4}$ \\
\hline كبيرة & 0.88 & 4.81 & مهارات تنفيذ الابتكارات في مجال دراسته. & $-r V$ \\
\hline كبيرة & 0.74 & 4.94 & صهورة معلومات اقتصاد البيانات أي ترتيب وتنظيم وتحليل البيانات لتحويلها في & $-{ }^{\prime} \wedge$ \\
\hline كبيرة & 0.69 & 4.53 & مهارة إصدار الأحكام بعد تحليل وتقويم الحجج والأدلة، والبراهين & $-r_{9}$ \\
\hline كبيرة & 2.78 & 4.77 & المتوسط الحسابي لمجال مهارات التعلم والإبداع & --- \\
\hline الأهمية & 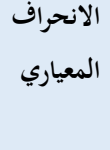 & المتوسط الحسابي المبي & المهارات الفرعية المنبثة عن مجال مهارات المو اطنة العالمية & الفهم \\
\hline كبيرة & 0,44 & 4.85 & التفكير النقدي في القضايا والمشكلات الإنسانية. & $-r$. \\
\hline 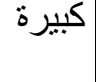 & 0,51 & 4.13 & بناء التعاطف الإنساني مع الشعوب الأخرى. & $-r_{1}$ \\
\hline
\end{tabular}


مجلة الدراسات التريوية والانسانية ـ كلية التربية ـ جامعة دمنهور ـ المجلد الحادى عشر - العدد الرابع - الجزع الثانى - لسنة 9 ـ ب

\begin{tabular}{|c|c|c|c|c|}
\hline كبيرة & 0.59 & 4.77 & التعاون مع الآخرين لتحقيق أهداف إنسانية مشتركة. & $-r t$ \\
\hline كبيرة & 0.59 & 4.93 & الحوار والتواصل بلغات مختلفة لفهم ثقافات الثعوب الأخرى. & Lr \\
\hline كبيرة & 0.61 & 4.91 & مالدولة الحقوق وأداء الواجبات في السياقات المحلية والإقليمية & $-r \varepsilon$ \\
\hline كبيرة & 0.53 & 4.89 & التعايش السلمي والتكيف في عالم متداخل متعدد الديانات والثقافات. & $-r_{0}$ \\
\hline كبيرة & 0.45 & 4.15 & وحل النزاعات بين الأفراد. & $-r$ צ \\
\hline كبيرة & 0.48 & 4.17 & مهارة أداء أدوار وأنشطة لمواجهة المشكلات والتحديات العالمية. & $-r v$ \\
\hline كبيرة & 2.56 & 4. 60 & المتوسط الحسابي لمجال مهارة المواطنة العالمية & -- \\
\hline درجة الأهمية & الانحراف & المتوسط الحسابي & مجال مهار ات التفكير الأخلاقي & رقمارة \\
\hline كبيرة & 0.53 & 4.16 & تحديد المشكلة الأساسية في الموقف الأخلاقي بالبيئة الرقمية. & $-r \wedge$ \\
\hline كبيرة & 0.54 & 4.75 & فهم المعايير الأخلاقية وتبريرها اجتماعيا. & $-r q$ \\
\hline كبيرة & 0.60 & 4.83 & 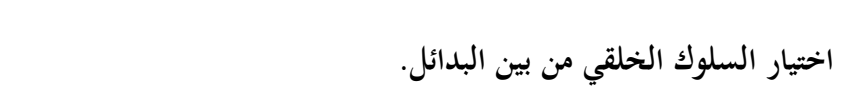 & $-\varepsilon$. \\
\hline كبيرة & 0.69 & 4.74 & اتخاذ القرارات التي تتعلق بالمشكلات الأخلاقية وفق معايير محددة. & $-\varepsilon 1$ \\
\hline كبيرة & 0.58 & 4.19 & استنتاج الأدلة المنطقية حول القضية الأخلاقية . & $-\varepsilon r$ \\
\hline كبيرة & 0.81 & 4.18 & فهم الميثاق الأخلاقي للتعامل مع البيئات الرقمية. & $-\varepsilon r$ \\
\hline كبيرة & 0.85 & 4.87 & تفسير السلوك الخلقي في البيئات المختلفة في ضوء المعايير الأخلاقية. & $-\varepsilon \varepsilon$ \\
\hline
\end{tabular}




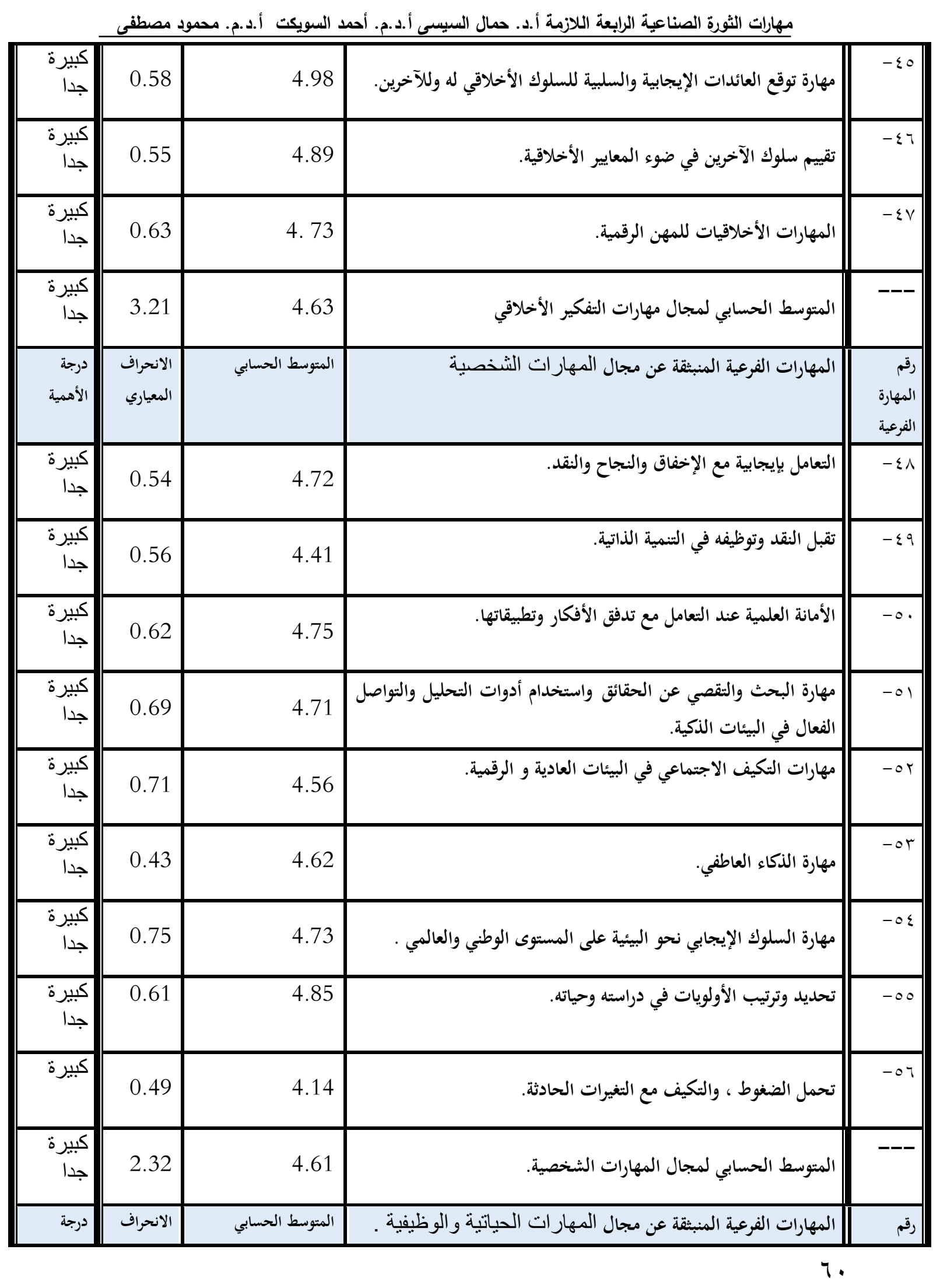


مجلة الدراسات التريوية والانسانية ـ كلية التربية ـ جامعة دمنهور ـ المجلد الحادى عشر - العدد الرابع - الجزء الثانى - لسنة 9 ـ ب

\begin{tabular}{|c|c|c|c|c|}
\hline الأهمية & 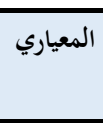 & & & الفرعية \\
\hline كبيرة & 0.59 & 4.95 & مهارات العمل في البيئات الافتراضية وغير الافتراضية. & $-O V$ \\
\hline جديرة & 0.51 & 4.86 & مهارات وضع خطط عمل وخطط بديلة لها. & $-0 \wedge$ \\
\hline كبيرة & 0.76 & 4.75 & مهارات تنفيذ خطط العمل وتقييمها & -09 \\
\hline جبيرة & 0.53 & 4.72 & 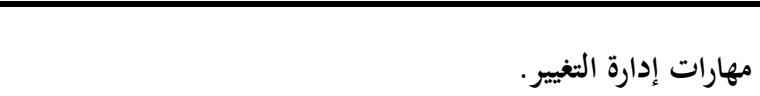 & -7 \\
\hline كبيرة & 0.61 & 4.15 & التعامل مع أهداف متعددة المهام في نفس الوقت. & -71 \\
\hline كبيرة & 0.99 & 4.19 & مهارة إدارة المشروعات التعليمية افتراضيا. & Tr \\
\hline كدبيرة & 0.82 & 4.62 & اتخاذ القرارات داخل فرق العمل في ضوء المعلومات اللازمة. & $-7 t$ \\
\hline كبيرة & 0.72 & 4.81 & مهارات القيادة وبناء الفريق للعمل في البيئات الرقمية. & $-7 \varepsilon$ \\
\hline كبيرة & 0.74 & 4.17 & استحداث طرق جديدة لحل المشكلات القائمة في العمل الفريقي. & -70 \\
\hline كبيرة & 0.59 & 4.85 & مهارة تحمل مسؤولية قيادة فرق العمل. & -77 \\
\hline كبيرة & 0.44 & 4.16 & توجيه سلوك فريق العمل بأسلوب يحقق أهدافهم. & $-7 V$ \\
\hline جدبيرة & 0.39 & 4.92 & إدارة وقت العمل بكفاءة. & $-7 \wedge$ \\
\hline كبيرة & 0.57 & 4.91 & مهارات التواصل الاجتماعي والقدرة على الإقناع. & -79 \\
\hline كدبيرة & 3.07 & 4.67 & متوسط مهارات الثورة الصناعية الرابعة ككل & --- \\
\hline
\end{tabular}




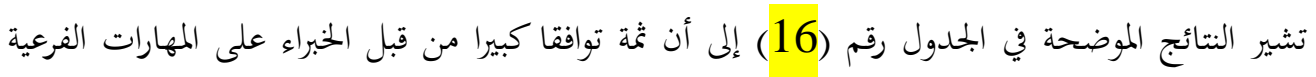

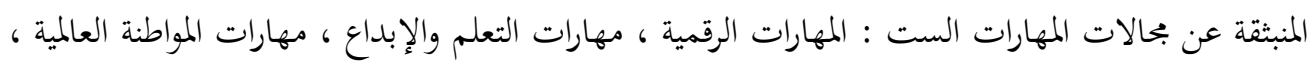
مهارات التفكير الأخلاقي، المهارات الشخصية ،المهارات الحياتية والوظيفية ، كما أها تتوافق مع النتيجة العامة للمجالات ككل ، وكل بحال منها، حيث جاءت 56 مهارة منها مهمة بدرجة كبيرة ، بمتوسطات التهات الحسابية تتراوح ما بين 4.41 ، 4.97، بينما جاءت 13 مهمة بدرجة كبيرة ،بمتوسطات حسابية تتراوح

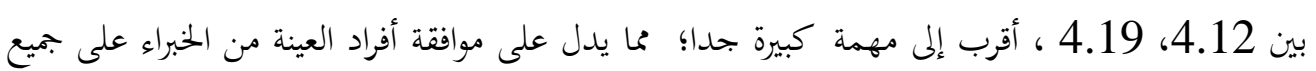
المهارات الفرعية المنبثقة من البحالات الستة ، وعلى توافقها فيما بينها، ومع النتيجة العامة.

9-مناقشة نتائج الدراسة :

يتضح من خلال العرض السابق لنتائج المقابلة التي تم الحصول منها على بيانات نوعية استكشافية لمجالات

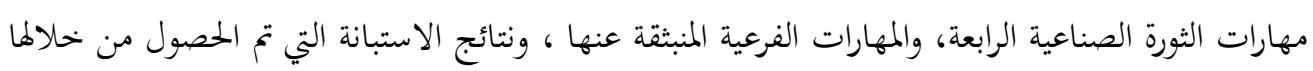
على نتائج تأكيدية يمكن إجمالها فيما يلي: - أن ثمة بحالات ستة لمهارات الثورة الصناعية الرابعة اللازمة لطلاب المرحلة الثانوية العامة ، توافق على يلى الخبراء على أفها مهمة بدرجة كبيرة جدا.

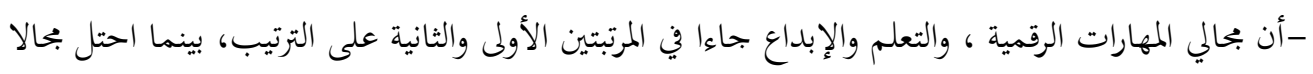
المهارات الشخصية والمواطنة العالمية المرتبتين الخامسة والسادسة على الترتيب كذلك.

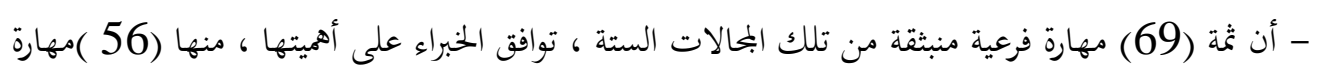

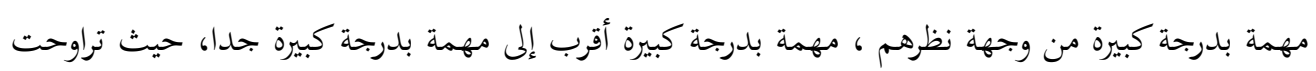

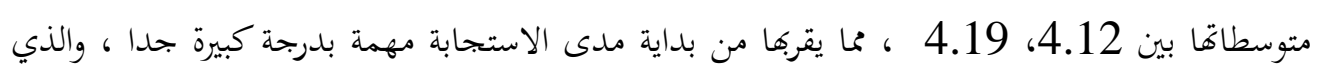
يمتد مداه من 4.2 إلى 5 .

ويمكن على ضوء الأدب التربوي المرتبط بمتغيرات الدراسة، والدراسات السابقة ذات الصلة؛ تفسير تلك ملك Yusuf et النتائج استنادا إلى تداعيات الثورة الصناعية الرابعة على العالم والحياة ، ووفق دراسة (

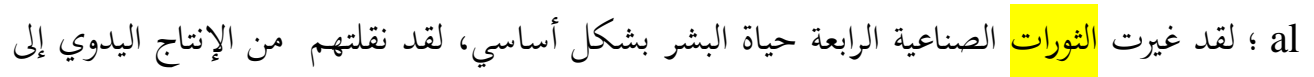

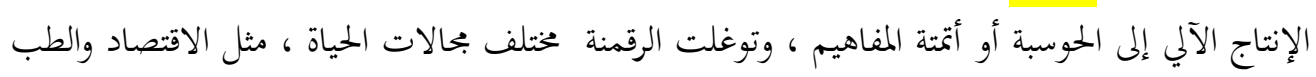
والتعليم والتجارة وغيرها، ومن ثم فهناك حاجة ماسة إلى إعادة هيكلة المؤسسات التعليمية من أجل التنمية والتطور ، والنظر إلى ما وراء النهج التعليمي التقليدي، وتوظيف الاستخدام الإستراتيجي للتقنيات الشائعة

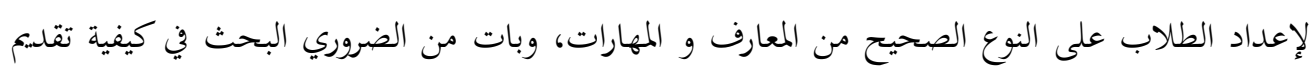

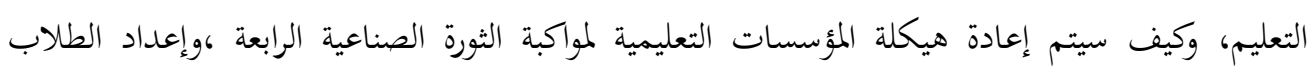
لمواجهة التحديات المقبلة ،وبالنسبة لنوعية بحالات المهارات التي توافق عليها خبراء التربية من أفراد العينة ، 
فلعل ذلك يرجع لنوعية تلك المهارات وضرورةها للعمل والحياة ،فالمهارات الرقمية مثلا باتت عماد الحياة في ظل تحديات الثورة الصناعية الرابعة، وقد أشار ( Karunanayaka et al 2020 إلى أن التكنولوجيات

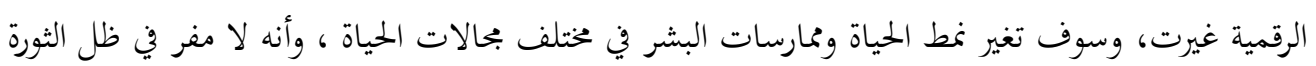
الصناعية الرابعة من تمكين الأفراد من المهارات الرقمية، وإعداد الطلاب طبقا للتقنيات الفائقة، مع اعتماد

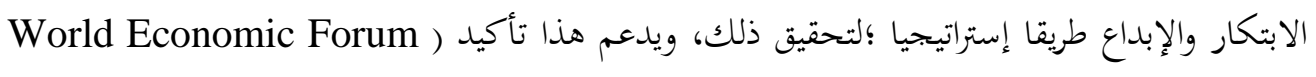
2020) على أن الابتكار والمرونة والتكيف مع التغيير أصبحت من المحركات الرئيسة للنمو، وخلق القيمة

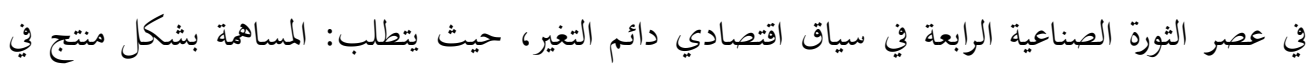
الاقتصاد المستقبلي ، وتطوير مهارات الأطفال لتوليد أفكار ومفاهيم جديدة، وتحويل تلك الأفكار و المفاهيم إلى حلول وأنظمة ومنتجات قابلة للتطبيق وقابلة للتبني ، باستخدام أساليب تعلم نشطة ومتعة

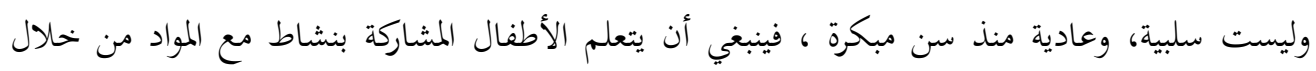

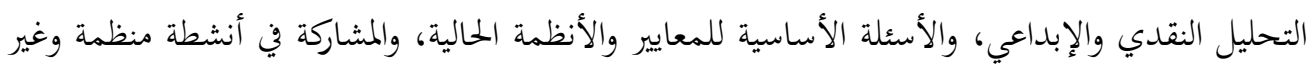

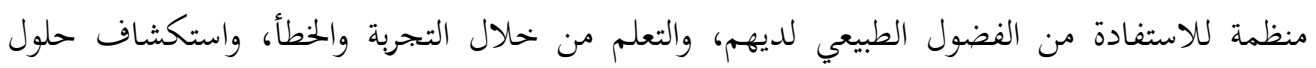

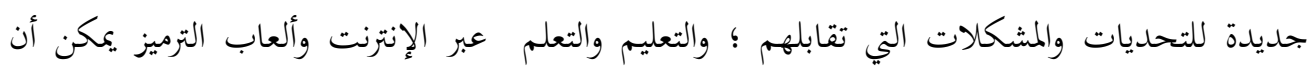
تساعد في تسهيل التجارب للأطفال التي تسمح بوضع التعلم في سياقه، أثناء توجيه إبداعات الأطفال نحو خلق عوالمهم الخاصة عبر الإنترنت ،حتى يتمكنوا من مهارات الإبداع والابتكار.

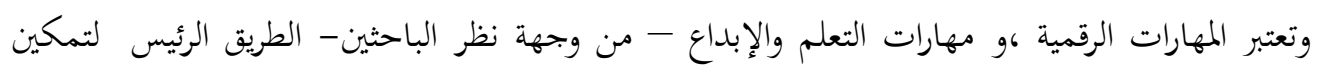
الطلاب من المهارات اللازمة للعمل والحياه مستقبلا، وهي التي تتأسس وتقوم على المهارات الشخصية

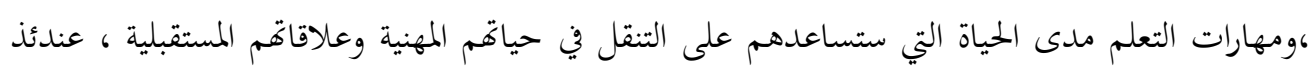

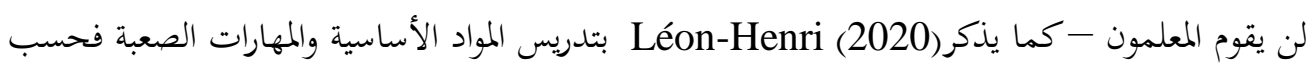
، بل يجب التركيز كذلك على تدريس المهارات اللينة، والتي تشكل المهارات الشخصية و الاجتماعية جزءا

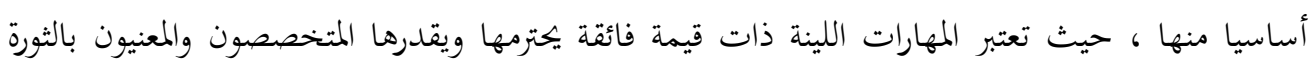

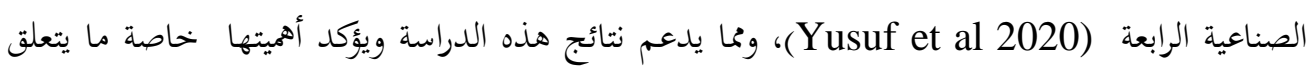
بمجال مهارات المواطنة الرقمية؛ دعوة ( World Economic Forum (2020) إلى ضرورة أن يتمتع الأطفال بالمهارات اللازمة للتنقل في السياق العالمي الجديد ، والحفاظ على التماسك الاجتماعي ، وتعزيز

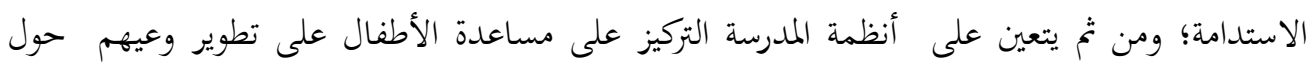

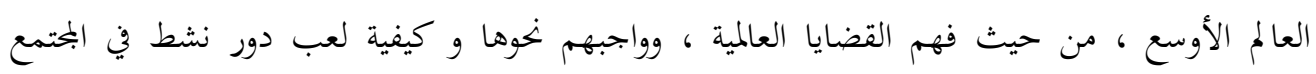
العالمي،وأوصت بضرورة دمج هذه المهارات على نطاق واسع في بيئات التعلم و في المناهج الحالية . وفيما 


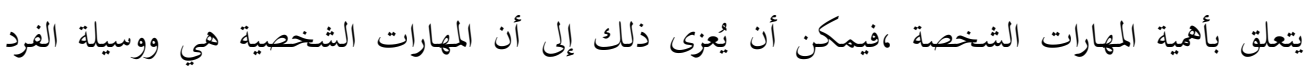
لاكتساب المهارات الأخرى، هذا من ناحية ، ومن ناحية أخرى فإن المهارات الشخصية أساس تكيف الفرد اجتماعيا، وإدارة حياته آنيا ومستقبليا، وطريقه للتعامل بفاعلية مع متطلبات حياته اليومية ، ويدعم ذلك تأكيد دراسة (2020) Sharma et al على أهمية المهارات الشخصية لمواكبة الثورة الصناعية الرابعة ، كمهارات الذكاء العاطفي ، ومهارات التفاوض ،والوعي الاجتماعي والقيادة . وفيما يتعلق بأهمية مهارات التفكير الأخلاقي فإن ثمة تحديات عديدة للثورة الصناعية الرابعة وتطبيقاتما ، تستوجب ضرورة تشكيل فرق عمل من الخبراء في بحال أخلاقيات العلم والتقنية ؛ لمناقشة التحديات الأخلاقية المتعلقة بتطبيقات الثورة الصناعية الرابعة وتطوراما، وتطوير الأطر الأخلاقية وكذلك القانونية التي تضبط وتنظم عمل تلك التطبيقات وأنظمتها ، وتضمن أن تكون تلك الأنظمة وتطبيقاها آمنة وعادلة ، بما يضمن الثقة في كيفية الاستفادة منها وتطويرها وتقنينها، واستخدامها لحل مشكلات البشر وتحقيق رفاهيتهم( الدهشان

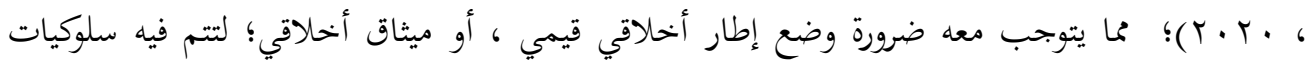
البشر مع تحديات وتداعيات وتطبيقات الثورة الصناعية الرابعة؛ مما يهق أقصى نفع لهم ، ويدفع عنهم شرورها، ويؤكد ذلك ما توصلت له دراسة (2020) Penprase من ضرورة توفير استخدامات مستدامة وأخلاقية للعلم والتكنولوجيا، وتطبيقات الثورة الصناعية الرابعة، ولعله مهم وعاجل أكثر من أي بحال آخر ، ويحتاج المنهج الدراسي إلى مساعدة الطلاب على تطوير القدرة على التفكير الأخلاقي ؛ من أجل الوعي

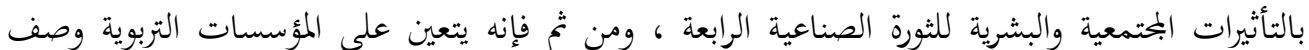
وتحديد مهارات الثورة الصناعية الرابعة اللازمة لطالب المرحلة الثانوية العامة في ضوء تحديات الثورة الصناعية الرابعة ، وخاصة الوظائف المستقبلية عالية الطلب ، وكذلك بحموعات المهارات الفرعية اللازمة للوفاء بهذه الوظائف ؛لإعداد الطلاب وخريجي المستقبل لواقع سوق العمل الجحديد الذي فرضته الثورة الصناعية الرابعة

.(Eberhard et al.2017)

وربما يتصور البعض عدم مناسبة بعض بحالات مهارات الثورة الصناعية الرابعة ، وربما بعض المهارات الفرعية المنبثقة عنها للمرحلة العمرية التي استهدفتها الدراسة، وهي مرحلة الثانوية العامة، ، كمهارة ريادة الأعمال الرقمية ، مهارات تأسيسية للتعامل مع تطبيقات الثورة الصناعية الرابعة، توظيف الأفكار المبتكرة في المواقف الجحديدة، مهارات تنفيذ الابتكارات في بحال دراسته، مهارات تنفيذ خطط العمل وتقييمها، مهارة إدارة المشروعات التعليمية افتراضيا، التعامل مع مجموعة متنوعة من المحالات المعرفية، مهارات تحويل الأفكار إلى تهات مشروعات قابلة للتطبيق، المهارات الأخحلاقيات للمهن الرقمية، مهارة أداء أدوار وأنشطة لمواجهة المشكلات والتحديات العالمية، التفكير النقدي في القضايا والمشكلات الإنسانية، بناء التعاطف الإنساني مع الشعوب الأخرى ؛ يرى الفريق البحثي بالدراسة الراهنة أن جميع المهارات ينبغي البدء بتنميتها والتأسيس لها تدريجيا 
منذ مرحلة الطفولة، شأفا شأن القيم، حيث لا يتم بناؤها فجأة، وهذا ما أكدت عليه دراسات عديدة ،

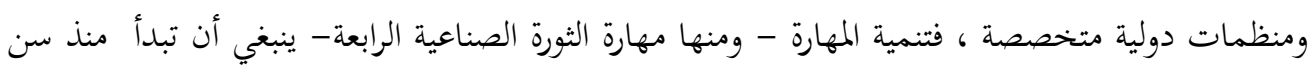
مبكرة (2020, World Economic Forum; 2018, Shahroon et al)

\section{• 1 - موصيات الدراسة}

بناء على نتائج الدراسة الراهنة يتببن أن الثورة الصناعية الرابعة تتطلب نوعا من الخريجين يمتلكون مهارات

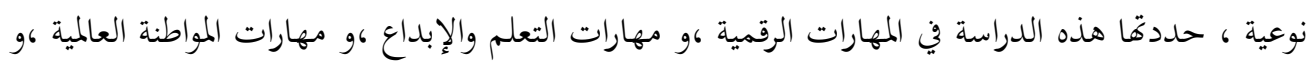
مهارات التفكير الأخلاقي، و المهارات الشخصية، والمهارات الحياتية والوظيفية، وأن هذه المهارات الجحديدة قد أصبحت مطلبا ملحا ؛ مما يوجب على مؤسساتنا التعليمية تغيير إستراتيجياتما ووظائفها وبرابجها لإعداد

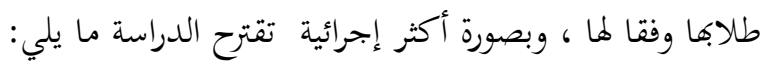
-تشكيل للجنة من خبراء التعليم بتمع بين أعضاء هيئة التدريس بالمامعات ، والقيادات التعليمية بالميدان التعليمي، والجهات العليا، والمسؤولين على المستوى العام؛ لوضع خطة تنفيذية لتحديد المتطلبـات اللازم توافرها لإعداد الطلاب بمرحلة التعليم العام، تتضمن كل بحال من المهارات ، والمهارات الفرعية

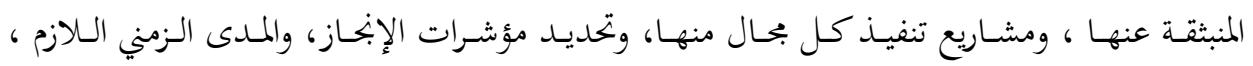

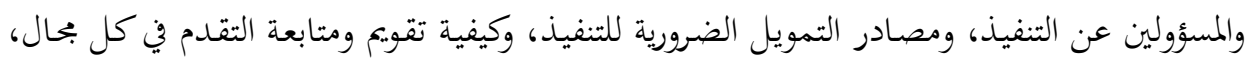

ويتم مراجعة الخطة وتقويمها بصفة مستمرة، وفق معايير ومؤشرات محددة منبثقة منها.

-وضع إستراتيجية للتطوير المنظومي لمرحلة التعليم العام، بحيث تشمل كافة عناصرها من حيث الرؤية،

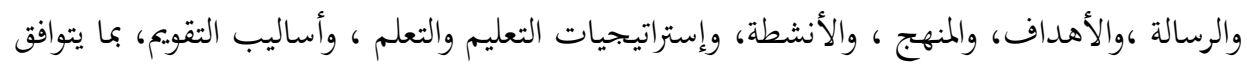
مع متطلبات مواجهة الثورة الصناعية الرابعة وتداعياتا على البحتمع والتعليم والحياة. -وضع الخطط المناسبة لمواجهة المقاومة المحتملة لعمليات التطوير المنشود، ونشر ثقافة التطوير بين أعضاء المجتمع التعليمي بمراحل التعليم العام وخارجهه، خاصة من أصحاب المصالح ، وممن لهم صلة مباشرة

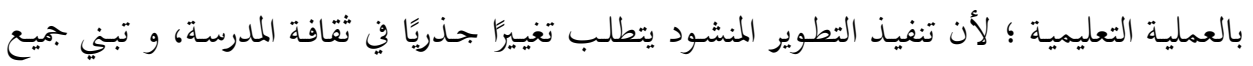

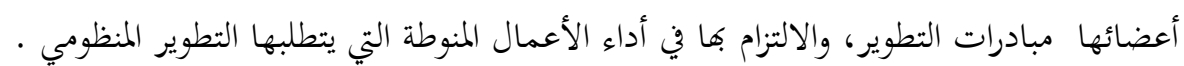

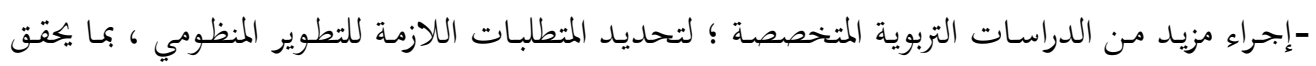

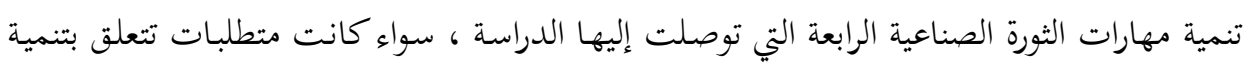

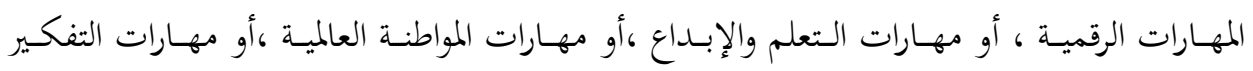
الأخلاقي، أو المهارات الشخصية والمهارات الحياتية والوظيفية، والتي تقتضي بنـاء الرؤى والرسائل، 
مهارات الثورة الصناعية الرابعة اللازمة أ.د. حمال السيسى أ.د.م. أحمد السويكت أ.د.م. محمود مصطفى

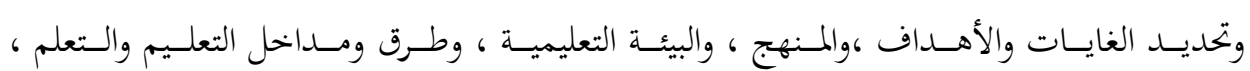
وإستراتيجيات التقويم ،بما يتوافق مع متطلبات تنمية مهارات الثورة لصناعية الرابعة. 


\section{قائمة المراجع}

أولاً: المراجع العربية.

ا ـالبيطار ، حمدي محمد أحمد(· · · ·). المهارات الرقمية لمعلمي التعليم الثانوي الفني الصناعي في مصـر في ضـوء الثـورة الصـناعية الرابعـة، الملحلة التربويـة، كليـة التربيـة ، جامعـة سـوهاج، $.1 \leqslant r 4-1 \leqslant 106(\vee 9)$

Y.الدهشان ، جمال علي( ·.r.r). المعضلات الأخلاقية لتطبيقات الثورة الصناعية الرابعة، المجلة

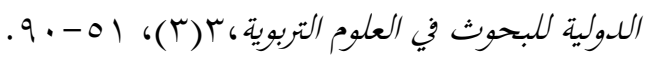

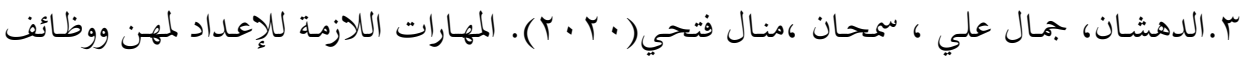
المستقبل لمواكبة الثورة الصناعية الرابعة ومتطلبات تنميتها : رؤية مقترحة ، البحلة التربوية،

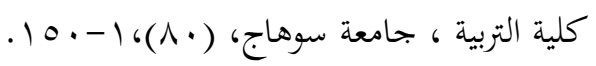

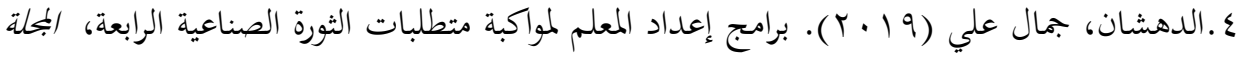

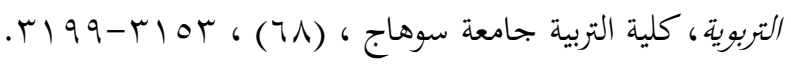

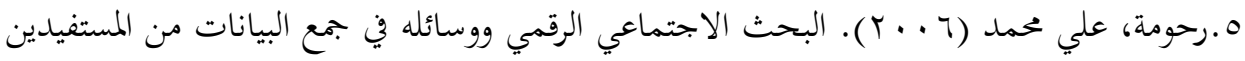
الافتراضيين، المؤتمر السابع عشر للاتحاد العربي للمكتبات والمعلومات - الشراكة بين

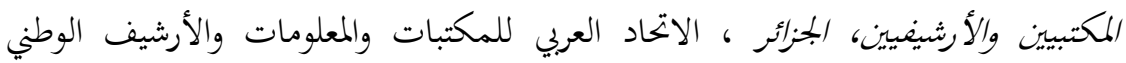

$$
\text { الجزائري، (IV) }
$$

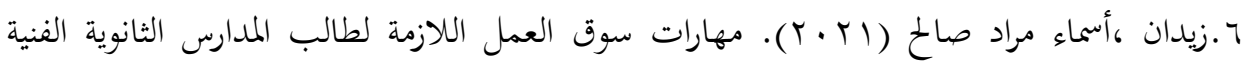
الصناعية بمصر على ضوء الثورة الصناعية الرابعة ،المجلة التربوية، كلية التربية ، جامعة

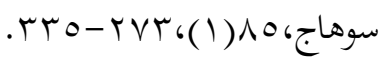

V. شلبي، نوال محمد (ع ا • r ). إطار مقترح لدمج مهارات القرن الحادي والعشرين في مناهج العلوم

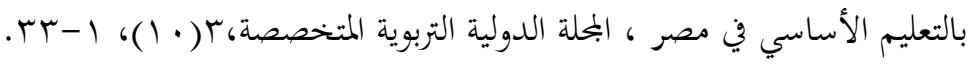

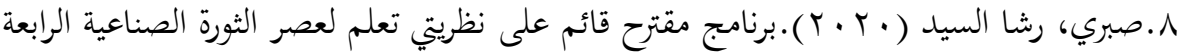
باستخدام إستراتيجيات التعلم الرقمي وقياس فاعليته في تنمية البراعة الرياضية والاستمتاع

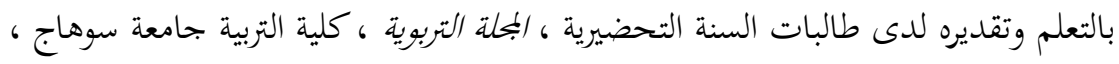
. Orq- $\varepsilon r q 6(V r)$

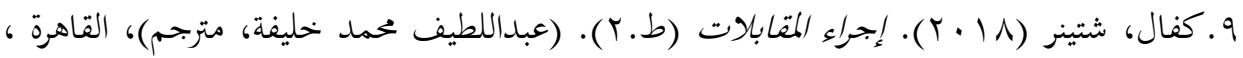

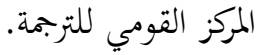




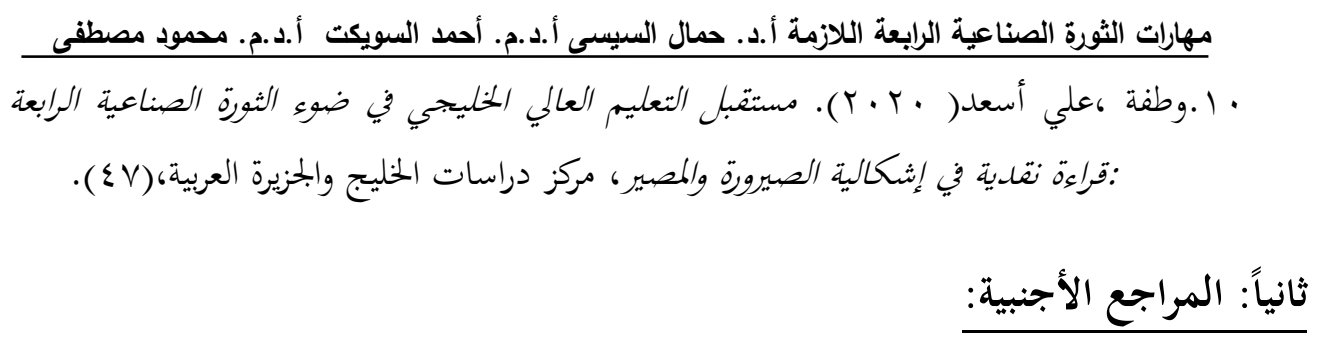

1.Belisle , P. (1998). Digital recording of qualitative interviews, Quirk's Marketing Research Review, 12(18), 60-61.

2.Braun, V., \& Clarke, V. (2006). Using thematic analysis in psychology, Qualitative Research in Psychology, 3(2), 77-101.

3.Creswell, W. J .(2014). Research design : qualitative, quantitative, and mixed methods approaches, 4th ed., Sage Publications Los Angeles.

4.Creswell, W. J. (2012). Educational Research: Planning, Conducting, and Evaluating Quantitative and Qualitative Research, (4th ed.). New York, NY: Pearson.

5.Centre for Future-ready Graduates. (2017). The NUS Future-Ready Report 2017 , Journal of Chemical Information and Modeling . Singapore.,Avialable at http://www.nus.edu.sg/CFG/students, in 30/7/2020.

6.Coberly-Holt, P \& Elufiede, K.(2019). Preparing for the Fourth Industrial Revolution with Creative and Critical Thinking, Adult Higher Education Alliance, Paper presented at the Annual Meeting of the Adult Higher Education Alliance ,43rd, Orlando, Florida, Mar (7-8).,21-25.

7.Collins, K. M. T., Onwueguzie, A. J. \& Jiao, Q. G. (2006). Prevalence of mixed-methods sampling designs in social science research and beyond, Paper presented at the annual meeting of the American Educational Research Association, San Francisco, CA.

8.Deepak,S \& Durgansh, S.(2020). Employability Skills to Thrive during Fourth Industrial Revolution: Up skilling Secondary School Learners, Jaipuria International, Journal of Management Research , 6(1), 3-12.

9.Dewi, P, D., Soekopitojo, S., Larasati, A., Kurniawan , F, M.\& Hartanti, S, E.(2020). Developing Instrument to Measure Student's Capability for Future Work in Industry 4.0 at Vocational Education Culinary Program, iJIM,14(12),110-122.

10.Durmus, A \& Dağl1, A.(2017): Integration of Vocational Schools to Industry 4.0 by Updating Curriculum and Programs, International 
مجلة الدراسات التربوية والانسانية ـ كلية التربية ـ جامعة دمنهور ـ المجلد الحادى عشر - العدد الرابع - الجزع الثانى - لسنة 9 ـ ـ

Journal of Multidisciplinary Studies and Innovative Technologies, 1(1), 1-3.

11.Dwiyanti, V, A \& Widianingsih, I. (2018). Industrial Education Impact on Vocational Student Social Skills, Innovation of Vocational Technology Education, invotec, XIV(2 ),98- 103.

12.Eberhard, B., Podio, M., Alonso, A, P., Radovica, E., Avotina, L., Peiseniece, L., Sendon ,M,C., Lozano, A, G \& Solé-Pla ,J.(2017). Smart work: The transformation of the labour market due to the fourth industrial revolution (I4.0), International Journal of Business and Economic Sciences Applied Research, 10(3), 47-66.

13.Farisi, I. M. (2016). Developing the 21st Century Social Studies Skills Through Technology Integration, Turkish Online Journal of Distance Education , 17( 1) 16-30.

14.Fouda, T. (2020). Impact of the fourth industrial revolution on the development of scientific research in the field of agricultural engineering in Egypt and Arab world, Scientific Papers Series Management, Economic Engineering in Agriculture and Rural Development,20(3),253-259.

15.Gillies, A.(2015). Where are the $T$ and E in STEM Education?, Magazine article Techniques, Available at, https://www.questia.com/read/1G1-412275498/where-are-the-tand-e-in-stem-education, in 20/7/2020.

16.Green, F .(2011). What is Skill? An Inter-Disciplinary Synthesis published by the Centre for Learning and Life Chances in Knowledge Economies and Societies at: http://www.llakes.org

17.Karpov, A. O. (2017). University 3.0 - Social Mission and Reality. Sotsiologicheskie Issledovaniya [Sociological Studies], ( 9 ), 114-124. Available at https://Socis.isras.ru/en/art , in 20/2/2021.

18.Karsten,I., van der Merwe,M.\& Steenekamp, K. (2020). Empowering accounting students to enhance the self-determination skills demanded by the fourth industrial revolution, South African ,Journal of Higher Education,34(20),36-59.

19.Karunanayaka, S, S \& Weerakoon, W. M. S. (2020). Fostering Digital Education among Teachers and Learners in Sri Lankan Schools, Journal of Learning for Development, 7(1), 61-77.

20.Kemp,C. (2018) .Top 5 Skills Teachers Need to Flourish in the Fourth Industrial Revaluation, Available at, 
مهارات الثورة الصناعية الرابعة اللازمة أ.د. حمال السيسى أ.د.م. أحمد السويكت أ.د.م. محمود مصطفى

http://mrkempnz.com/2018/05/top-5-skills-teachers-need-to-

flourish-in-the-fourth-industrial-revolution.html,in 25/7/2020

21.Léon-Henri ,D, D, P. (2020). Going beyond words and actions: teaching metacognitive and soft skills to ESP communication students at the dawn of the fourth industrial revolution, University de Franche-Comté, Besançon, France, available at https://orcid.org/0000-0001-6196-6173.

22.Marr, B. (2019). Things Every School Must Do to Prepare for the 4th Industrial Revolution , available at https://www.forbes.com/sites/bernardmarr, in /22/7/2020.

23.Organisation for Economic Co-operation and Development. (2019). Future of education and skills 2030. OECD.

24.Penprase , E .B (2018). The Fourth Industrial Revolution and Higher Education, First Online: 22 June, Higher Education in the Era of the Fourth Industrial Revolution , 207-229, available at , https://link.springer.com/chapter/10.1007\%2F978-981-13-01940_9,1n

25.Reaves, J.(2019). 21ST-Century skills and the fourth industrial revolution: A critical future role for online education, International Journal on Innovations in Online Education, 3(1),121.

26.Richert, A., S, M., Plumanns, L., Schuster, K., Jeschke S., Shehadeh, M \& Gros,K. (2016). Educating Engineers for Industry 4.0: Virtual Worlds and Human-robot-Teams: Empirical Studies Towards a new Educational Age, IEEE Global Engineering Education Conference (EDUCON),Abu Dhabi, UAE: IEEE ,142149, https://doi.org/10.1109/EDUCON.2016.7474545 in 20/7/2020.

27.Schwab, K. ( 2016). The Fourth Industrial Revolution. Retrieved from World Economic Forum, available at https://www.weforum.org/about/the-fourth-industrial- revolutionby-klaus-schwab, in 21/6/2019.

28.Shahroom, A, A \& Hussinm, N.(2018). Industrial Revolution 4.0 and Education, International Journal of Academic Research in Business and Social Sciences, 8(9),314-319.

29.Villaseñor, P.(2018). The skill of developing skills. World Bank Blogs. Retrieved at 13 June,2021 from: https://blogs.worldbank.org/developmenttalk/skill-developing$\underline{\text { skills }}$ 
مجلة الدراسات التريوية والانسانية ـ كلية التربية ـ جامعة دمنهور ـ المجلد الحادى عشر - العدد الرابع - الجزء الثانى - لسنة 9 . ب

30.Vincent, P.T.(2016). Research Methods-Quantitative, Qualitative, and Mixed methods,DOI: 10.13140/RG.2.1.1262.4886.

31.Winterton J., Le Deist, F, D., Delamare, F \& Stringfellow, E. (2005). Typology of knowledge, skills and competences: clarification of the concept and prototype. Office for Official Publications of the European Communities.

32.World Economic Forum.(2020). Schools of the Future Defining New Models of Education for the Fourth Industrial Revolution, World Economic Forum,91-93route de la Capite CH-1223, Cologny/Geneva Switzerland, available at contact@weforum.orgwww.weforum.org, www.oecd.org/site/educeri21st/40554299.pdf.

33.Xing, B \& Marwala, T.(2017). Implications of the Fourth Industrial Age for Higher Education, SCIENCE AND TECHNOLOGY,(73),10-15.

34.Yusuf, f,B., Walter, L, M \& Sailin, S, N. (2020). Restructuring educational institutions for growth in the Fourth Industrial Revolution (4IR): A Systematic Review. 
مهارات الثورة الصناعية الرابعة اللازمة أ.د. حمال السيسى أ.د.م. أحمد السويكت أ.د.م. محمود مصطفى 